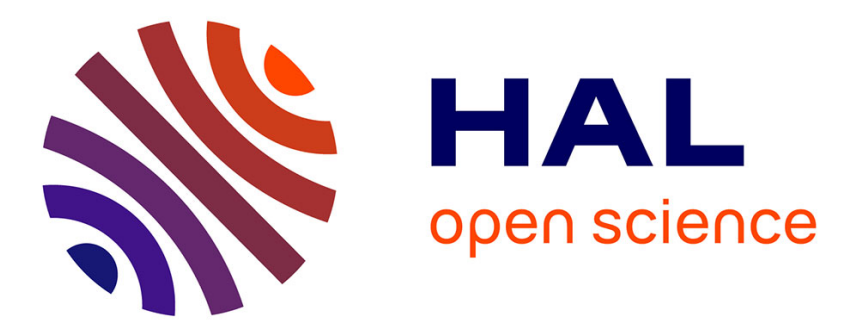

\title{
Rate of Slip From Multiple Quaternary Dating Methods and Paleoseismic Investigations Along the Talas-Fergana Fault: Tectonic Implications for the Tien Shan Range
}

M. Rizza, K. Abdrakhmatov, R. Walker, R. Braucher, V. Guillou, A. Carr, G. Campbell, D. Mckenzie, J. Jackson, G. Aumaître, et al.

\section{To cite this version:}

M. Rizza, K. Abdrakhmatov, R. Walker, R. Braucher, V. Guillou, et al.. Rate of Slip From Multiple Quaternary Dating Methods and Paleoseismic Investigations Along the Talas-Fergana Fault: Tectonic Implications for the Tien Shan Range. Tectonics, 2019, 38 (7), pp.2477-2505. 10.1029/2018TC005188 . hal-02268970

\section{HAL Id: hal-02268970 https://hal.science/hal-02268970}

Submitted on 16 Dec 2019

HAL is a multi-disciplinary open access archive for the deposit and dissemination of scientific research documents, whether they are published or not. The documents may come from teaching and research institutions in France or abroad, or from public or private research centers.
L'archive ouverte pluridisciplinaire HAL, est destinée au dépôt et à la diffusion de documents scientifiques de niveau recherche, publiés ou non, émanant des établissements d'enseignement et de recherche français ou étrangers, des laboratoires publics ou privés. 


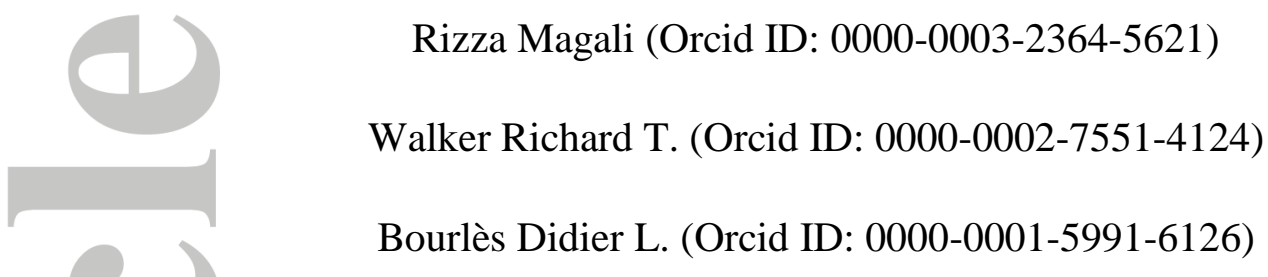

\section{Rate of slip from multiple Quaternary dating methods and paleoseismic investigations along the Talas-Fergana Fault: tectonic implications for the Tien Shan Range.}

Rizza. M. ${ }^{1}$, Abdrakhmatov, $K .{ }^{2}$, Walker.$^{3}$, , Braucher R. ${ }^{1}$, Guillou V. ${ }^{1}$, Carr A.S. ${ }^{4}$, Campbell G. ${ }^{5}$, McKenzie D. ${ }^{3}$, Jackson J. ${ }^{5}$, Aumaître, G. ${ }^{1}$, Bourlès, D.L. ${ }^{1}$, and Keddadouche $K^{1}$.

\section{Affiliations}

1 Aix Marseille Univ, CNRS, IRD, INRA, Coll France, CEREGE, Aix-en-Provence, France

2 Kyrgyz Institute of Seismology, Asanabai 52/1, Bishkek 720060, Kyrgyz Republic

3 Department of Earth Sciences, Oxford University, South Parks Road, Oxford, OX1 3AN

4 School of Geography, Geology and the Environment, University of Leicester, University Road, Leicester, LE1 7RH, UK

5 Bullard Laboratories, Department of Earth Sciences, University of Cambridge, Madingley Road, Cambridge, CB3 0EZ

* G. Aumaître, D.L. Bourlès, K. Keddadouche.

Corresponding author : $\underline{\text { rizza@ cerege.fr }}$

This article has been accepted for publication and undergone full peer review but has not been through the copyediting, typesetting, pagination and proofreading process which may lead to differences between this version and the Version of Record. Please cite this article as doi: 10.1029/2018TC005188 


\section{$\underline{\text { Key points : }}$}

- The $400 \mathrm{~km}$-long Talas-Fergana fault (TFF) can be subdivided into 9 geometric segments.

- A first geological slip rate of 2.2-6.3 mm/yr is constrained by geochronological dating of an alluvial fan.

- New paleoseismic investigations show at least 2 surface ruptures in the last 3800 years.

- The TFF may act as a strike-slip fault and is associated with possible counterclockwise rotations around a vertical axis to accommodate the regional deformation. This model reconciles geodetic and geologic slip-rate estimates.

Key Words: Tectonic geomorphology, active faults, Paleoseismology, Luminescence dating, Cosmogenic dating, Tien Shan.

\section{Abstract:}

The $400 \mathrm{~km}$-long Talas-Fergana fault (TFF) is one of a series of major right-lateral strike-slip faults that cross the Tien Shan Range. This fault has been recognized as active in the late-Holocene and accommodates part of the deformation induced by the ongoing IndoAsian collision. The kinematics and the role of this strike-slip fault are poorly understood with no large earthquakes reported in the instrumental or historical catalogs, and no wellconstrained geological slip-rate estimates. Here we used high-resolution satellite imagery to present a first detailed analysis of the fault segmentation. We identified nine geometric segments based on strike variations for the TFF. Along the Kyldau segment, through morphological analyses of an offset alluvial fan and the application of multiple dating methods $\left({ }^{10} \mathrm{Be},{ }^{26} \mathrm{Al},{ }^{36} \mathrm{Cl}\right.$, luminescence and radiocarbon), we calculated a late Quaternary slip rate ranging from 2.2 to $6.3 \mathrm{~mm} / \mathrm{yr}$. This rate is higher than the geodetic measurements, but the discrepancy can be partly explained if the TFF accommodates shortening by counterclockwise rotation around a vertical axis. Paleo-earthquakes identified by trenching indicate that at least two primary surface ruptures (and possibly a third) occurred in the past 3800 years, and that no large earthquake has ruptured the Kyldau segment since at least 420 years BP (possibly within the last 2700 years), making this fault segment a potential candidate to generate an earthquake with $M>7$ in the near future. 


\section{Introduction}

The Tien Shan Range forms an active intracontinental elongated mountain belt $2500 \mathrm{~km}$ long, which extends from Uzbekistan to western China (Figure 1). This intracontinental range has a complex geological history, comprising multiple orogeneses since the Palaeozoic (Burtman, 1975). During the Cenozoic, the Tien Shan Range was reactivated due to the ongoing India-Eurasia collision and to Pamir indentation (Bande et al., 2015; Bosboom et al., 2014). Low-temperature thermochronological data indicate that this Cenozoic reactivation began in the late Eocene-Oligocene (35-25 Ma) (Bande et al., 2015; Buslov et al., 2007; De Grave et al., 2013; Jia et al., 2015; Sobel et al., 2006). Presently, the range absorbs the active deformation between two stable crustal blocks: the Kazak Platform and the Tarim Basin to the north and south, respectively (Figure 1). The range is seismically active, having generated large intraplate earthquakes $(\mathrm{M}>7.5)$ over the past centuries along large-scale E-W faults. Active faults have been mapped from satellite images (Abdrakhmatov et al., 2016; Molnar \& Dayem, 2010; Molnar \& Qidong, 1984; Molnar \& Tapponnier, 1977; Tapponnier et al., 1986) and Global Positionning System (GPS) data indicate that, at the longitude of Kyrgyzstan, shortening across the Tien Shan range is $\sim 20 \mathrm{~mm} / \mathrm{yr}$ (Abdrakhmatov et al., 1996; Zubovich et al., 2010).

The compressive to transpressive deformation in the western Tien Shan area is distributed across the entire width of the range, mainly along thrust faults, with millimetric late Quaternary slip rates of $\sim 0.1$ to $3 \mathrm{~mm} / \mathrm{yr}$ (Thompson et al., 2002; Zubovich et al., 2010; Goode et al., 2014). The India-Eurasia collision has also reactivated a series of large continental strike-slip faults (Figure 1), which may play a major role in accommodating crustal shortening and in causing block rotations (Bande et al., 2015; Bosboom et al., 2014; Campbell et al., 2013; Yin, 2010). These right-lateral strike slip faults, trending NW-SE, cut the interior of the Tien Shan range (Figure 1) and are recognized as active due to obvious offsets of Quaternary landforms (Burtman et al., 1996; Campbell et al., 2013; Tapponnier \& Molnar, 1979). These offset landforms however are not associated with large earthquakes during the past century. Recent paleoseismological studies conducted in the eastern Tien Shan Range suggest that these large-scale faults have the potential to be reactivated during large earthquakes $(\mathrm{Mw}>7.5)$ and have long recurrence times (e.g. several thousand years) 
(Abdrakhmatov et al., 2016; Campbell et al., 2013, 2015; Grützner et al., 2017; Landgraf et al., 2016)

In the central Tien Shan, the largest intracontinental strike-slip fault is the northwest trending Karatau-Talas-Fergana Fault (Figures $\mathbf{1}$ and 2A). This fault is classically subdivided into two main segments: the Karatau segment to the north and the Talas-Fergana Fault (TFF) to the south (Alexeiev et al., 2017; Allen, 2001; Burtman et al., 1996; Rolland et al., 2013). The TFF delineates a boundary between the Fergana Basin rotating counterclockwise to the west and the central Tien Shan Range to the east (Bande et al., 2015; Reigber et al., 2001; Zubovich et al., 2010). Burtman et al. (1996) proposed that the onset of the reactivation of the TFF occurred at 12.5-4 Ma, while Bande et al. (2015) placed it around $25 \mathrm{Ma}$. Along the TFF, the lateral maximum cumulative offset of bedrock is estimated to be 12-14 km (Burtman et al., 1996), making this fault one of the major structures in the region. The TFF connects with numerous thrusts and sub-ranges in its northern and southern part (Figure 2), which are interpreted as transpressional pop-up structures of the TFF (Bande et al., 2015). However, the southern extent of the TFF remains debated. The fault has been proposed to terminate in the Atushi Basin or to continue southward into the Tarim Basin (Bande et al., 2015; Jia et al., 2015; Wei Hong- Hong et al., 2013).

Offset landforms are recognized along the entire section of the fault (Burtman et al., 1996; Korzhenkov et al., 2014; Molnar \& Dayem, 2010; Rust et al., 2018; Tapponnier \& Molnar, 1979), but the role, kinematics and rates of deformation for the TFF during the Quaternary period are debated and poorly constrained. In terms of slip rates, studies have variously argued that: (1) the TFF has a geological slip rate around 10-20 mm/yr (Burtman et al., 1996; Korzhenkov et al., 2014; Rust et al., 2018); (2) the TFF is a boundary with a slow slip rate around $\sim 4 \mathrm{~mm} / \mathrm{yr}$ (Avouac \& Tapponnier, 1993; England \& Molnar, 2005); or (3) the geodetic rates are around $2 \mathrm{~mm} / \mathrm{yr}$ (Abdrakhmatov et al., 1996; Reigber et al., 2001; Zubovich et al., 2010).

To discriminate between these various hypotheses concerning the role and functioning of the TFF, we initiated paleoseismic and morphotectonic analyses in the Kyldau Valley, located in the southern section of the TFF (star symbol on Figure 1). We used $0.7 \mathrm{~m}$ highresolution satellite images (Worldview) to map the geomorphic expression of the TFF in this mountainous region and to detect streams and alluvial surfaces exhibiting offsets. To 
determine a geological slip rate, an alluvial fan surface on the Kyldau Valley $\left(41.140^{\circ} \mathrm{N}\right.$, $73.937^{\circ} \mathrm{E}$ ) was surveyed using a Real Time Kinematic (RTK) GPS, allowing construction of a 1-m resolution Digital Elevation Model (DEM). To determine the age of this alluvial surface, we collected samples of embedded surficial boulders and depth profiles on recent outcrops in the alluvial fan sediments. We applied all available dating methods (Terrestrial Cosmogenic Nuclides (TCN), luminescence and radiocarbon) to accurately date the deposition of the fan and from this estimate a Quaternary slip rate. To consider occurrences of past earthquakes on the Kyldau segment, a paleoseimic trench was excavated across a pond formed within this alluvial surface. Together, these approaches allow us to discuss the fault segmentation and potential magnitudes for the TFF, earthquake geology and the wider role of this major structure in the Tien Shan Range.

\section{Seismicity, kinematics and fault segmentation of the Talas-Fergana Fault (TFF)}

\subsection{Historical and instrumental seismicity in Central Tien Shan.}

Several destructive historical earthquakes have occurred in western and central parts of the Tien Shan Range, (Kalmetieva et al., 2009) (Figure 1 and 2A). Bishkek, the capital of Kyrgyzstan, was severely damaged by a destructive earthquake in 1885 (M 6.9), probably related to the reactivation of thrust faults on the northern border of the Kyrgyz Range (Figure 2) (Landgraf et al., 2016). In 1911, the Chon-Kemin event (Ms 8.2, Figure 1) activated several fault segments with average slip of $\sim 4 \mathrm{~m}$ over more than $180 \mathrm{~km}$ of observed surface rupture (Arrowsmith et al., 2017), while large landslides affected the whole region (Delvaux et al., 2001). The Ms 7.3 Suusamyr earthquake in 1992 (Figure 1) was the most recent earthquake to strike western Kyrgyzstan and this event is reported as a large thrust-type earthquake (Ghose et al., 1997). This earthquake produced a $\sim 7.6 \mathrm{~km}$-long surface rupture distributed along different fault segments (Ainscoe et al., 2019), and net slip measurements up to $\sim 4.2 \mathrm{~m}$ were reported, as well as secondary surface effects (landslides, earthflows, cracks and fissures).

Despite clear morphological evidence of Quaternary faulting along the TFF, there are no historical or instrumental records of large earthquakes $(M>7)$ along the fault since 250 B.C (Figure 2A) (Kalmetieva et al., 2009). The only potential candidate for an historical earthquake of this magnitude is the 1946 M 7.6 Chatkal event (Figure 1), which produced strong building damage, within an epicentral zone of $1500 \mathrm{~km}^{2}$ (Bindi et al., 2014). The 
precise position of this epicentral zone is still debated and is located in a sparsely populated area where the TFF fault crosses narrow valleys and high relief (Kalmetieva et al., 2009; Molnar \& Dayem, 2010; Simpson et al., 1981) (Figure 3B). No clear surface ruptures have been reported along the TFF, but large landslides and rockfalls clustered in the Chatkal Range have been linked to the 1946 Chatkal event (Januzakov et al., 2003; Kalmetieva et al., 2009). For these reasons, it was proposed that this earthquake was triggered by reactivation of a southwest fault parallel to the TFF (Molnar \& Qidong, 1984) or by a thrust fault striking ENE, approximately parallel to the Chatkal range (Simpson et al., 1981). No strong earthquakes have occurred near the TFF since 1946 and although sparse, the instrumental seismicity record suggests the fault is presently locked. More recently a seismotectonic study conducted in the Fergana basin and surrounding areas presents evidence for a cluster of events in 2009. Fault plane solutions showed a clear strike-slip mechanism (strike $=20^{\circ}$, dip $=$ $80^{\circ}$, rake $=-10^{\circ}$ ), which is in good agreement with the general strike of the TFF (Feld et al., 2015).

\subsection{Previous paleoseismic investigations along the TFF}

Some fault segments of the TFF have been extensively studied (Burtman et al., 1996; Rust et al., 2018; Tibaldi et al., 2015). These include paleoseismic investigations along the TFF, focusing on morphological analysis of offset streams and ridges. The first field measurements of offsets along the fault and the first radiocarbon ages collected from associated organic sediments were made in the 1990s (Burtman et al., 1996; Trifonov et al., 2015). These authors assumed that the onset of organic deposition in sag ponds along the TFF could be related to seismic events. Similar studies (Korjenkov et al., 2010; Rust et al., 2018) updated the interpretation of these offsets and complemented the radiocarbon ages to deduce slip rates ranging from $\sim 10$ to $\sim 20 \mathrm{~mm} / \mathrm{yr}$. However, none of those slip rates are based on offsets determined via quantitative geochronologic analysis of the alluvial surfaces themselves and should therefore be considered as maximum slip rates (Molnar \& Dayem, 2010).

Paleoseimic data suggest that the TFF produced a series of strong earthquakes in the $14^{\text {th }}$ to $17^{\text {th }}$ centuries, with potential co-seismic lateral offsets of several meters (Korjenkov et

al., 2010; Trifonov et al., 2015). Despite the dense catalog of radiocarbon dates, these published studies do not present stratigraphic relationships between the dated Quaternary units and the fault zones. Close to Karasu Lake $\left(41.565^{\circ} \mathrm{N} ; 73.239^{\circ} \mathrm{E}\right.$, Figure 2B), large 
landslides have been mapped and may have been triggered by strong shaking during the second half of the $16^{\text {th }}$ century (Korjenkov et al., 2010; Korzhenkov, et al., 2014). More recently, a trench excavated along the southern part of the Saty segment (see location in Figure 2) showed evidence for a single surface rupture younger than 2600 years BP (Tibaldi et al., 2015).

\section{Fault geometry and segmentation of the TFF based on high-resolution images.}

High-resolution mapping of large intracontinental strike-slip faults shows that faults are often segmented and are connected by thrust faults and step overs (i.e. Klinger, 2010; Perrin et al., 2016). Mapping of surface ruptures and fault segmentation is necessary to constrain scaling laws (Manighetti et al., 2007; Wells \& Coppersmith, 1994) and is often an indicator of a fault's long-term propagation and evolution (Perrin et al., 2016). Although recognized as a major strike-slip fault, the TFF is classically mapped as a single linear segment that continues for more than $500 \mathrm{~km}$. To provide an accurate segmentation map, we used high-resolution imagery (Worldview, Pleaides and available Google Earth images) and field observations to survey the active fault trace of the TFF. Based on our remote sensing mapping, we propose (Figure 2B) to subdivide the TFF into nine geometric segments based on its variation in strike.

[1] At the northwestern tip of the TFF, the Këksay segment strikes $120^{\circ} \mathrm{N}$ for $41 \mathrm{~km}$. Along this segment, the morphology of the surface rupture is subtle on aerial images, showing a series of en echelon reverse scarps that we interpret as splay faults. This fault segment marks the end of the active fault trace. Cumulative right-lateral slips are also observed in Holocene landforms when the fault crosses steep glacial valleys and offset moraines $\left(42.348^{\circ} \mathrm{N} ; 71.084^{\circ} \mathrm{E}\right)$.

[2] Around $42.30^{\circ} \mathrm{N}$, the TFF bends to a $110^{\circ} \mathrm{N}$ azimuth along a $47 \mathrm{~km}$-long-section, which defines the Kara-Kulja segment. Quaternary surface ruptures are not observed between $42.24^{\circ} \mathrm{N}$ and $42.23^{\circ} \mathrm{N}$. Along the Kara-Kulja segment, fault splays are between 4 to $8 \mathrm{~km}$ long and show clear dextral offsets of several tens of meters to a few hundred meters when they cut moraines (Figure 3A), ridges and river beds.

[3] At $42.16^{\circ} \mathrm{N}$, the TFF changes strike by $5^{\circ}$, defining the start of the Chatkal segment. The fault trace here is more linear along a $10 \mathrm{~km}$-long section, but around $42.11^{\circ} \mathrm{N}$ 
and $71.83^{\circ} \mathrm{E}$, the TFF divides into several splays with a reverse fault segment striking $\mathrm{N} 90^{\circ}$ and dipping to the north. Toward the SE, the fault scarps are steep and continuous, with unvegetated free-faces along a $47 \mathrm{~km}$-long section (Figure 3B). We observed numerous dextral well-preserved offset gullies ranging from $\sim 5 \mathrm{~m}$ to $\sim 200 \mathrm{~m}$, attesting to repeated earthquakes during the Holocene. The southward continuation of the Chatkal segment across the Chatkal valley is unclear, with a 5-km-long gap in surface morphology before the transition to the Sary segment. We interpret this area as a possible step-over.

[4] To the south, the Sary segment, strikes $N 113^{\circ}$ for $\sim 53 \mathrm{~km}$ and reveals clear segmentation, with 4- to 6-km-long linear scarps associated with releasing steps. Numereous offset landforms are identified in ridges, streams and alluvial surfaces (e.g. Rust et al., 2018).

[5] At $41.67^{\circ} \mathrm{N}$, the Karasu segment bends to $\mathrm{N} 125^{\circ}$, the fault trace crosses mountainous areas, and is more segmented and difficult to follow in the high topography, with discontinuous and more distributed surface faulting along a $45 \mathrm{~km}$-long section.

[6] Along the Kelkibel segment, striking $\mathrm{N} 125^{\circ}$ for $35 \mathrm{~km}$, the fault morphology is not well-preserved, but it presents a clear segmentation (there is a gap of $7 \mathrm{~km}$ in our mapping where we could not find a late Pleistocene/Holocene scarp) and reveals splay faults at both of its ends.

[7] At $41.42^{\circ} \mathrm{N}$, the Kyldau segment strikes $\mathrm{N} 140^{\circ}$ along a $28 \mathrm{~km}$-long section, with clear evidence of recent activity, including well-preserved scarps and offset streams. The fault trace appears linear and runs along incised valleys up to $41.04^{\circ} \mathrm{N}$ where the fault trace splays into two main geometric segments, one striking $\mathrm{N} 140^{\circ}$, and the other one a curvedfault strand striking N95 . In the Kazarman Basin (Figure 2B), we mapped normal fault scarps affecting alluvial surfaces that we interpret as a possible fold bend extrado expression of a blind reverse fault dipping to the south, striking SSE-NNW and possibly connected to the TFF at depth.

[8] The Pchan segment, striking $\mathrm{N} 140^{\circ}$, runs for more than $24 \mathrm{~km}$ with clear reverse splays recognized. The continuation of the TFF to the south is unclear and, in our surface rupture mapping, it is difficult to follow the trace of the TFF along a $9 \mathrm{~km}$-long section.

[9] Finally, it seems that the southernmost segment of the strike-slip TFF ends in a thrust fault system within the Arpa Basin (see location in Figure 2) where two parallel reverse fault scarps with an azimuth of $\mathrm{N} 93^{\circ} \mathrm{E}$, dipping to the south, are separated by a 
distance of $\sim 10 \mathrm{~km}$ (Figure 3C). However, these two reverse segments have, until now, not been described. Using SPOT 6/7 images, we observed clear evidence of recent faulting, with well-preserved fault scarps running at the toe of the mountain ranges. Detailed mapping reveals offset in moraines and uplifted abandoned alluvial and fan surfaces (Figure 3D).

Quaternary surface faulting within the Arpa basin dies out near longitude $74.88^{\circ} \mathrm{E}$. The geological trace of the TFF to the south is easily observed on satellite images, but we were unable to map Quaternary surface ruptures associated with recent faulting on those segments. Contrary to previous studies in which the authors proposed the continuation of the TFF to the Tarim Basin (Bande et al., 2015), we propose that these two reverse faults can be interpreted as horsetails marking the southern end of the active TFF.

\section{Late Quaternary cumulative offsets and dating of the displaced markers}

\subsection{Morphotectonic analyses along the Kyldau segment}

We re-investigated the Kyldau valley where cumulative ridges and streams are offset from 12 m to 250 m (Burtman et al., 1996; Korzhenkov, Rogozhin, et al., 2014; Trifonov et al., 2015). The only prior geochronological constraint in the area is a radiocarbon age of 3670 $\pm 80{ }^{14} \mathrm{C}$ yr BP (Beta-47555) from an organic-rich layer sampled in a pit opened in the middle of a 125 m offset marker (see site 11 in Burtman et al., 1996 and in Figure 4A). Burtman et al. (1996) proposed that this radiocarbon age corresponds to only half of the development of the $125 \mathrm{~m}$ offset and estimated the bound of the slip rate to be between 8 and $21 \mathrm{~mm} / \mathrm{yr}$.

We surveyed the fault trace and the Quaternary alluvial surfaces of the valley using 0.7 m-high resolution Worldview images (Figure 4). Measurements of offsets (Table 1) of drainage patterns, ridges and risers were performed using retrofitting methods (i.e. Klinger et al., 2011; Zielke et al., 2015). The minimum offset value that we were able to measure on this section of the fault was $\sim 10-11 \mathrm{~m}$, which may therefore correspond to the co-seismic slip for the last strong earthquake or may result from multiple slips. In the northern section of the study area (Figure 4A), the TFF crosses high bedrock terrain where clear cumulative offsets of abandoned stream valleys range from 90 to $220 \mathrm{~m}$ (maximum measured offset). The TFF then cuts the Kyldau river and crosses fluvial and alluvial surfaces and slope deposits.

Our present study site is located where the TFF cuts an alluvial fan surface standing $20 \mathrm{~m}$ above the present Kyldau River (location on Figure 4A). Using a Real Time Kinematic 
(RTK) GPS, we made a detailed topographic survey (Figure 5). The fault zone is expressed by a small 0.5 - 1.5 m-high northeast-facing scarp and a small depression within an extensional step-over (Figures 4B, 4C and 5). Shallow stream channels incised into the alluvial fan surface are right-laterally offset (Figures 4 and 5) and parts of the upstream channels are blocked by the fault scarp and flow into a small pond (see Figure 5). On the western side of the fan surface, one deeply incised stream flows in the present-day channel (Figures 4 and 5). This channel is right-laterally offset. The cumulative offset was measured using piercing lines corresponding to both sides of the main channel (see white dashed lines on Figure 5C). Restoration of $27 \pm 5 \mathrm{~m}$ of slip produces the best fit for the initial geometry of this incision (Figure 5B). It also shows that the initial shape of the channel and the risers between the fan and the bedrock were probably already curved before successive co-seismic displacements (Figure 5B).

\subsection{Sampling strategy and stratigraphic description of the depth profiles}

To date the deposition of the alluvial fan displaced along the dextral TFF, we collected samples to determine ages using in situ produced cosmogenic nuclide $\left({ }^{10} \mathrm{Be},{ }^{26} \mathrm{Al},{ }^{36} \mathrm{Cl}\right)$ concentrations. We collected samples from the top of large boulders $(>1 \mathrm{~m})$ presently standing above the surface, but still partially encased within it and from areas where the fan topography remains undissected by contemporary channels. Ten samples from the tops of large boulders were collected to determine cosmic ray exposure ages (Figure 5). Fresh roadcuts (Figure 6) allowed the collection of samples along two depth profiles (see locations in Figure 5) for cosmogenic isotope analysis to complement the surface exposure ages. Additional samples for radiocarbon and luminescence methods were taken from these cuttings.

In Figure 6, profile 1 reveals an organic-rich soil (5-20 cm thick) at the top of a brown layer composed of angular to sub-rounded pebbles in a sandy-clay organic-rich matrix (unit 1). Unit 2, between 70 and $200 \mathrm{~cm}$, coarsens upwards from its a basal subunit (unit 2b), which is composed of poorly sorted cobbles in a sandy matrix with beds parallel to the fan surface at the top, to an upper subunit (unit $2 b$ ) composed of rounded pebbles to boulders in a coarse sandy matrix. Unit $3(30-50 \mathrm{~cm}$ thick), whose the base is marked by an erosive contact, comprises sands and clays with rare pebbles. It overlays a massive layer (unit 4) of sub-rounded pebbles to cobbles in a coarse sand matrix, interstratified with thin layers of 
sands and clays where cross-bedding are observed. Along this depth profile, from the surface and down to $300 \mathrm{~cm}$ (Figure 7A), one amalgamated bag of $\sim 40-50$ pebbles (typical diameter of 2-5 cm) was collected at each sampling depth (Repka et al., 1997; Rizza et al., 2011, 2015). In parallel, one sample (TAL13-OSL3) was collected for luminescence dating by hammering a steel tube into a sandy unit $\sim 210 \mathrm{~cm}$ below the fan surface (Figure 6). Four shells of terrestrial gastropods were collected from units $2 \mathrm{a}$ and $2 \mathrm{~b}$ in profile 1 (see location on Figure 6 and labeled TAL-S1, S2, S3 and S4).

Profile 2 is located on the south-east part of the alluvial fan surface (Figure 5). However, due to its location in the morphology and limited stratigraphic observations, we suspect that this profile might belong to an abandoned infilled terrace of the Kyldau river. A detailed stratigraphic log of this section is not provided because the roadcut instability impeded safe access to the natural exposure in its upper part (Figure 6C). However, in general the section comprises a modern soil 10-20 cm wide composed of rounded cobbles to boulders in a sandclay matrix. This is underlain by a massive layer of sub-rounded pebbles to cobbles with uncommon boulders in a coarse sand matrix interstratified with layers of coarse- to mediumsands. In one of these layers, we were able to collect one sample for luminescence dating (TAL13-OSL1, see location in Figure 6C and 6D) at a depth of $\sim 4.5 \mathrm{~m}$. At this depth, very close to TAL13-OSL1 sample (see Figure 6D), we also found a piece of burned wood (TAL13-C1, Figure 6E) embedded in the alluvial sediments and this sample was collected for ${ }^{14} \mathrm{C}$ age analysis.

\subsection{Methods for Quaternary Geochronology dating}

Part of the novelty of this study lies in the application of multiple dating methods on a same depth profile. To our knowledge, no previous studies have estimated ages of alluvial deposits using three different cosmogenic nuclides $\left({ }^{10} \mathrm{Be},{ }^{26} \mathrm{Al}\right.$ and $\left.{ }^{36} \mathrm{Cl}\right)$ concentrations combined with luminescence dating and radiocarbon dating, as was applied on Profile 1. This is significant as it allows us to compare independent Quaternary dating methods to date an alluvial deposit and discuss some potential age discrepancies. 


\subsubsection{In situ produced cosmogenic nuclide dating}

\section{Sample preparation and instrumentation}

Terrestrial in situ cosmogenic nuclides have been extensively used as a surface dating method and the theory underlying this application is described by Gosse \& Phillips (2001). Initially, carbonate clasts were collected to determine their exposure duration via their accumulated ${ }^{36} \mathrm{Cl}$ concentrations. All samples were crushed and the $250-500 \mu \mathrm{m}$ fraction leached and dissolved following Stone et al. (1996) and the protocols modified by Schlagenhauf et al. (2011 and references therein). As the amount of residue containing siliceous minerals after the total dissolution of the original sample was important, these residues were processed for determination of the ${ }^{10} \mathrm{Be}$ and ${ }^{26} \mathrm{Al}$ concentrations accumulated in quartz. All samples were prepared as described in Braucher et al. (2011). ${ }^{10} \mathrm{Be},{ }^{26} \mathrm{Al}$ and ${ }^{36} \mathrm{Cl}$ concentrations were calculated from measurements performed at the French 5MV national AMS facility ASTER (CEREGE, Aix-en-Provence).

\section{Beryllium-10 and aluminium-26}

${ }^{10} \mathrm{Be}$ and ${ }^{26} \mathrm{Al}$ production rates at the sampling locations were calculated using the Stone scaling polynomial (Stone, 2000) from a Sea Level High Latitude (SLHL) spallation production rate of $4.02 \pm 0.18$ at/g/yr (Borchers et al., 2016) and muon contributions based on Braucher et al. (2013). The standardization method used at ASTER (SM-Al-11/07KNSTD) implies that the ${ }^{26} \mathrm{Al} /{ }^{10} \mathrm{Be}$ spallation production ratio is $6.61 \pm 0.52$. The used half-lives $\left(\mathrm{T}_{1 / 2}\right)$ were $1.387 \pm 0.012 \mathrm{Ma}$ (Chmeleff et al., 2010; Korschinek et al., 2010) and $0.705 \pm 0.024$ $\mathrm{Ma}$ (Norris et al., 1983) for ${ }^{10} \mathrm{Be}$ and ${ }^{26} \mathrm{Al}$, respectively. The measured ${ }^{10} \mathrm{Be} /{ }^{9} \mathrm{Be}$ ratios were calibrated against the ${ }^{10} \mathrm{Be} /{ }^{9} \mathrm{Be}$ SRM4325 NIST (National Institute of Standards and Technology) standard with an assigned value of $(2.79 \pm 0.03) \times 10^{-11}$ (Nishiizumi et al., 2007). The measured ${ }^{26} \mathrm{Al} /{ }^{27} \mathrm{Al}$ ratios were calibrated against the ASTER in-house standard SM-Al11 with a nominal ${ }^{26} \mathrm{Al} /{ }^{27} \mathrm{Al}$ value of $(7.401 \pm 0.064) \times 10^{-12}$ (Merchel \& Bremser, 2004). Analytical uncertainties included counting statistics, machine stability (Arnold et al., 2010) and blank correction. Beryllium and aluminium concentrations are presented in Table 2.

\section{Chlorine-36}

Both ${ }^{36} \mathrm{Cl}$ and $\mathrm{Cl}$ concentrations were measured at the French national AMS facility ASTER. The scaling scheme of Stone (2000) was used to determine the local production rates from the Schimmelpfennig et al. (2011) production rate $\left(42.2 \pm 4.8\right.$ atoms $\left./ \mathrm{gCa} / \mathrm{yr}^{-1}\right)$. The 
decay constant $2.303 \pm 0.016 \times 10^{-6} \mathrm{yr}^{-1}$ corresponds to a ${ }^{36} \mathrm{Cl}$ half-life $\left(\mathrm{T}_{1 / 2}\right)$ of $3.014 \times 10^{5}$ years. The concentrations were normalized to a ${ }^{36} \mathrm{Cl}$ standard (KNSTD1600) with a nominal ${ }^{36} \mathrm{Cl} /{ }^{35} \mathrm{Cl}$ value of $(2.11 \pm 0.06) \times 10^{-12}$ (Fifield et al., 1990; Sharma et al., 1990). Analytical uncertainties included counting statistics and blank correction. To determine the ${ }^{36} \mathrm{Cl}$ concentrations produced from $\mathrm{Ca}$, this concentration in all sample was measured using inductively coupled plasma-atomic emission spectrometry (ICP-AES) (Table 3). The $\mathrm{Cl}$ concentrations in samples were also measured (Table 3 ) because the ${ }^{36} \mathrm{Cl}$ production mechanism is directly related to the concentration of $\mathrm{Cl}$ in the rock samples. Indeed, fluxes of thermal and epithermal neutrons that produce ${ }^{36} \mathrm{Cl}$ through low-energy neutron capture on ${ }^{35} \mathrm{Cl}$ are poorly constrained when samples present high $\mathrm{Cl}$ concentrations (Schimmelpfenig et al., 2009; Masarik et al., 2007). Finally, all ${ }^{36} \mathrm{Cl}$ production pathways were considered using the Excel spreadsheet provided by Schimmelpfennig et al. (2009) and a density of $2.0 \mathrm{~g} / \mathrm{cm}^{3}$ was been applied to all samples from profile 1 and a density of $2.2 \mathrm{~g} / \mathrm{cm}^{3}$ for the superficial samples.

As we are unable to meaningfully quantify the likely average snow cover at the study site, we did not consider the impact of snow cover on the production rates of ${ }^{36} \mathrm{Cl}$. A snow cover may increase the thermal neutron flux and therefore induce an underestimation of production rates (Dunai et al., 2013). Thus, both the high $\mathrm{Cl}$ concentrations and unaccounted role of snow cover may lead to overestimate the ages of the alluvial units.

\subsubsection{Luminescence dating}

\section{Sample preparation and instrumentation:}

Samples were processed under red light conditions to obtain sand-sized potassium feldspar (K-feldspar). Carbonates were removed through $\mathrm{HCl}$ treatment and organics through $\mathrm{H}_{2} \mathrm{O}_{2}$ treatment. The desired size fractions (90 to $250 \mu \mathrm{m}$ ) were obtained through wet sieving. The sieved fractions were then density separated to obtain K-rich feldspar grains $(<2.58$ $\mathrm{g} / \mathrm{cm}^{3}$ ). Analysis were performed on material in the $180-220 \mu \mathrm{m}$ size range for sample TAL13-OSL1 analysis and on material in the 150-180 $\mu \mathrm{m}$ size range for sample TAL13OSL3. Both samples each received a brief (10 minutes) etch in $10 \% \mathrm{HF}$. 


\section{Environmental dose rate determination:}

The total uranium (U), thorium (Th) and potassium (K) contents of the samples were determined from sub-samples of the sampling tubes using inductively-coupled plasma mass spectrometry, carried out in the School of Geography, Geology and the Environment, University of Leicester. Elemental concentrations were converted to dose rates using the conversion factors of Guérin et al. (2011), with appropriate adjustment for grain size (Mejdahl, 1979; Readhead, 2002) and sample water content (Adamiec \& Aitken, 1998) (see Table 4). Assumed internal $\mathrm{K}$ and $\mathrm{Rb}$ concentrations were $12.5 \pm 0.5 \%$ and $400 \pm 100 \mathrm{ppm}$, respectively (Huntley et al., 2001; Huntley \& Baril, 1997). It was also assumed that the measured water content (Table 4) was appropriate and a 3\% (absolute) uncertainty in water content was propagated into the final dose rate uncertainties. Appropriate estimation of the average sample water content during burial represents a potential constraint on the accuracy of the luminescence ages. As a guide, a 3\% change in sample water content translates to a 300-year change in sample age. Cosmic dose rates were determined following Prescott \& Hutton (1994) based on the present sample depths and are shown in Table 4.

\section{Equivalent dose determination:}

All luminescence measurements were performed on a Risoe DA20 TL/OSL reader. Laboratory irradiation was performed using a ${ }^{90} \mathrm{Sr}$ beta source with a dose rate at the time of measurement of $8.16 \mathrm{~Gy} / \mathrm{min}$. A beta source calibration uncertainty (3\%) was also propagated into the final equivalent dose uncertainty (Armitage \& Bailey, 2005). The K-feldspars were analysed using the post-IR IRSL (pIRIR) single aliquot regeneration (SAR) method (Buylaert et al., 2009; Murray \& Wintle, 2000; Thomsen et al., 2008). This approach comprises an initial low temperature $\left(50^{\circ} \mathrm{C}\right)$ IR stimulation followed by a higher temperature $\left(225^{\circ} \mathrm{C}\right)$ IR stimulation. Analyses were initially conducted on small (2mm) aliquots, which likely contained the 100-200 grains (Duller, 2008). Subsequently, due to relatively high interaliquot scatter observed in the initial measurements, fewer grains were placed on each disk for equivalent dose estimates, with the number of grains per disk used the final pIRIR ${ }_{225}$ SAR measurements reduced to 10-50 grains.

\section{Anomalous fading correction:}

Anomalous fading rates were estimated using a subset of aliquots from the equivalent dose determinations. Following Auclair et al. (2003), the samples were preheated immediately 
after dosing and then stored for varying periods before measurement. The $\mathrm{IR}_{50}$ signal in both samples shows clear evidence of anomalous fading (Table 4), with g-values ranging between $\sim 4.7 \%$ and $\sim 3.8 \%$ per decade for TAL13-OSL1 and TAL13-OSL3, respectively. The final ages for the $\mathrm{IR}_{50}$ measurements were corrected for fading following Huntley \& Lamothe (2001). On the other hand, the pIRIR 225 signals exhibited significantly less evidence of fading, with g-values ranging from $\sim 1.2$ to $\sim 1.8 \%$ per decade for TAL13-OSL1 and TAL13OSL3, respectively. The final pIRIR 225 ages were not fading corrected (e.g. Buylaert et al., 2012).

\subsubsection{Radiocarbon dating}

We collected a total of 12 detrital charcoal samples from depth profile 2 and from the paleoseismic trench, as well as two bulk samples of organic-rich sediments from the trench. In addition, four gastropod shells were sampled from profile 1 (See Table 5). As gastropod shells have been shown to sometimes exhibit significant inheritance effects because carbonates chemically interact with the environment (e.g. Ascough et al., 2005), there may also be an unquantified reservoir effect, depending on the source of carbon. As such three additional modern shells were collected from the alluvial surface adjacent to the profile 1 in order to provide estimates of the potential range of age offset due to radiocarbon reservoir effects. Details of the chemical pretreatment, target preparation, and AMS measurement can be found in Ramsey et al. (2002 ; 2004). Radiocarbon samples (labels "SUERC" in Table 5) were graphitized at the NERC Radiocarbon Facility-East Kilbride and analyzed for their ${ }^{14} \mathrm{C}$ concentration at the SUERC AMS Laboratory. A second set of samples (labels "Beta" in Table 5) was analyzed by Beta Analytic. We calibrated each individually sample using Calib Radiocarbon Calibration Program 7.0.4 (Stuiver \& Reimer, 1993) and the Intcal13 calibration curve (Reimer et al., 2013). 


\subsection{Quaternary dating results}

\subsubsection{In situ produced cosmogenic nuclide dating}

\section{${ }^{36}$ Cl dating of surficial samples}

A total of ten surficial samples (see location on Figure 5A) were collected, of which four were analyzed for ${ }^{36} \mathrm{Cl}$ concentrations. The ${ }^{36} \mathrm{Cl}$ concentrations range from $34.9 \times 10^{4}$ to $51.1 \times 10^{4}$ atoms/g whereas the chlorine $(\mathrm{Cl})$ concentrations range between 6 and $249 \mathrm{ppm}$ (Table 3). The calculated minimum exposure ages (assuming no inheritance and no denudation) show two different populations. TAL17-01 and TAL17-10 indicate exposure durations of $5274 \pm 231$ yrs and $5316 \pm 225$ yrs, respectively, while TAL13-03 and TAL1307 imply exposure durations of $2239 \pm 127 \mathrm{yrs}$ and $2344 \pm 140 \mathrm{yrs}$, respectively.

To explain the two different age populations, we note that samples TAL13-03 and TAL13-07 contain high chlorine concentrations (>50 ppm, see Table 3), which represent a significant source of uncertainty regarding exposure durations. An alternative explanation is that these surficial boulders were deposited on top of the fan surface by different alluvial flow events.

\section{${ }^{10} \mathrm{Be},{ }^{26} \mathrm{Al}$ and ${ }^{36} \mathrm{Cl}$ concentrations along profile 1}

Figure 7 presents the depth distribution of ${ }^{10} \mathrm{Be},{ }^{26} \mathrm{Al}$ and ${ }^{36} \mathrm{Cl}$ concentrations along profile 1. ${ }^{10} \mathrm{Be},{ }^{26} \mathrm{Al}$ and ${ }^{36} \mathrm{Cl}$ concentrations present similar patterns with depth (Figure 7, Tables 2 and 3). The concentrations do not show a single exponential decrease (as would be expected in the case of a single deposition event), but three independent evolutions may to be distinguished. Thus, the depth distribution of the cosmogenic nuclides concentrations is consistent with the different stratigraphic units logged in the field suggesting at least three depositional events. Samples TAL13-40 and TAL13-60 belong to the first group. Samples TAL-80 to TAL-190, whose concentrations exponentially decrease with depth, belong to the second group lying between 80 and $190 \mathrm{~cm}$. Finally, samples TAL-250 and TAL-300, whose ${ }^{10} \mathrm{Be},{ }^{26} \mathrm{Al}$ and ${ }^{36} \mathrm{Cl}$ concentrations are significantly higher than those of the second group samples, are assigned to a third group.

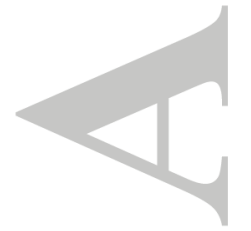




\section{Age calculations in a profile with multiple layers}

The concentration evolution with respect to depth in profile 1 is not composed of a unique exponential decrease as would be expected in a simple exposure history. We observe three superimposed exponential decreases, which result from multiple depositions successively aggraded through time. Therefore, we have to adapt the depth profile approach (Braucher et al., 2009) to provide age estimates. First, in order to determine exposure ages from the measured concentrations, the following equation is used:

$C(x, \varepsilon, t)=$

$$
\begin{aligned}
& \mathrm{C}\left(\mathrm{X}, \varepsilon^{\prime}, \mathrm{t}^{\prime}\right) \exp (-\lambda \mathrm{t})+\frac{\mathrm{P}_{\text {sp }} \cdot \exp \left(-\frac{\mathrm{x}}{\mathrm{L}_{\mathrm{n}}}\right)\left(1-\exp \left(-\mathrm{t}\left(\frac{\varepsilon}{\mathrm{L}_{n}}+\lambda\right)\right)\right)}{\frac{\varepsilon}{\mathrm{L}_{\mathrm{n}}}+\lambda}+ \\
& \frac{\mathrm{P}_{\mu \text { slow }} \cdot \exp \left(-\frac{\mathrm{x}}{\mathrm{L}_{\mu \text { slow }}}\right)\left(1-\exp \left(-\mathrm{t}\left(\frac{\varepsilon}{\mathrm{L}_{\mu \text { slow }}}+\lambda\right)\right)\right)}{\frac{\varepsilon}{\mathrm{L}_{\text {slow }}}+\lambda}+\frac{\mathrm{P}_{\mu \text { fast }} \cdot \exp \left(-\frac{\mathrm{x}}{\mathrm{L}_{\mu \text { fast }}}\right)\left(1-\exp \left(-\mathrm{t}\left(\frac{\varepsilon}{\mathrm{L}_{\mu \text { fast }}}+\lambda\right)\right)\right)}{\frac{\varepsilon}{\mathrm{L}_{\mu \text { fast }}}+\lambda}
\end{aligned}
$$

where $\mathrm{C}(\mathrm{x}, \varepsilon, \mathrm{t})$ is the nuclide concentration as a function of the attenuation depth $x$ (typically expressed as a function of depth in $\mathrm{cm}$, and bedrock density $\rho$, in $\mathrm{g} / \mathrm{cm}^{3}$ ), denudation rate $\varepsilon$, $\varepsilon^{\prime}$ (in $\mathrm{g} / \mathrm{cm}^{2} / \mathrm{yr}$ ), and exposure times $t, t^{\prime}$ (in years). $\mathrm{P}_{\mathrm{sp}}, \mathrm{P}_{\mu \mathrm{slow}}$, and $\mathrm{P}_{\mu \mathrm{fast}}$ and $\mathrm{L}_{\mathrm{sp}}\left(160 \mathrm{~g} / \mathrm{cm}^{2}\right)$, $\mathrm{L}_{\mu \text { slow }}\left(1500 \mathrm{~g} / \mathrm{cm}^{2}\right)$, and $\mathrm{L}_{\mu f a s t}\left(4320 \mathrm{~g} / \mathrm{cm}^{2}\right)$ (Braucher et al., 2011) are the production rates and attenuation lengths of neutrons, slow muons and fast muons, respectively; $\lambda$ is the radioactive decay constant of the TCN under investigation. The term $C\left(x, \varepsilon^{\prime}, t^{\prime}\right)$ is the inherited concentration which corresponds to the concentration accumulated within the samples before each depositional events. In Figure 8, this inherited concentration is labelled $\mathrm{C}_{\mathrm{inh}}$. It corresponds to the accumulated concentration before the exposure and denudation episodes of the sampled deposits. To calculate the inherited concentrations, we then used equation 1 with $x=0$ (the samples are at the surface) and $t=\infty$.

We now consider three depositional events (step 1, step 2 and step 3 ) that have been successively exposed to cosmic rays (Figure 8). We modelled the amount of ${ }^{10} \mathrm{Be},{ }^{26} \mathrm{Al}$ and ${ }^{36} \mathrm{Cl}$ accumulated in unit 4, then in units $2 / 3$ and finally in unit 1 by implementing different steps of burial sequences (Figure 8) (Sanchez et al., 2010). Equation 1 is used three times to model the concentrations accumulated during the three depositional events. The main assumption in the approach outlined below is that each unit, delimited by major discontinuities at $80 \mathrm{~cm}$ and $200 \mathrm{~cm}$, was exposed at the surface before burial, but the 
samples remained in the same relative position within each unit. This approach is synthetized in Figure 8 and detailed below.

Step 1: Samples from unit 4 were exposed to the surface before deposition and may contain some inherited concentrations $\left(\mathrm{C}_{\mathrm{inh}}[1]\right)$. Unit 4 is deposited and samples TAL-250 and TAL300 accumulate ${ }^{10} \mathrm{Be},{ }^{26} \mathrm{Al}$ or ${ }^{36} \mathrm{Cl}$ at $0 \mathrm{~cm}$ and $50 \mathrm{~cm}$ depth, respectively. These samples accumulate a given concentration (C1) corresponding to a duration $\mathrm{t} 1$ and a denudation rate $\varepsilon 1$ calculated following equation 1 .

Step 2: A set of new samples (units 3 and 2) are deposited simultaneously on top of unit 4 and may contain some inherited concentrations $\left(\mathrm{C}_{\mathrm{inh}}[2]\right)$. Unit 2 is exposed to the surface whereas samples from unit 4 are buried and consequently their depths increase relative to surface. The previously accumulated concentrations in the samples from unit 4 are now considered as inheritance. During a duration t2, all samples (from units 4 to 2) will accumulate ${ }^{10} \mathrm{Be},{ }^{26} \mathrm{Al}$ or ${ }^{36} \mathrm{Cl}$ concentrations (C2), depending on a denudation rate $\varepsilon 2$.

Step 3: Samples from unit 1 may contain some inherited concentrations $\left(\mathrm{C}_{\mathrm{inh}}[3]\right)$ and are deposited on top of unit 2. Unit 1 is exposed to the surface and samples from units 2,3 and 4 are buried. Consequently, their depths increase and correspond to their final sampling depths. All sample concentrations accumulated during step 2 are now considered as inheritance. All samples from units 1 to 4 then accumulate ${ }^{10} \mathrm{Be},{ }^{26} \mathrm{Al}$ or ${ }^{36} \mathrm{Cl}$ concentrations (C3) for a duration $\mathrm{t} 3$ (and corresponding denudation rate 83 ). From this it follows that unit 1 was exposed for a time span of $\mathrm{t} 3$ years, units $2 / 3$ for a time span of $t_{2}+t_{3}$ years and unit 4 for a total time span of $t_{1}+t 2+t 3$ years.

Best fit models using a chi-square inversion $\left(\square^{2}\right)$ are used to minimize the difference between observed and modeled data (i.e. Braucher et al., 2011; Rizza et al., 2011). Finally, ${ }^{10} \mathrm{Be}$ and ${ }^{26} \mathrm{Al}$ concentrations from all units are modeled (Figure 7B) with denudation $(\varepsilon 1, \varepsilon$ $2, \varepsilon 3)$ and time $(t 1, t 2$ and $t 3)$ free to vary. The best model $\left(X^{2}: 14.8\right)$ is obtained for total exposure ages of $5850 \pm 350 \mathrm{yrs}$ for unit $1,7230 \pm 470 \mathrm{yrs}$ for units $2 / 3$ and $8880 \pm 600 \mathrm{yrs}$ for unit 4 (uncertainties given at $1 \sigma)$ with no denudation $(\varepsilon 1=\varepsilon 2=\varepsilon 3=0)$. We modelled the evolution of the ${ }^{36} \mathrm{Cl}$ concentrations and the best-fit model leads to total exposure durations of $5489 \pm 320$ yrs for unit $1,8226 \pm 500$ yrs for units $2 / 3$ and $16259 \pm 907$ yrs for unit 4 .

The modeled age of unit 1 is not significantly different from the surface exposure duration of $5274 \pm 231$ yrs and $5316 \pm 225$ yrs for samples TAL13-01 and TAL13-10, 
respectively. However, the calculated ages using ${ }^{36} \mathrm{Cl}$ concentrations in unit 4 , and units $2 / 3$ are older than those calculated with ${ }^{10} \mathrm{Be}$ and ${ }^{26} \mathrm{Al}$ concentrations. This discrepancy might result from the high $\mathrm{Cl}$ concentrations measured in all samples ( $>50 \mathrm{ppm}$, see Table 3). Indeed, in profile 1, the $\mathrm{Cl}$ concentrations in all samples are larger than $150 \mathrm{ppm}$ and increase with respect to depth, reaching a maximum value of $304.8 \mathrm{ppm}$ at $300 \mathrm{~cm}$. As consequence, for sample TAL13-300, ${ }^{36} \mathrm{Cl}$ production by neutron capture represents $67.4 \%$ of the total ${ }^{36} \mathrm{Cl}$ production (see Table 3). Therefore, due to the poor constraints we have for the ${ }^{36} \mathrm{Cl}$ production mechanism, the calculated ${ }^{36} \mathrm{Cl}$ exposure ages are not used to date the deposition of unit 4 in profile 1.

\subsubsection{Luminescence dating results}

\section{Equivalent doses}

All samples show typical K feldspar dose response curves, with equivalent doses well below typical feldspar luminescence signal saturation levels. Recycling ratios were consistently ( $>85 \%$ of measured aliquots) within $10 \%$ of unity and average recuperation values for both the IR50 and the pIRIR 225 measurements were $0.5 \%-1.1 \%$ of the natural sensitivity-corrected IRSL for TAL13-OSL1 and TAL13-OSL3.

A summary of the resulting equivalent dose distributions is provided in Table 4. The yield of sand-sized K-Feldspar from TAL13- OSL3 was low, which limited the number of analyses and equivalent dose replicates for this sample. The distributions are shown graphically in radial plots (Figure 9). As implied by the high to very high over-dispersion (OD) values reported in Table 4, for the $\operatorname{IR}_{50}$ or pIRIR 225 data, there is significant interaliquot scatter unaccounted for by individual measurement uncertainties. The $\mathrm{D}_{\mathrm{e}}$ distributions are all positively skewed, with tail of relatively high equivalent dose aliquots (e.g. Ainscoe et al., 2019). It must be noted that for TAL13-OSL3 the equivalent dose distribution is more difficult to evaluate given the limited number of available aliquots.

\section{Central Age Model (CAM)}

The equivalent doses $\left(D_{e}\right)$ and standard errors were initially based on the Central Age Model (CAM; Galbraith et al., 1999). The CAM mean $\mathrm{D}_{\mathrm{e}}$ s for $\mathrm{IR}_{50}$ analyses of TAL13-OSL1 and TAL13-OSL3 are $54.7 \pm 6.3 \mathrm{~Gy}$ and $36.6 \pm 6.8 \mathrm{~Gy}$, giving ages of $17.9 \pm 2.7 \mathrm{ka}$ and 17.3 
$\pm 3.6 \mathrm{ka}$ after fading correction (see Table 4). For the pIRIR 225 analyses, the CAM mean $\mathrm{D}_{\mathrm{e}} \mathrm{S}$ are $96.2 \pm 11.1 \mathrm{~Gy}$ and $61.1 \pm 13.3 \mathrm{~Gy}$, giving ages of $19.1 \pm 2.3 \mathrm{ka}$ and $19.9 \pm 4.4 \mathrm{ka}$ for TAL13-OSL1 and TAL13-OSL3, respectively. These CAM ages are therefore significantly older ( $>10 \mathrm{kyrs}$ ) than the modeled-TCN ages and radiocarbon ages (see section 4.4.1 and section 4.4.3).

\section{Minimum Age Model (MAM)}

Given that these are alluvial fan deposits, and the fact that we are analyzing Kfeldspars, which are known to bleach more slowly than quartz (particularly the post-IR IRSL signal; e.g. Lowick et al. 2012). These positively skewed $D_{e}$ distributions and seemingly ageoverestimating CAM ages are interpreted as evidence of partial bleaching of some proportion of the analyzed grains (e.g. Kars et al., 2014; Olley et al., 1999). As such, we anticipate that the $D_{e}$ closest to the true burial dose will be better estimated using a leading edge or Minimum Age in the $D_{e}$ distribution (e.g. Olley et al. 2004). We therefore applied a Minimum Age Model (MAM; Galbraith et al., 1999) to identify a burial $D_{e}$ from such a distribution. In this case some caution is warranted as these equivalent doses are derived from multi-grain aliquots and there is no guarantee that any one aliquot or subset of aliquots contains a signal derived only from fully bleached grains.

However, if we model the MAM for $\mathrm{IR}_{50}$ analyses we obtain (fading corrected) ages of $7.5 \pm 0.6 \mathrm{ka}$ for TAL13-OSL1 and $8.5 \pm 1.3 \mathrm{ka}$ for TAL13-OSL3. For the pIRIR 225 analyses, the MAM results are notably similar, with ages of $7.8 \pm 0.8 \mathrm{ka}$ and $8.1 \pm 1.2 \mathrm{ka}$ for TAL13OSL1 and TAL13-OSL3, respectively. Some confidence in this approach is provided by the good agreement between the more rapidly bleached (fading-corrected) IR50 signal and the pIRIR $_{225}$ signal (Kars et al., 2014). The MAM ages from unit 3 are therefore consistent (i.e. not younger than) with the TCN-derived ages of the overlying units 1 and 2, and with the radiocarbon dates sampled in unit 2 (see above section). These MAM ages also agree with the TCN-derived age calculated for unit 4 , all in a good stratigraphic order.

\subsubsection{Radiocarbon analyses}

The "modern" samples (labelled KGZ13-TF-SM1 to SM3 in Table 5) returned postbomb ages, indicating that the shells were living within last 60 years and that there is probably no significant radiocarbon reservoir effect in the study area. Along profile 1, the 
four shells produced to calibrated ${ }^{14} \mathrm{C}$ ages of $6527 \pm 112 \mathrm{cal} \mathrm{BP}(\mathrm{TAL} 13-\mathrm{S} 1-130 \mathrm{~cm}), 5775$ $\pm 118 \mathrm{cal}$ BP (TAL13-S2- $120 \mathrm{~cm}), 6113 \pm 185 \mathrm{cal} \mathrm{BP}($ TAL13-S3 $-120 \mathrm{~cm})$ and $7238 \pm 77$ cal BP (TAL13-S4- $100 \mathrm{~cm}$ ). The ${ }^{14} \mathrm{C}$ ages of these shells are little scattered and are not in a correct stratigraphic order. Given the depositional context with mixed sediments deposited on an alluvial fan, it is possible that some shells were reworked and therefore do not represent the surrounding sediment deposition. Another possibility that cannot not to be ruled out at present is that shells have burrowed into the pre-existing alluvial sediment. Conservatively, we propose that unit 2 was deposited in the range 5670 - $7310 \mathrm{cal} \mathrm{BP}$, which is in agreement with TCN and OSL dating.

In profile 2 , TAL13-C1 has a radiocarbon age of $4698 \pm 130$ cal BP, younger than the MAM ages of $7.5 \pm 0.6 \mathrm{ka}$ and $7.8 \pm 0.8 \mathrm{ka}$ on TAL13-OSL1. This may reflect that we may underestimate the effect of partial bleaching processes in the OSL age.

\subsection{Determination of Holocene slip rate}

The slip rate values relate to $v=\frac{x}{t}$ and $\frac{\Delta v}{v}=\frac{\Delta x}{x}+\frac{\Delta t}{t}$, where $v$ is the slip rate, $x$ is the measured offset across the fault and $t$ is the age estimate, with the corresponding errors $\Delta v, \Delta x$ and $\Delta t$, respectively. In our study, the displaced marker $(27 \pm 5 \mathrm{~m})$ used as a piercing point is a channel incision (Figures 4 and 5) and because we do not know when the stream incision occurred, we bracket the maximum and minimum slip rates using different incision histories.

Firstly, incision may have started when the alluvial fan was still depositing and from this assumption we then calculate a minimum slip rate. If we consider that the stream incision was synchronous with overall fan aggradation, and we use unit 4 as a maximum age, the ${ }^{10} \mathrm{Be}-{ }^{26} \mathrm{Al}$ age of $8880 \pm 600 \mathrm{yrs}$ (unit 4) provides an estimate of the minimum slip rate of 3.0 $\pm 0.8 \mathrm{~mm} / \mathrm{yr}$.

Alternatively, if the stream incision started after overall abandonment of the alluvial fan surface, we can estimate the maximum slip rate. In this case, the cumulative offset of $27 \pm$ $5 \mathrm{~m}$ is considered to have accumulated after the deposition of unit 1 . The exposure durations from the surficial boulders on top of the alluvial surface are also used as minimum ages. The ${ }^{10} \mathrm{Be}-{ }^{26} \mathrm{Al}$ and ${ }^{36} \mathrm{Cl}$ ages for unit 1 of $5845 \pm 350 \mathrm{yrs}$ and $5489 \pm 320 \mathrm{yrs}$ indicate maximum slip rates of $4.6 \pm 1.1 \mathrm{~mm} / \mathrm{yr}$ and $4.9 \pm 1.2 \mathrm{~mm} / \mathrm{yr}$, respectively. Using the ${ }^{36} \mathrm{Cl}$ surficial 
exposure ages of $5274 \pm 231$ yrs (TAL17-01) and $5316 \pm 225$ yrs (TAL17-10), we calculate non-significantly different maximum slip rate of $5.1 \pm 1.2 \mathrm{~mm} / \mathrm{yr}$.

Overall, using the ages range from 5043 yrs to $9480 \mathrm{yrs}$ and offsets from $22 \mathrm{~m}$ to 32 $\mathrm{m}$, we estimate the minimum and maximum slip rate bounds at 2.2 and $6.3 \mathrm{~mm} / \mathrm{yr}$.

\section{Paleoseismic analysis}

\subsection{Description of stratigraphy in the paleoseismic trench}

The fault crosses the alluvial fan surface forming a $\sim 0.5$ to $1.5 \mathrm{~m}$-high north-facing scarp that ponds water and sediments in a small basin (Figures 3, 4 and 10). In a 4 m-long trench (Figure 4D) we logged the eastern wall at a scale of 1:10 using a $0.5 \mathrm{~m}$ grid spacing (Figure 10). The trench exposes, at its base, with sub-rounded pebbles and cobbles supported in a fine-silty matrix, interpreted as alluvial fan deposits (unit 10). The top of this unit is marked by an erosive contact with an organic-rich unit (20) filling a channel base, which marks a remnant of a paleo-ground surface. This organic-rich layer is overlain by a series of channel units composed of sub-rounded coarse pebbles (1 to $7 \mathrm{~cm}$-size), poorly sorted in a carbonaterich silty matrix. We distinguish three units $(40,50$ and 60$)$ by their different colors, silty textures and massive or unsorted characters. In the southern part of the trench, a second organic-rich horizon (30) is logged and the alluvial deposits on top are composed of massive, angular, unsorted pebbles to cobbles in a loose coarse matrix (C1). This unit exhibits a thinner nose farther north and seems to overlie the ancient topography of the alluvial fan surface. A light-colored alluvial unit (80) made of sub-rounded pebbles in a silty matrix covers this massive unit $\mathrm{C} 1$. In this unit, we observe that beds are folded with oriented pebbles. Coarse organic-rich units with rounded to sub-rounded gravels and pebbles (90) and a soil horizon (100) are found on top of the trench.

\subsection{Faulting and earthquake series}

\section{Evidence for the last surface rupture (Event 1)}

Units 90 and 100 are undeformed and therefore were deposited after the last surface rupturing earthquake. These units sealed the fault zone (FZ), which is about $20 \mathrm{~cm}$ wide, is made of sheared pebbles and breaks units 10, 40, 50 and 80 (Figure 10B.). The FZ fault zone upper termination coincides with a fissure (f1) that is filled with chaotic, loose unsorted 
materials composed of pebbly and silty sands. The FZ fault zone juxtaposes these different alluvial units due to a lateral slip. In unit 80 , we logged oriented pebbles and folded beds that we interpret as evidence for small-scale drag folding along the FZ fault zone during the most recent earthquake. We then place an earthquake horizon between the base of units 90/100 and the top of units 60, 50 and 80 (labelled "event horizon 1" in Figure 10B). This horizon represents the ground surface just before the infill by units 90 and 100 of a sag pond created at the toe of the topographic fault scarp.

\section{Evidence for a penultimate earthquake (Event 2)}

A potential second earthquake is marked by the unsorted and loose deposits $\mathrm{C} 1$. This $\sim 70$ cm-thick body may be interpreted as a colluvial wedge associated with an older fault slip event. Indeed, this kind of scarp-derived colluvial material is accumulated on the ground surface above the footwall each time that the fault breaks and that the scarp is refreshed by erosive processes. We suspect that this colluvial wedge is derived from the main scarp located $\sim 2-3 \mathrm{~m}$ farther south (Figure 10A), that we unfortunately could not access due to massive boulders impeding excavation. We then place a second earthquake horizon at the base of C1 (labelled "event horizon 2" in Figure 10B). However, because we do not have clear evidence of a link between this colluvial wedge and a primary surface rupture, we presently identify this event as "hypothetic".

\section{Evidence for a third earthquake (Event 3)}

We propose that the erosive contact found on top of the alluvial fan deposit (10) marks a former ground alluvial surface and an earthquake horizon (labelled "event horizon 3" in Figure 10B). We suspect that a third event therefore occurred during the late stages of alluvial fan deposition (10) and before the deposition of units 20 and 40, which represent the beginning of stream incision into the alluvial fan surface. The channels deposits (40 to 60) may be associated with the filling of a small graben created at the toe of a topographic scarp, as seen for Event 1 . The channels and the alluvial fan were subsequently offset by the FZ fault zone, as evidenced by the apparent vertical offset of $\sim 15 \mathrm{~cm}$ found at the top of unit 10 and the apparent lateral slip.

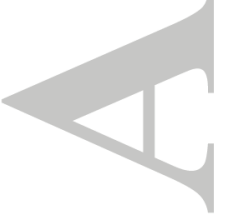




\subsection{Age controls of past earthquakes}

Sixteen detrital charcoal samples, one snail shell and two bulk samples were collected to constrain the chronology of past earthquakes from this trench. All dated radiocarbon samples are presented in Table 5.

The six detrital charcoals (TR 1, TR4, TR 10, TR 11, TR 13 and TR 14) sampled in units 90 and 100 post-date the last surface rupture and produced ages ranging from 12 to 939 cal BP (at $2 \sigma$ limit). However, the ages are not in the correct stratigraphic order, suggesting potential reworking of the detrital charcoal. The two oldest samples, TR1 (785-939 cal BP) and TR10 (673-892 cal BP), are considered as having been reworked and therefore only the TR4, TR11, TR13 and TR14 radiocarbon ages are used to postdate the last earthquake horizon E1. Sample TR2 (snail shell) was collected from the fissure fill (f1) created at the time of the last earthquake. Because it is difficult to tell if the material within the fissure is made of inherited sediments derived from unit 50 and 80 or not, the radiocarbon age of 27282836 cal BP conservatively provides a maximum age for the last surface rupture.

The timing of the event 2 is poorly constrained and we use the bulk sample TR-B2 (collected at the base of unit C1) to post-date the earthquake horizon. The calibrated radiocarbon age ranges are 2544 and 2768 cal BP.

The occurrence of the third event is post-dated by charcoals TR5, TR15, TR16 and by the bulk sample TR-B1, all of which were collected from units 40 and 20. Taking all uncertainties into account, these radiocarbon ages span the range 3174 to 3864 cal BP. Detrital charcoals TR6 and TR8 collected from within the alluvial fan deposits predate this event and produced ages of 3574 to 3827 cal BP. These ages are indistinguishable from those obtained in units 20 and 40.

In a second step, based on the stratigraphic observations, groups of charcoals with no fixed relations located between earthquake horizons were integrated and added into the radiocarbon calibration program Oxcal 4.2.4 (Ramsey et al., 2013) in order to refine the chronology. The resulting chronological model yields occurrence dates between 424 and $2715 \mathrm{BP}$ for the last surface rupture E1, between 2756 and $3273 \mathrm{BP}$ for the possible event horizon E2, and between 3667 and 3810 BP for the earthquake horizon E3.

Given the large uncertainties associated to the ages of the identified seismic events, it is difficult to propose precise recurrence times. If we consider that 3 earthquakes occurred over 
the past $3810 \mathrm{BP}$, the mean recurrence times are $~ 730$ years between E3-E2 and $\sim 1450$ years between E2-E1, respectively. This implies there is no characteristic interval between large earthquakes. If we favour a scenario with only 2 earthquakes (E1 and E3), the mean recurrence time is $\sim 2200$ years.

\section{Discussions - Conclusions}

\subsection{The value of using multiple geochronological proxies to estimate geological slip rates.}

\subsubsection{Timing of alluvial fan deposition in the Kyldau valley}

The determination of fault slip rate relies on numerical age estimates for geomorphological surfaces affected by the fault motion over multiple earthquake cycles. For this reason, cosmogenic and luminescence methods are widely applied to date the emplacement of geomorphic markers, but each method relates to a different geomorphic process. While the cosmogenic method generally dates the exposure duration of the rock surface to cosmic rays, the luminescence method provides burial duration of the sediment after deposition. Age differences between these two methods may relate to the erosiontransport-deposition processes experienced by the sediment prior its final deposition but combined may provide new insights into the processes affecting alluvial landforms.

Here we used multiple Quaternary dating methods to date the deposition of one displaced alluvial fan in the Kyldau Valley. Despite scientific works devoted to the dating of geomorphic surfaces in Tien Shan Range or in similar climatic settings, only a few have sought to combine multiple dating methods (Burgette et al., 2017; DeLong \& Arnold, 2007; Le Dortz et al., 2009; Nissen et al., 2009; J. A. Thompson et al., 2018; S. C. Thompson et al., 2002) . This study shows that it is informative to have an exhaustive, detailed, and direct comparison between dating methods on a single depth profile.

In summary, the ${ }^{10} \mathrm{Be},{ }^{26} \mathrm{Al}$ and ${ }^{36} \mathrm{Cl}$ concentrations and our stratigraphic observations show that the sampled alluvial fan comprises three main sedimentary units. The top surface of the alluvial fan has been exposed to cosmic rays for $\sim 5300 \mathrm{yrs}$ and the modeled exposure durations constrain the deposition of unit 1 to $5850 \pm 350 \mathrm{yrs}\left({ }^{10} \mathrm{Be}-{ }^{26} \mathrm{Al}\right)$ and $5489 \pm 320 \mathrm{yrs}$ $\left({ }^{36} \mathrm{Cl}\right)$. Units $2 / 3$ were deposited between $7230 \pm 470$ yrs $\left({ }^{10} \mathrm{Be}-{ }^{26} \mathrm{Al}\right)$ and $8226 \pm 500\left({ }^{36} \mathrm{Cl}\right)$, 
ages that are consistent with the radiocarbon ages of $5670-7310$ cal BP. These results show good agreement with MAM IRSL ages of $8500 \pm 1300$ yrs $\left(I_{50}\right)$ and $8100 \pm 1200 \mathrm{yrs}$ $\left(\mathrm{pIRIR}_{225}\right)$ for TAL13-OSL3 sample collected in unit 3, although the luminescence results demonstrate that the complete bleaching of the K-feldspar IRSL signal cannot be assumed in these environments. In this study at least, identifying and correcting for these issues is a larger constraint on age accuracy than other assumptions inherent in this method (e.g. appropriate burial water content estimate). Finally, the deepest unit 4 is dated at $8880 \pm 600$ $\operatorname{yrs}\left({ }^{10} \mathrm{Be}-{ }^{26} \mathrm{Al}\right)$.

\subsubsection{A first ${ }^{36} \mathrm{Cl}$ dating in the Tien Shan Range reveals high $\mathrm{Cl}$ concentrations.}

This study is the first to apply ${ }^{36} \mathrm{Cl}$ analyses to date an alluvial fan surface in the Tien Shan Range. The ${ }^{36} \mathrm{Cl}$ concentrations led to exposure durations ranging between 5489 and $16259 \mathrm{yrs}$. This higher exposure duration is older than those calculated using the ${ }^{10} \mathrm{Be}$ and ${ }^{26} \mathrm{Al}$ concentrations, luminescence dating and radiocarbon dating methods and inferred to reflect the high $\mathrm{Cl}$ concentrations measured in all samples (>50 ppm). These have direct implications for the ${ }^{36} \mathrm{Cl}$ production mechanisms (Masarik J. \& Beer J., 2009; Schimmelpfennig et al., 2009). In our study, we show that for samples with high $\mathrm{Cl}$ concentrations, the calculated ${ }^{36} \mathrm{Cl}$ production through the capture of thermal and epithermal neutrons is predominant and may represent 36 to $67 \%$ of the total production (see Table 3). High $\mathrm{Cl}$ concentrations can easily induce overestimations of exposure durations because the fluxes of thermal and epithermal neutrons are poorly constrained and the ${ }^{36} \mathrm{Cl}$ production mechanism directly related to the concentration of $\mathrm{Cl}$ in rock samples is very sensitive to several compositional and time dependent external factors that are difficult to accurately estimate. No satisfactory explanation can be provided regarding the $\mathrm{Cl}$ concentration increase as a function of depth along profile 1. It raises the question of whether the high $\mathrm{Cl}$ concentration is a systematic bias that may be encountered in this region. This is a critical aspect because large epistemic uncertainties in dating alluvial surfaces in carbonate environments severely limit our ability to understand behavior of active faults in regard of the seismic cycle.

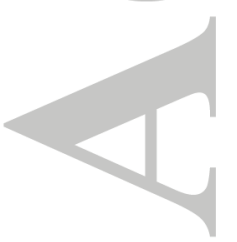




\subsubsection{Geological slip rates}

By combining all three dating methods we calculate that the maximum and minimum slip rates range between 2.2 and $6.3 \mathrm{~mm} / \mathrm{yr}$, respectively. Given the limited data available along the TFF, this study therefore provides the first geological slip rates well-constrained by several Quaternary dating methods for the TFF. These Holocene slip rates are lower than those ( 10-20 mm/yr) proposed in previous studies (Rust et al., 2018 and references therein) and the minimum bound instead overlaps with the geodetic rate of $\sim 2 \mathrm{~mm} / \mathrm{yr}$ (Zubovich et al., 2010).

\subsection{The role of fault segmentation along the TFF}

In Central Asia, large earthquakes ( $M>7.5)$ involving strike-slip faults have generated surface ruptures of several hundred kilometers length with co-seismic offsets of several meters (Choi et al., 2018; Klinger et al., 2011; Molnar \& Dayem, 2010; Rizza et al., 2011, 2015; Tapponnier \& Molnar, 1979). For example, the $2001 \mathrm{Mw} 7.8$ Koxokili earthquake ruptured the Kunlun fault with co-seismic offsets of several meters (Haibing et al., 2005; Klinger et al., 2006; Klinger et al., 2005; Woerd et al., 2002). The largest continental strikeslip surface rupture ever documented is the Bulnay fault system on which two large earthquakes in 1905 ruptured a $\sim 670 \mathrm{~km}$-length of the fault, with co-seismic offsets up to 10 m (Choi et al., 2018; Rizza et al., 2015).

Despite clear morphological evidence of Quaternary faulting along the TFF, there are no historical or instrumental records of large earthquakes $(M>7)$ (Kalmetieva et al., 2009). However, if the TFF breaks during a single event, it may be responsible for large earthquakes. If we consider that an earthquake breaks the entire fault trace length $(400 \mathrm{~km})$, assuming a minimum $20 \mathrm{~km}$ seismogenic thickness (Sloan et al., 2011) and using scaling regressions, we estimate minimum potential moment magnitudes from $\mathrm{M}_{\mathrm{w}} \sim 7.8$ (Wesnousky, 2008) to $M_{w} \sim 8.3$ (Hanks \& Bakun, 2008). These calculated potential magnitudes agree with historical earthquakes reported in central and western Tien Shan. The most recent large earthquake that generated a long surface rupture is the 1911 Chon-Kemin earthquake with a cumulative fault rupture length of 155-195 km (Arrowsmith et al., 2017). During this earthquake, 13 fault patches were activated, with 3-4 m of average slip, with peak slip <14 m, corresponding to moment magnitudes $\mathrm{M}_{\mathrm{w}}$ ranging from 7.8 to 7.9 (Arrowsmith et al., 2017). In 1889, the Chilik earthquake ruptured at least $175 \mathrm{~km}$, involving three oblique strike-slip 
fault patches separated by step overs of several kilometers (Abdrakhmatov et al., 2016). The co-seismic slips are estimated to reach up to $10 \mathrm{~m}$ for a potential magnitude $\mathrm{M}_{\mathrm{w}}$ 8.0-8.3. In the north-eastern part of the Tien Shan, the Lepsy fault is likely to have ruptured at least 120 $\mathrm{km}$ of the fault in a $\mathrm{M}_{\mathrm{w}}$ 7.5-8.2 earthquake, generating $10 \mathrm{~m}$ of vertical offset combined with a substantial strike-slip component (Campbell et al., 2015).

In this study, by revisiting the mapping of the Holocene fault trace, based on variations in strike direction, we propose that the TFF is segmented into nine geometric segments. We observed that the degree of fault scarp preservation in the morphology varies along segments. Along the Kara-Kulja and Chatkal segments, we observe "fresh" rupture surfaces (Figures 3A and 3B), while along the other segments the fault scarps are less well-preserved. The preservation of the fault morphology, as observed in our satellite imagery and in the field (Figure 3B), suggests that the Chatkal segment may have been recently reactivated during an earthquake (Rizza et al., 2017). A potential candidate for the reactivation of this segment would be the 1946 Chatkal earthquake (Figures 1 and 2A), but new investigations are required to confirm this hypothesis.

We also propose that the different fault segments are separated by geometric discontinuities (step-overs and bends), which have a direct impact on the initiations, locations and ends of earthquake ruptures (Choi et al., 2012; Duan \& Oglesby, 2006; Klinger et al., 2006) and may play a role in inhibiting the propagation of the rupture of moderate earthquakes (Wesnousky, 2008). All these morphological and geometric observations have strong implications for the seismogenic potential of the TFF fault. Indeed, if we consider that only one segment of the TFF may rupture during a single event, the expected magnitude is lowered. Based on this assumption, the potential rupture length for each segment is between 35 and $50 \mathrm{~km}$, the moment magnitudes ranging from $\mathrm{M}_{\mathrm{w}} 6.9$ to 7.1 (Hanks and Bakun, 2008; Wesnousky, 2008). Given the determined slip-rate of 2.2 to $6.3 \mathrm{~mm} / \mathrm{yr}$ for this section of the TFF, we expect recurrence on the order of 500-1500 years between earthquakes. Earthquakes of $M>8$ imply recurrence times on the order of several thousand years to accumulate enough strain to rupture, which is in better agreement with paleoseismic and historical catalogs of earthquakes. 


\subsection{Paleoseismic investigations at Kyldau, earthquake recurrences and seismogenic}

\section{potential}

Our paleoseismic investigations are the first to present clear correlation between sediment ponding and surface faulting along the Kyldau segment. Our log interpretation shows that at least two earthquakes (and possibly a third) ruptured the surface after Holocene alluvial fan deposition. Combining this new data set with previously published paleoseismic data and the fault segmentation based on our mapping, we now discuss the seismic behavior of the TFF.

In our trench, an important result is that the radiocarbon ages indicate that the last large earthquake is older than 420 years but occurred within the last 2700 years. Along the Karasu segment, Korzhenkov et al. (2014) proposed that the ages of rockslides can be related to paleoearthquakes. Buried paleosoils dated by radiocarbon are interpreted as recording an earthquake at $\sim 1000$ BP. Moreover, our paleoseismic result is consistent with interpretations of a trench excavated across the Sary segment, close to the Toktogul reservoir (Tibaldi et al. 2015). There, log interpretations show one primary surface rupture over the past $2617 \pm 430$ years. Similarly, $\sim 22 \mathrm{~km}$ northward, Rust et al. (2018) found evidence of a surface rupture younger than 2330-2470 cal BP. This raises the question of whether the TFF has generated a large earthquake involving at least the Kyldau, Kelkilbel, Karasu and Sary segments (See Figure 2B). If we accept that these segments of the fault were reactivated during a single event, the potential surface rupture between the Kyldau valley and the Toktogul reservoir is $120 \mathrm{~km}$ and the associated moment magnitude is $\mathrm{Mw} \sim 7.5$ using Hanks and Bakun (2008) scaling relations. Furthermore, the values of co-seismic offsets along the different fault segments are still missing, but the minimum offset that we measured on the Kyldau segment is $\sim 10-11 \mathrm{~m}$, similar to offset of $12 \mathrm{~m}$ reported by Burtman et al., (1996). This offset value is surprisingly high, but in the range of coseismic slips reported for large earthquakes. The calculated potential magnitudes are thus comparable with historical and paleo-earthquakes reported for the Tien Shan range and its surroundings (Abdrakhmatov et al., 2016; Arrowsmith et al., 2017; Campbell et al., 2015).

We found evidence for a second seismic event potentially recorded by the colluvial wedge C1. This event horizon is bracketed between 2756 and 3273 BP. With a cumulative geomorphic offset of 23-24 m, Trifonov et al. (1990) also report a similar radiocarbon date of 
$2320 \pm 40$ years (2163 to 2459 cal BP) for an organic-rich sag pond unit that they interpreted as post-dating a paleo-rupture along the Kyldau segment.

The third event horizon in our trench is dated between 3667 and 3810 cal BP. Interestingly, only few hundred meters from our trench site, Burtman et al. (1996) reported a similar age of 3729-4241 cal BP (3670 \pm 80 BP; Beta-47555, Figure 4), from an organic-rich level buried below sands, clays and gravels. However, the authors used this radiocarbon age to estimate a slip rate by associating it with a $60 \mathrm{~m}$-offset from which they derived a geological slip-rate of $8-21 \mathrm{~mm} / \mathrm{yr}$. Our data agree with the likely occurrence of an earthquake around $\sim 3700$ years ago, but we argue that it is unrealistic that $60 \mathrm{~m}$ of slip accumulated during only three earthquakes.

Our paleoseismic investigations suggest that at least 2 earthquakes occurred between 420 and $3810 \mathrm{BP}$, implying a mean recurrence time of $\sim 2200$ years. This recurrence time is similar to that expected assuming that the smallest offset of $\sim 10 \mathrm{~m}$ measured along the Kyldau segment is a representative value (characteristic slip) for past strong earthquakes and an averaged maximum slip rate of $4.9 \mathrm{~mm} / \mathrm{yr}$. This calculated recurrence time favors the occurrence of $\mathrm{M} \sim 8$ earthquakes with long intervals. However, if we assume a scenario with three earthquakes, smaller recurrence times of $\sim 730$ years and $\sim 1450$ years are deduced, implying a variable behavior in the seismic cycle on the TFF. Given the limited number of data presently available along the TFF, it is impossible to verify if the fault breaks by segments or sometimes breaks during very large events. Only systematic paleoseismic studies conducted on individual segments will resolve this debate.

In the Tien Shan, a close analogue of the TFF is the $300 \mathrm{~km}$-long strike-slip Dzungarian fault bordering the eastern border of the Tien Shan range, a major structure segmented into three $\sim 100 \mathrm{~km}$ sections. Campbell et al. (2015) found evidence of a paleo-earthquake rupture of only $\sim 30 \mathrm{~km}$-long in the central section of the fault system. The 2-3 $\mathrm{m}$ of coseismic offsets may be representative of an earthquake of magnitude $\mathrm{M}_{\mathrm{w}} \sim 7$, but the Dzungarian fault also has the potential to generate greater earthquakes $\left(\mathrm{M}_{\mathrm{w}} 7.5\right.$ or more) if the three sections rupture in a single event.

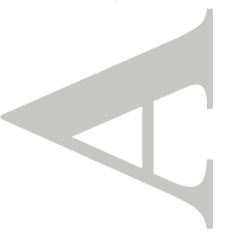




\subsection{TFF fault rotation and geodynamic implications}

We now discuss in the regional context our results obtained from the Kyldau valley site. We note that our minimum bound of $2.2 \mathrm{~mm} / \mathrm{yr}$ agrees with the $\sim 2 \mathrm{~mm} / \mathrm{yr}$ inferred from the GPS velocity field (Zubovich et al., 2010). But, if we use the maximum bound of 6.3 $\mathrm{mm} / \mathrm{yr}$, this slip rate is faster than the right-lateral geodetic rate. To reconcile the potential discrepancy of these rates, we can infer variations between Holocene rates and present-day rates due to variations in the accumulation of strain over multiple seismic cycles (Gold et al., 2017; Gold \& Cowgill, 2011; Rust et al., 2018). However, recent studies also show that strain accumulation and release along major active faults appear relatively constant over a range of different time scales (Gold et al., 2017; Vernant, 2015).

We propose a new geometric fault for the TFF and show that both fault terminations are expressed by en echelon thrust faulting on the Këksay segment (see Figure 2) and by two parallel thrust strands in the Arpa basin (Figures 2 and 3C). This observation supports the idea that the activity on the TFF system does not continue substantially into the Asia platform to the north or into the Tarim block to the south but is contained within the Tien Shan Range. There are two possible roles the right-lateral TFF may play in accommodating shortening in the Tien Shan Range related to Indo-Eurasian collision. The first is that the TFF acts as a transform fault and its motion is simply taken up by thrusting at each end terminations. The second (which may be additional to the first) is associated with possible counterclockwise rotations around a vertical axis to accommodate the regional deformation. These suggestions are supported by the observed GPS velocities relative to stable Eurasia and by the slip vectors from earthquake fault-plane solutions across the western Tien Shan (Figure 11). In the Fergana area, earthquake slip vectors are mostly parallel to the GPS velocities, but then rotate to become parallel to the TFF fault either side of the fault itself (see Suusamyr area on figure 11), without changing the GPS velocities substantially. This may imply that the strike-slip motion along the TFF is very small $(<1 \mathrm{~mm} / \mathrm{yr})$ or that block rotations may take place across the TFF system. It is also possible that rotations about a vertical axis may help reconcile geodetic slip-rate estimates (Zubovich et al., 2010) with the geologic rates discussed earlier. To test this assumption, we use the rotation model proposed by Campbell et al. (2013) for the Dzhungarian fault, a major right-lateral fault located in the eastern Tien Shan Range (Figure 12). In this fault rotation model, we assume that $S$ is 1 to $2 \mathrm{~mm} / \mathrm{yr}$ (the approximate shortening rate measured with GPS, Zubovich et al., 2010), an average distance across-strike 
(D) of $150 \mathrm{~km}$, an angle $\phi$ of $40^{\circ}$ corresponding to the angle between the fault strike and the GPS vector azimuth (Figure 12). We also input the value $\Theta$ of $0.73^{\circ} / \mathrm{Ma}$ for counterclockwise rotation rate, a value corresponding to the angular velocity of the Fergana Basin with respect to Eurasia rotation (Zubovich, 2010). We then calculate that the model requires a total slip-rate of 4.5-5.2 $\mathrm{mm} / \mathrm{yr}$, which agrees well with our calculated geological slip rate of 2.2 to $6.3 \mathrm{~mm} / \mathrm{yr}$.

A series of major NW-SE trending right-lateral strike-slip faults approximately spaced by $300 \mathrm{~km}$ cut the Kazakh platform and the Tien Shan Range (Figure 12). These strike-slip fault zones might be described as accommodating a part of the Indo-Eurasia shortening ( $2 \mathrm{~mm} / \mathrm{yr}$ over a north-south width of $\sim 500 \mathrm{~km}$ according to GPS (Zubovich et al., 2010) by counterclockwise vertical axis rotation in a bookshelf arrangement (i.e. Campbell et al., 2013; Davy \& Cobbold, 1988; Gregory et al., 2018; Yin, 2010). Our data along the TFF and the rates published in Campbell et al. (2013) for the Dzhungarian Fault also support the idea that geological slip rates for these two large strike-slip faults are strongly linked to fault rotation processes along a vertical axis. In Figure 12, we propose a speculative model with possible fault rotation processes distributed along $\sim 2500 \mathrm{~km}$ reactivating the Karatau-TFF and Dzhungarian-Chingiz fault systems. However, we only compared GPS and geological rates along two major strike-slip fault systems and more geological slip rates are needed along all major strike-slip faults (Dzhalair-Naiman, Aktas) distributed across the Kazakh platform to better constrain and validate fault rotation models. Indeed, only two studies examine recent activity on those strike-slip faults, showing slips in very large infrequent earthquakes (Campbell et al., 2015; Hollingsworth et al., 2016).

\section{Conclusion}

We identified nine geometric segments based on high-resolution imagery and propose that the fault segmentation may have strong implications for the seismogenic potential of the TFF fault.

Along the Kyldau segment, we opened a paleoseismic trench and identified that at least two primary surface ruptures (and possibly a third) occurred in the past 3800 years. We found that the Kyldau segment has not ruptured the surface since at least 420 years BP (possibly within the last 2700 years), making this fault segment a potential candidate to generate an earthquake with $\mathrm{M}>7$ in the future. 
Through morphological analyses of an offset alluvial fan and the application of multiple dating methods $\left({ }^{10} \mathrm{Be},{ }^{26} \mathrm{Al},{ }^{36} \mathrm{Cl}\right.$, luminescence and radiocarbon), we calculated a late Quaternary slip rate ranging from 2.2 to $6.3 \mathrm{~mm} / \mathrm{yr}$. The minimum bound for this slip rate agrees with geodetic rates. The maximum bound, however, is higher than the geodetic rates, but this discrepancy can be partly explained if the TFF accommodates shortening by counterclockwise rotation around a vertical axis. This geodynamic view has implications for seismic hazards in the Tien Shan Range because if apparent GPS rates are slower than the late Quaternary geological rates we may underestimate the probability of large earthquakes occurring along these major strike-slip faults. Indeed, the inferred rates from GPS measurements are very slow and therefore recurrence times are very long. As such, these faults are not always considered as potential sources for large seismic events. Moreover, we know that the absence of large earthquakes $(M>7.5)$ in the instrumental or historical records does not truly represent the full spatial extent of the deformation, and that active faults in the Tien Shan Range rupture during occasional large earthquakes that have been shown to have recurrence times of several thousand years (Abdrakhmatov et al., 2016; Campbell et al., 2013, 2015; Grützner et al., 2017; Hollingsworth et al., 2016; Landgraf et al., 2016).

\section{Acknowledgments}

This research was partly run under the Earthquakes without Frontiers project, funded by NERC and ESRC (grant code: EwF_NE/J02001X/1_1). This work was supported by the NERC Radiocarbon Facility NRCF010001 (allocation number 1763.1013). We are grateful to the expertise of Dr Xiaomei Xu at the Keck C cycle AMS Lab, University of California, Irvine for radiocarbon analyses of TAL-13 TR2. This work was supported by public funds received in the framework of GEOSUD, a project (ANR-10-EQPX-20) of the program "Investissements d'Avenir" managed by the French National Research Agency (ANR). Pléiades images provided by the French Space Agency CNES in the framework of ISIS Programme. We are grateful to Jules Fleury who has taken the aerial pictures of the TalasFergana Fault using a drone in summer 2017. The cosmogenic nuclides dating was supported by the National Program TelluS-ALEAS (SHEAR project) of CNRS/INSU. The cosmogenic measurements were performed at the ASTER AMS National Facility (CEREGE, Aix-enProvence), which is supported by the INSU/CNRS, the ANR through the "Projets thématiques d'excellence" program for the "Equipements d'excellence" ASTER-CEREGE action and IRD. We would like to thank I. Schimmelpfennig and L. Benedetti for fruitful discussions in the use and calculation of ${ }^{36} \mathrm{Cl}$. We thank all those involved in the 2013 and 2017 field-seasons, in particular Anaigul for her efficient camp management, our drivers Mokhtar, Sogon and Ivan and Azat Moldobayev, Sultan Baikulov and Erkin Rahimdinov for their field assistance. K. Blisniuk, J.A. Thompson Jobe, Taylor Schildgen and J. Bruce H. Shyu provided constructive reviews and comments that helped improve the original manuscript. The data used in this study are available in the tables. 


\section{References}

Abdrakhmatōv, Walker, R. T., Campbell, G. E., Carr, A. S., Elliott, A., Hillemann, C., et al. (2016). Multisegment rupture in the 11 July 1889 Chilik earthquake (Mw 8.0-8.3), Kazakh Tien Shan, interpreted from remote sensing, field survey, and paleoseismic trenching. Journal of Geophysical Research: Solid Earth, 121(6), 2015JB012763. https://doi.org/10.1002/2015JB012763

Abdrakhmatov, K. Y., Aldazhanov, S. A., Hager, B. H., Hamburger, M. W., Herring, T. A., Kalabaev, K. B., et al. (1996). Relatively recent construction of the Tien Shan inferred from GPS measurements of presentday crustal deformation rates. Nature, 384(6608), 450-453. https://doi.org/10.1038/384450a0

Adamiec, G., \& Aitken, M. J. (1998). Dose-rate conversion factors: update. Ancient TL, 16(2), 37-50.

Ainscoe, E. A., Abdrakhmatov, K. E., Baikulov, S., Carr, A. S., Elliott, A. J., Grützner, C., \& Walker, R. T. (2019). Variability in surface rupture between successive earthquakes on the Suusamyr Fault, Kyrgyz Tien Shan: implications for palaeoseismology. Geophysical Journal International, 216(1), 703-725. https://doi.org/10.1093/gji/ggy457

Alexeiev, D. V., Bykadorov, V. A., Volozh, Y. A., \& Sapozhnikov, R. B. (2017). Kinematic analysis of Jurassic grabens of soulthern Turgai and the role of the Mesozoic stage in the evolution of the Karatau-TalasFerghana strike-slip fault, Southern Kazakhstan and Tian Shan. Geotectonics, 51(2), 105-120. https://doi.org/10.1134/S0016852117020029

Allen, M. B. (2001). Dome and basin refolding and transpressive inversion along the Karatau Fault System, southern Kazakstan. Journal of the Geological Society (Abstracts), 158(1), 83-95.

https://doi.org/10.1144/jgs.158.1.83

Armitage, S. J., \& Bailey, R. M. (2005). The measured dependence of laboratory beta dose rates on sample grain size. Radiation Measurements, 39(2), 123-127. https://doi.org/10.1016/j.radmeas.2004.06.008

Arnold, M., Merchel, S., Bourlès, D. L., Braucher, R., Benedetti, L., Finkel, R. C., et al. (2010). The French accelerator mass spectrometry facility ASTER: Improved performance and developments. Nuclear Instruments and Methods in Physics Research Section B: Beam Interactions with Materials and Atoms, 268(11), 1954-1959. https://doi.org/10.1016/j.nimb.2010.02.107

Arrowsmith, J. R., Crosby, C. J., Korzhenkov, A. M., Mamyrov, E., Povolotskaya, I., Guralnik, B., \& Landgraf, A. (2017). Surface rupture of the 1911 kebin (Chon-Kemin) earthquake, Northern tien shan, kyrgyzstan. Geological Society Special Publication, 432(1), 233-253. https://doi.org/10.1144/SP432.10

Ascough, P., Cook, G., \& Dugmore, A. (2005). Methodological approaches to determining the marine radiocarbon reservoir effect. Progress in Physical Geography: Earth and Environment, 29(4), 532547. https://doi.org/10.1191/0309133305pp461ra

Avouac, J.-P., \& Tapponnier, P. (1993). Kinematic model of active deformation in central Asia. Geophysical Research Letters, 20(10), 895-898. https://doi.org/10.1029/93GL00128 
Bande, A., Sobel, E. R., Mikolaichuk, A., \& Acosta, V. T. (2015). Talas-Fergana Fault Cenozoic timing of deformation and its relation to Pamir indentation. Geological Society, London, Special Publications, 427, SP427.1. https://doi.org/10.1144/SP427.1

Bindi, D., Parolai, S., Gómez-Capera, A., Locati, M., Kalmetyeva, Z., \& Mikhailova, N. (2014). Locations and magnitudes of earthquakes in Central Asia from seismic intensity data. Journal of Seismology, 18(1), 1-21. https://doi.org/10.1007/s10950-013-9392-1

Borchers, B., Marrero, S., Balco, G., Caffee, M., Goehring, B., Lifton, N., et al. (2016). Geological calibration of spallation production rates in the CRONUS-Earth project. Quaternary Geochronology, 31, 188-198. https://doi.org/10.1016/j.quageo.2015.01.009

Bosboom, Dupont- Nivet, Huang, Yang, \& Guo. (2014). Oligocene clockwise rotations along the eastern Pamir: Tectonic and paleogeographic implications. Tectonics, 33(2), 53-66. https://doi.org/10.1002/2013TC003388

Braucher, R., Merchel, S., Borgomano, J., \& Bourlès, D. L. (2011). Production of cosmogenic radionuclides at great depth: A multi element approach. Earth and Planetary Science Letters, 309(1), 1-9. https://doi.org/10.1016/j.eps1.2011.06.036

Braucher, R., Bourlès, D., Merchel, S., Vidal Romani, J., Fernadez-Mosquera, D., Marti, K., et al. (2013). Determination of muon attenuation lengths in depth profiles from in situ produced cosmogenic nuclides. Nuclear Instruments and Methods in Physics Research Section B: Beam Interactions with Materials and Atoms, 294, 484-490. https://doi.org/10.1016/j.nimb.2012.05.023

Bronk Ramsey, C., Higham, T., Bowles, A., \& Hedges, R. (2004). Improvements to the Pretreatment of Bone at Oxford. Radiocarbon, 46(1), 155-163. doi:10.1017/S0033822200039473

Bronk Ramsey, C., Higham, T.F.G., Owen, D.C., Pike, A.W.G. and Hedges, R.E.M. (2002) Radiocarbon dates from the Oxford AMS system: Archaeometry datelist 31. Archaeometry, 44, supplement s1, 1-150. (doi:10.1111/j.1475-4754.2002.tb01101.x).

Burgette, R. J., Weldon, R. J., Abdrakhmatov, K. Y., Ormukov, C., Owen, L. A., \& Thompson, S. C. (2017). Timing and process of river and lake terrace formation in the Kyrgyz Tien Shan. Quaternary Science Reviews, 159, 15-34. https://doi.org/10.1016/j.quascirev.2017.01.003

Burtman, V. (1975). Structural geology of variscan Tien Shan, USSR. American Journal of Science (Abstracts), $275,157$.

Burtman, V. S., Skobelev, S. F., \& Molnar, P. (1996). Late Cenozoic slip on the Talas-Ferghana fault, the Tien Shan, central Asia. GSA Bulletin, 108(8), 1004-1021. https://doi.org/10.1130/00167606(1996)108\&lt;1004:LCSOTT\&gt;2.3.CO;2

Buslov, M. M., De Grave, J., Bataleva, E. A. V., \& Batalev, V. Y. (2007). Cenozoic tectonic and geodynamic evolution of the Kyrgyz Tien Shan Mountains: A review of geological, thermochronological and geophysical data. Journal of Asian Earth Sciences, 29(2), 205-214. https://doi.org/10.1016/j.jseaes.2006.07.001 
Buylaert, J. P., Murray, A. S., Thomsen, K. J., \& Jain, M. (2009). Testing the potential of an elevated temperature IRSL signal from K-feldspar. Radiation Measurements, 44(5), 560-565. https://doi.org/10.1016/j.radmeas.2009.02.007

Campbell, G. E., Walker, R. T., Abdrakhmatov, K., Schwenninger, J., Jackson, J., Elliott, J. R., \& Copley, A. (2013). The Dzhungarian fault: Late Quaternary tectonics and slip rate of a major right-lateral strikeslip fault in the northern Tien Shan region. Journal of Geophysical Research: Solid Earth, 118(10), 5681-5698. https://doi.org/10.1002/jgrb.50367

Campbell, G. E., Walker, R. T., Abdrakhmatov, K., Jackson, J., Elliott, J. R., Mackenzie, D., et al. (2015). Great earthquakes in low strain rate continental interiors: An example from SE Kazakhstan. Journal of Geophysical Research: Solid Earth, 120(8), 2015JB011925. https://doi.org/10.1002/2015JB011925

Chmeleff, J., von Blanckenburg, F., Kossert, K., \& Jakob, D. (2010). Determination of the 10Be half-life by multicollector ICP-MS and liquid scintillation counting. Nuclear Instruments and Methods in Physics Research Section B: Beam Interactions with Materials and Atoms, 268(2), 192-199. https://doi.org/10.1016/j.nimb.2009.09.012

Choi Jin- Hyuck, Jin Kwangmin, Enkhbayar Dandar, Davvasambuu Battogtokh, Bayasgalan Amgalan, \& Kim Young- Seog. (2012). Rupture propagation inferred from damage patterns, slip distribution, and segmentation of the 1957 MW8.1 Gobi- Altay earthquake rupture along the Bogd fault, Mongolia. Journal of Geophysical Research: Solid Earth, 117(B12). https://doi.org/10.1029/2011JB008676

Choi Jin- Hyuck, Klinger Yann, Ferry Matthieu, Ritz Jean- François, Kurtz Robin, Rizza Magali, et al. (2018). Geologic Inheritance and Earthquake Rupture Processes: The 1905 M $\geq 8$ Tsetserleg- Bulnay StrikeSlip Earthquake Sequence, Mongolia. Journal of Geophysical Research: Solid Earth, 123(2), 19251953. https://doi.org/10.1002/2017JB013962

Davy, P., \& Cobbold, P. . (1988). Indentation tectonics in nature and experiment. 1. Experiments scaled for gravity. Bull. Geol. Inst. Univ. Uppsala, 14, 129-141.

De Grave, J., Glorie, S., Buslov, M. M., Stockli, D. F., McWilliams, M. O., Batalev, V. Y., \& Van den haute, P. (2013). Thermo-tectonic history of the Issyk-Kul basement (Kyrgyz Northern Tien Shan, Central Asia). Gondwana Research, 23(3), 998-1020. https://doi.org/10.1016/j.gr.2012.06.014

DeLong, S. B., \& Arnold, L. J. (2007). Dating alluvial deposits with optically stimulated luminescence, AMS 14C and cosmogenic techniques, western Transverse Ranges, California, USA. Quaternary Geochronology, 2(1-4), 129-136. https://doi.org/10.1016/j.quageo.2006.03.012

Delvaux, Abdrakhmatov, Lemzin, \& Strom. (2001). Landslides and surface breaks of the 1911 Ms 8.2 Kemin earthquake, Kyrgyzstan. Russian Geology and Geophysics, 42(10), 1667-1677.

Duan, \& Oglesby. (2006). Heterogeneous fault stresses from previous earthquakes and the effect on dynamics of parallel strike- slip faults. Journal of Geophysical Research: Solid Earth, 111(B5). https://doi.org/10.1029/2005JB004138

Duller, G. a. T. (2008). Single-grain optical dating of Quaternary sediments: why aliquot size matters in luminescence dating. Boreas, 37(4), 589-612. https://doi.org/10.1111/j.1502-3885.2008.00051.x

England, \& Molnar. (2005). Late Quaternary to decadal velocity fields in Asia. Journal of Geophysical Research: Solid Earth, 110(B12). https://doi.org/10.1029/2004JB003541 
Feld, C., Haberland, C., Schurr, B., Sippl, C., Wetzel, H.-U., Roessner, S., et al. (2015). Seismotectonic study of the Fergana Region (Southern Kyrgyzstan): distribution and kinematics of local seismicity. Earth, Planets and Space, 67(1), 40. https://doi.org/10.1186/s40623-015-0195-1

Fifield, L. K., Ophel, T. R., Allan, G. L., Bird, J. R., \& Davie, R. F. (1990). Accelerator mass spectrometry at the Australian National University's 14UD accelerator: experience and developments. Nuclear Instruments and Methods in Physics Research Section B: Beam Interactions with Materials and Atoms, 52(3), 233-237. https://doi.org/10.1016/0168-583X(90)90412-N

Galbraith, R. F., Roberts, R. G., Laslett, G. M., Yoshida, H., \& Olley, J. M. (1999). Optical Dating of Single and Multiple Grains of Quartz from Jinmium Rock Shelter, Northern Australia: Part I, Experimental Design and Statistical Models*. Archaeometry, 41(2), 339-364. https://doi.org/10.1111/j.14754754.1999.tb00987.x

Ghose, S., Mellors, R. J., Korjenkov, A. M., Hamburger, M. W., Pavlis, T. L., Pavlis, G. L., et al. (1997). The MS = 7.3 1992 Suusamyr, Kyrgyzstan, earthquake in the tien shan: 2. Aftershock focal mechanisms and surface deformation. Bulletin of the Seismological Society of America, 87(1), 23-38.

Gold, R. D., \& Cowgill, E. (2011). Deriving fault-slip histories to test for secular variation in slip, with examples from the Kunlun and Awatere faults. Earth and Planetary Science Letters, 301(1), 52-64. https://doi.org/10.1016/j.eps1.2010.10.011

Gold, R. D., Cowgill, E., Arrowsmith, J. R., \& Friedrich, A. M. (2017). Pulsed strain release on the Altyn Tagh fault, northwest China. Earth and Planetary Science Letters, 459, 291-300. https://doi.org/10.1016/j.eps1.2016.11.024

Goode, J. K., Burbank, D. W., \& Ormukov, C. (2014). Pliocene-Pleistocene initiation, style, and sequencing of deformation in the central Tien Shan. Tectonics, 33(4), 464-484.

https://doi.org/10.1002/2013TC003394

Gosse, J. C., \& Phillips, F. M. (2001). Terrestrial in situ cosmogenic nuclides: theory and application. Quaternary Science Reviews, 20, 1475-1560. https://doi.org/10.1016/S0277-3791(00)00171-2

Gregory, L. C., Mac Niocaill, C., Walker, R. T., Bayasgalan, G., \& Craig, T. J. (2018). Vertical axis rotation (or lack thereof) of the eastern Mongolian Altay Mountains: Implications for far-field transpressional mountain building. Tectonophysics, 736, 31-46. https://doi.org/10.1016/j.tecto.2018.03.020

Grützner, C., Carson, E., Walker, R. T., Rhodes, E. J., Mukambayev, A., Mackenzie, D., et al. (2017). Assessing the activity of faults in continental interiors: Palaeoseismic insights from SE Kazakhstan. Earth and Planetary Science Letters, 459, 93-104. https://doi.org/10.1016/j.epsl.2016.11.025

Guérin, G., Mercier, N., \& Adamiec, G. (2011). Dose-rate conversion factors: update. Ancient TL, 29(1), 5-8.

Haibing, L., Van der Woerd, J., Tapponnier, P., Klinger, Y., Xuexiang, Q., Jingsui, Y., \& Yintang, Z. (2005). Slip rate on the Kunlun fault at Hongshui Gou, and recurrence time of great events comparable to the 14/11/2001, Mw 7.9 Kokoxili earthquake. Earth and Planetary Science Letters, 237(1), 285-299. https://doi.org/10.1016/j.eps1.2005.05.041

Hanks, T. C., \& Bakun, W. H. (2008). M-logA Observations for Recent Large EarthquakesShort Note. Bulletin of the Seismological Society of America, 98(1), 490-494. https://doi.org/10.1785/0120070174 
Hollingsworth, J., Walker, R. T., Abdrakhmatov, K., Campbell, G., Mukambayev, A., Rhodes, E., \& Rood, D. H. (2016). Active fault slip and potential large magnitude earthquakes within the stable Kazakh Platform (Central Kazakhstan). AGU Fall Meeting Abstracts, 32, T32B-05.

Huntley, D. ., \& Baril, M. . (1997). The K content of the K-feldspars being measured in optical dating or in thermoluminescence dating. Ancient TL, 15(1), 11-13.

Huntley, D. ., Hancock, R. ., \& Ancient, T. . (2001). The Rb contents of the K-feldspar grains being measured in optical dating. Ancient TL, 19(2), 43-46.

Januzakov, K., Omuraliev, M., Omuralieva, A., Ilyasov, B. ., \& Grebennikova, V. . (2003). Strong Earthquakes of the Tien-Shan (within the Kyrgyzstan Territory and Adjacent Regions of the Countries of Central Asia). Ilim, Bishkek. (Ilim). Bishkek.

Jia, Y., Fu, B., Jolivet, M., \& Zheng, S. (2015). Cenozoic tectono-geomorphological growth of the SW Chinese Tian Shan: Insight from AFT and detrital zircon U-Pb data. Journal of Asian Earth Sciences, 111, 395-413. https://doi.org/10.1016/j.jseaes.2015.06.023

Kalmetieva, Z. ., Mikolaichuk, A. V., Moldobekov, B. D., Meleshko, Jantaev, \& Zubovich, A. V. (2009). The Atlas of Earthquakes in Kyrgyzstan.

Kars, R. H., Reimann, T., Ankjærgaard, C., \& Wallinga, J. (2014). Bleaching of the post-IR IRSL signal: new insights for feldspar luminescence dating. Boreas, 43(4), 780-791. https://doi.org/10.1111/bor.12082

Klinger, Y., Michel, R., \& King, G. C. P. (2006). Evidence for an earthquake barrier model from Mw 7.8 Kokoxili (Tibet) earthquake slip-distribution. Earth and Planetary Science Letters, 242(3), 354-364. https://doi.org/10.1016/j.epsl.2005.12.003

Klinger, Y., Etchebes, M., Tapponnier, P., \& Narteau, C. (2011). Characteristic slip for five great earthquakes along the Fuyun fault in China. Nature Geoscience, 4(6), 389-392. https://doi.org/10.1038/ngeo1158

Klinger Yann. (2010). Relation between continental strike- slip earthquake segmentation and thickness of the crust. Journal of Geophysical Research: Solid Earth, 115(B7). https://doi.org/10.1029/2009JB006550

Klinger, Yann, Xu, X., Tapponnier, P., Woerd, J. V. der, Lasserre, C., \& King, G. (2005). High-Resolution Satellite Imagery Mapping of the Surface Rupture and Slip Distribution of the Mw 7.8, 14 November 2001 Kokoxili Earthquake, Kunlun Fault, Northern Tibet, China. Bulletin of the Seismological Society of America, 95(5), 1970-1987. https://doi.org/10.1785/0120040233

Korjenkov, Bobrovskii, \& Mamyrov. (2010). Evidence for strong paleoearthquakes along the Talas-Fergana fault near the Kök-Bel Pass, Kyrgyzstan. Geotectonics, 44(3), 262-270. Geotectonics, 44(3), 262-270.

Korschinek, G., Bergmaier, A., Faestermann, T., Gerstmann, U. C., Knie, K., Rugel, G., et al. (2010). A new value for the half-life of 10Be by Heavy-Ion Elastic Recoil Detection and liquid scintillation counting. Nuclear Instruments and Methods in Physics Research Section B: Beam Interactions with Materials and Atoms, 268(2), 187-191. https://doi.org/10.1016/j.nimb.2009.09.020

Korzhenkov, A. M., Abdieva, S. V., Belousov, T. P., Rust, D., \& Tibaldi, A. (2014). An age of rockslides and paleoearthquakes in the Karasu River valley (Talas-Fergana Fault, Kyrgyzstan). Seismic Instruments, 50(2), 97-108. https://doi.org/10.3103/S0747923914020066

Korzhenkov, A. M., Rogozhin, E. A., Xuhui, S., Qinjian, T., \& Yueren, X. (2014). Strong paleoearthquakes along the Talas-Fergana Fault, Kyrgyzstan. Geodesy and Geodynamics, 5(1), 11-19. https://doi.org/10.3724/SP.J.1246.2014.01011 
Landgraf, A., Kuebler, S., Hintersberger, E., \& Stein, S. (2016). Active tectonics, earthquakes and palaeoseismicity in slowly deforming continents. Geological Society, London, Special Publications, 432, SP432.13. https://doi.org/10.1144/SP432.13

Le Dortz, K., Meyer, B., Sébrier, M., Nazari, H., Braucher, R., Fattahi, M., et al. (2009). Holocene right-slip rate determined by cosmogenic and OSL dating on the Anar fault, Central Iran. Geophysical Journal International, 179(2), 700-710. https://doi.org/10.1111/j.1365-246X.2009.04309.x

Lowick, S. E., Trauerstein, M., \& Preusser, F. (2012). Testing the application of post IR-IRSL dating to fine grain waterlain sediments. Quaternary Geochronology, 8, 33-40.

Manighetti, I., Campillo, M., Bouley, S., \& Cotton, F. (2007). Earthquake scaling, fault segmentation, and structural maturity. Earth and Planetary Science Letters, 253(3), 429-438. https://doi.org/10.1016/j.epsl.2006.11.004

Masarik J., \& Beer J. (2009). An updated simulation of particle fluxes and cosmogenic nuclide production in the Earth's atmosphere. Journal of Geophysical Research: Atmospheres, 114(D11). https://doi.org/10.1029/2008JD010557

Merchel, S., \& Bremser, W. (2004). First international 26Al interlaboratory comparison - Part I. Nuclear Instruments and Methods in Physics Research Section B: Beam Interactions with Materials and Atoms, 223-224, 393-400. https://doi.org/10.1016/j.nimb.2004.04.076

Molnar, P., \& Dayem, K. E. (2010). Major intracontinental strike-slip faults and contrasts in lithospheric strength. Geosphere, 6(4), 444-467. https://doi.org/10.1130/GES00519.1

Molnar, P., \& Qidong, D. (1984). Faulting associated with large earthquakes and the average rate of deformation in central and eastern Asia. Journal of Geophysical Research: Solid Earth, 89(B7), 62036227. https://doi.org/10.1029/JB089iB07p06203

Molnar, P., \& Tapponnier, P. (1977). The Collision between India and Eurasia. Scientific American, 236(4), 3041.

Murray, A. S., \& Wintle, A. G. (2000). Luminescence dating of quartz using an improved single-aliquot regenerative-dose protocol. Radiation Measurements, 32(1), 57-73. https://doi.org/10.1016/S13504487(99)00253-X

Nishiizumi, K., Imamura, M., Caffee, M. W., Southon, J. R., Finkel, R. C., \& McAninch, J. (2007). Absolute calibration of 10Be AMS standards. Nuclear Instruments and Methods in Physics Research Section B: Beam Interactions with Materials and Atoms, 258(2), 403-413. https://doi.org/10.1016/j.nimb.2007.01.297

Nissen, E., Walker, R. T., Bayasgalan, A., Carter, A., Fattahi, M., Molor, E., et al. (2009). The late Quaternary slip-rate of the Har-Us-Nuur fault (Mongolian Altai) from cosmogenic ${ }^{10} \mathrm{Be}$ and luminescence dating. Earth and Planetary Science Letters, 286(3-4), 467-478. https://doi.org/Nissen, E., Walker, R.T., Bayasgalan, A., Carter, A., Fattahi, M., Molor, E., Schnabel, C. <http://eprints.gla.ac.uk/view/author/3038.html>, West, A.J., and Xu, S. <http://eprints.gla.ac.uk/view/author/12708.html> (2009) The late Quaternary slip-rate of the Har-UsNuur fault (Mongolian Altai) from cosmogenic 10Be and luminescence dating. Earth and Planetary Science Letters 
<http://eprints.gla.ac.uk/view/journal_volume/Earth_and_Planetary_Science_Letters.html>, 286(3-4), pp. 467-478. (doi:10.1016/j.epsl.2009.06.048 <http://dx.doi.org/10.1016/j.epsl.2009.06.048>)

Norris, T. ., Gancarz, A. ., Rokop, D. ., \& Thomas, K. . (1983). Half-life of Al-26. Journal of Geophysical Research B, 88, B331-333.

Olley, J. M., Caitcheon, G. G., \& Roberts, R. G. (1999). The origin of dose distributions in fluvial sediments, and the prospect of dating single grains from fluvial deposits using optically stimulated luminescence. Radiation Measurements, 30(2), 207-217. https://doi.org/10.1016/S1350-4487(99)00040-2

Perrin Clément, Manighetti Isabelle, Ampuero Jean- Paul, Cappa Frédéric, \& Gaudemer Yves. (2016). Location of largest earthquake slip and fast rupture controlled by along- strike change in fault structural maturity due to fault growth. Journal of Geophysical Research: Solid Earth, 121(5), 3666-3685. https://doi.org/10.1002/2015JB012671

Prescott, J. R., \& Hutton, J. T. (1994). Cosmic ray contributions to dose rates for luminescence and ESR dating: Large depths and long-term time variations. Radiation Measurements, 23(2), 497-500. https://doi.org/10.1016/1350-4487(94)90086-8

Readhead, M. . (2002). Absorbed dose fraction for 87Rb $\beta$ particles. Anvient TL, 20(1), 25-28.

Reigber, C., Michel, G. W., Galas, R., Angermann, D., Klotz, J., Chen, J. Y., et al. (2001). New space geodetic constraints on the distribution of deformation in Central Asia. Earth and Planetary Science Letters, 191(1), 157-165. https://doi.org/10.1016/S0012-821X(01)00414-9

Reimer, P. J., Bard, E., Bayliss, A., Beck, J. W., Blackwell, P. G., Ramsey, C. B., et al. (2013). IntCal13 and Marine13 Radiocarbon Age Calibration Curves 0-50,000 Years cal BP. Radiocarbon, 55(4), 18691887. https://doi.org/10.2458/azu_js_rc.55.16947

Repka, J. L., Anderson, R. S., \& Finkel, R. C. (1997). Cosmogenic dating of fluvial terraces, Fremont River, Utah. Earth and Planetary Science Letters, 152(1), 59-73. https://doi.org/10.1016/S0012821X(97)00149-0

Rizza, M., Ritz, J.-F., Braucher, R., Vassallo, R., Prentice, C., Mahan, S., et al. (2011). Slip rate and slip magnitudes of past earthquakes along the Bogd left-lateral strike-slip fault (Mongolia). Geophysical Journal International, 186(3), 897-927. https://doi.org/10.1111/j.1365-246X.2011.05075.x

Rizza, M., Ritz, J.-F., Prentice, C., Vassallo, R., Braucher, R., Larroque, C., et al. (2015). Earthquake Geology of the Bulnay Fault (Mongolia). Bulletin of the Seismological Society of America. https://doi.org/10.1785/0120140119

Rizza, M., Dubois, C., Fleury, J., Abdrakhmatov, K., Pousse, L., Baikulov, S., \& Vezinet, A. (2017). Slipaccumulation patterns and earthquake recurrences along the Talas-Fergana Fault - Contributions of high-resolution geomorphic offsets. AGU Fall Meeting Abstracts, 42. Retrieved from http://adsabs.harvard.edu/abs/2017AGUFM.T42A..04R

Rolland, Y., Alexeiev, D. V., Kröner, A., Corsini, M., Loury, C., \& Monié, P. (2013). Late Palaeozoic to Mesozoic kinematic history of the Talas-Ferghana strike-slip fault (Kyrgyz West Tianshan) as revealed by 40Ar/39Ar dating of syn-kinematic white mica. Journal of Asian Earth Sciences, 67-68, 76-92. https://doi.org/10.1016/j.jseaes.2013.02.012 
Rust, D., Korzhenkov Andrey, \& Tibaldi Alessandro. (2018). Geologic Slip- Rate Determinations on the Talas- Fergana Fault: Mismatch With Geodetic Slip Rate. Geophysical Research Letters, O(0). https://doi.org/10.1002/2017GL076990

Sanchez, G., Rolland, Y., Corsini, M., Braucher, R., Bourlès, D., Arnold, M., \& Aumaître, G. (2010). Relationships between tectonics, slope instability and climate change: Cosmic ray exposure dating of active faults, landslides and glacial surfaces in the SW Alps. Geomorphology, 117(1), 1-13. https://doi.org/10.1016/j.geomorph.2009.10.019

Schimmelpfennig, I., Benedetti, L., Finkel, R., Pik, R., Blard, P.-H., Bourlès, D., et al. (2009). Sources of in-situ $36 \mathrm{Cl}$ in basaltic rocks. Implications for calibration of production rates. Quaternary Geochronology, 4(6), 441-461. https://doi.org/10.1016/j.quageo.2009.06.003

Schimmelpfennig, I., Benedetti, L., Garreta, V., Pik, R., Blard, P.-H., Burnard, P., et al. (2011). Calibration of cosmogenic $36 \mathrm{Cl}$ production rates from $\mathrm{Ca}$ and $\mathrm{K}$ spallation in lava flows from Mt. Etna $\left(38^{\circ} \mathrm{N}\right.$, Italy) and Payun Matru (36 S, Argentina). Geochimica et Cosmochimica Acta, 75(10), 2611-2632. https://doi.org/10.1016/j.gca.2011.02.013

Schlagenhauf, A., Manighetti, I., Benedetti, L., Gaudemer, Y., Finkel, R., Malavieille, J., \& Pou, K. (2011). Earthquake supercycles in Central Italy, inferred from $36 \mathrm{Cl}$ exposure dating. Earth and Planetary Science Letters, 307(3), 487-500. https://doi.org/10.1016/j.eps1.2011.05.022

Sharma, P., Kubik, P. W., Fehn, U., Gove, H. E., Nishiizumi, K., \& Elmore, D. (1990). Development of 36Cl standards for AMS. Nuclear Instruments and Methods in Physics Research Section B: Beam Interactions with Materials and Atoms, 52(3), 410-415. https://doi.org/10.1016/0168-583X(90)904473

Simpson, Hamburger, Pavlov, \& Nersesov. (1981). Tectonics and seismicity of the Toktogul Reservoir Region, Kirgizia, USSR. Journal of Geophysical Research: Solid Earth, 86(B1), 345-358. https://doi.org/10.1029/JB086iB01p00345

Sloan, R. A., Jackson, J. A., McKenzie, D., \& Priestley, K. (2011). Earthquake depth distributions in central Asia, and their relations with lithosphere thickness, shortening and extension. Geophysical Journal International, 185(1), 1-29. https://doi.org/10.1111/j.1365-246X.2010.04882.x

Sobel, E. R., Chen, J., \& Heermance, R. V. (2006). Late Oligocene-Early Miocene initiation of shortening in the Southwestern Chinese Tian Shan: Implications for Neogene shortening rate variations. Earth and Planetary Science Letters, 247(1), 70-81. https://doi.org/10.1016/j.eps1.2006.03.048

Stone, J. O., Allan, G. L., Fifield, L. K., \& Cresswell, R. G. (1996). Cosmogenic chlorine-36 from calcium spallation. Geochimica et Cosmochimica Acta, 60(4), 679-692. https://doi.org/10.1016/00167037(95)00429-7

Stone, John O. (2000). Air pressure and cosmogenic isotope production. Journal of Geophysical Research: Solid Earth, 105(B10), 23753-23759. https://doi.org/10.1029/2000JB900181

Stuiver, M., \& Reimer, P. . (1993). Extended 14C data base and revised CALIB 3.0 14C age calibration program,. Radiocarbon, 35, 215-230.

Tapponnier, \& Molnar, P. (1979). Active faulting and cenozoic tectonics of the Tien Shan, Mongolia, and Baykal Regions. Journal of Geophysical Research: Solid Earth, 84(B7), 3425-3459. https://doi.org/10.1029/JB084iB07p03425 
Tapponnier, Peltzer, \& Armijo. (1986). On the mechanics of the collision between India and Asia. Geological Society, London, Special Publications, 19(1), 113-157.

https://doi.org/10.1144/GSL.SP.1986.019.01.07

Thompson, J. A., Chen, J., Yang, H., Li, T., Bookhagen, B., \& Burbank, D. (2018). Coarse- versus fine-grain quartz OSL and cosmogenic 10Be dating of deformed fluvial terraces on the northeast Pamir margin, northwest China. Quaternary Geochronology, 46, 1-15. https://doi.org/10.1016/j.quageo.2018.01.002

Thompson, S. C., Weldon, R. J., Rubin, C. M., Abdrakhmatov, K., Molnar, P., \& Berger, G. W. (2002). Late Quaternary slip rates across the central Tien Shan, Kyrgyzstan, central Asia. Journal of Geophysical Research: Solid Earth, 107(B9), 2203. https://doi.org/10.1029/2001JB000596

Thomsen, K. J., Murray, A. S., Jain, M., \& Bøtter-Jensen, L. (2008). Laboratory fading rates of various luminescence signals from feldspar-rich sediment extracts. Radiation Measurements, 43(9), 14741486. https://doi.org/10.1016/j.radmeas.2008.06.002

Tibaldi, A., Corazzato, C., Rust, D., Bonali, F. L., Pasquarè Mariotto, F. A., Korzhenkov, A. M., et al. (2015). Tectonic and gravity-induced deformation along the active Talas-Fergana Fault, Tien Shan, Kyrgyzstan. Tectonophysics, 657, 38-62. https://doi.org/10.1016/j.tecto.2015.06.020

Trifonov, V. G., Korzhenkov, A. M., \& Omar, K. M. (2015). Recent geodynamics of major strike-slip zones. Geodesy and Geodynamics, 6(5), 361-383. https://doi.org/10.1016/j.geog.2015.06.003

Vernant, P. (2015). What can we learn from 20years of interseismic GPS measurements across strike-slip faults? Tectonophysics, 644-645, 22-39. https://doi.org/10.1016/j.tecto.2015.01.013

Wei Hong- Hong, Meng Qing- Ren, Ding Lin, \& Li Zhen- Yu. (2013). Tertiary evolution of the western Tarim basin, northwest China: A tectono- sedimentary response to northward indentation of the Pamir salient. Tectonics, 32(3), 558-575. https://doi.org/10.1002/tect.20046

Wells, D. L., \& Coppersmith, K. J. (1994). New empirical relationships among magnitude, rupture length, rupture width, rupture area, and surface displacement. Bulletin of the Seismological Society of America, 84(4), 974-1002.

Wesnousky, S. G. (2008). Displacement and Geometrical Characteristics of Earthquake Surface Ruptures: Issues and Implications for Seismic-Hazard Analysis and the Process of Earthquake RuptureDisplacement and Geometrical Characteristics of Earthquake Surface Ruptures. Bulletin of the Seismological Society of America, 98(4), 1609-1632. https://doi.org/10.1785/0120070111

Woerd, J. van der, Mériaux, A.-S., Klinger, Y., Ryerson, F. J., Gaudemer, Y., \& Tapponnier, P. (2002). The 14 November 2001, Mw = 7.8 Kokoxili Earthquake in Northern Tibet (Qinghai Province, China). Seismological Research Letters, 73(2), 125-135. https://doi.org/10.1785/gssrl.73.2.125

Yin, A. (2010). Cenozoic tectonic evolution of Asia: A preliminary synthesis. Tectonophysics, 488(1), $293-325$. https://doi.org/10.1016/j.tecto.2009.06.002

Zielke, O., Klinger, Y., \& Arrowsmith, J. R. (2015). Fault slip and earthquake recurrence along strike-slip faults -Contributions of high-resolution geomorphic data. Tectonophysics, 638, 43-62. https://doi.org/10.1016/j.tecto.2014.11.004

Zubovich, A. V., Wang, X., Scherba, Y. G., Schelochkov, G. G., Reilinger, R., Reigber, C., et al. (2010). GPS velocity field for the Tien Shan and surrounding regions. Tectonics, 29(6), TC6014. https://doi.org/10.1029/2010TC002772 
Table 1: Dextral offset measurements and associated uncertainties made along the Kyldau segment with worldview imagery $(0.7 \mathrm{~m}$ of resolution).

\begin{tabular}{|c|c|c|c|}
\hline Latitude $\left(^{\circ}\right)$ & Longitude $\left(^{\circ}\right)$ & Offset (m) & Uncertainty (m) \\
\hline $41.178589^{\circ}$ & $73.900286^{\circ}$ & 20 & 8.5 \\
\hline $41.169460^{\circ}$ & $73.908603^{\circ}$ & 220 & 15 \\
\hline $41.168493^{\circ}$ & $73.909924^{\circ}$ & 93 & 4 \\
\hline $41.156048^{\circ}$ & $73.920337^{\circ}$ & 35.5 & 10 \\
\hline $41.142221^{\circ}$ & $73.935035^{\circ}$ & 134 & 3 \\
\hline $41.141025^{\circ}$ & $73.936274^{\circ}$ & 27 & 3 \\
\hline $41.140331^{\circ}$ & $73.937030^{\circ}$ & 27.7 & 2 \\
\hline $41.140153^{\circ}$ & $73.937231^{\circ}$ & 10.5 & 5 \\
\hline $41.139851^{\circ}$ & $73.937317^{\circ}$ & 27.7 & 5 \\
\hline $41.115899^{\circ}$ & $73.968259^{\circ}$ & 12 & 5 \\
\hline $41.115589^{\circ}$ & $73.968561^{\circ}$ & 50 & 10 \\
\hline $41.106577^{\circ}$ & $73.979433^{\circ}$ & 22.5 & 5 \\
\hline $41.104628^{\circ}$ & $73.982037^{\circ}$ & 50 & 68 \\
\hline $41.092065^{\circ}$ & $73.998207^{\circ}$ & & 3 \\
\hline
\end{tabular}

(c) 2019 American Geophysical Union. All rights reserved. 


\begin{tabular}{|c|c|c|c|}
\hline $41.082396^{\circ}$ & $74.013628^{\circ}$ & 19 & 7 \\
\hline $41.057355^{\circ}$ & $74.041523^{\circ}$ & 25 & 4 \\
\hline $41.057116^{\circ}$ & $74.041651^{\circ}$ & 23 & 3 \\
\hline $41.046380^{\circ}$ & $74.049406^{\circ}$ & 29.7 & 5 \\
\hline
\end{tabular}

(c) 2019 American Geophysical Union. All rights reserved. 
Table 2: Sample information from profile 1. The profile is located at $41.1407^{\circ} \mathrm{N}, 73.9345^{\circ} \mathrm{E}$ and $2020 \mathrm{~m}$ above sea level. The scaling factor used is 4.77 based on Stone (2000). SLHL spallation production rate used for ${ }^{10} \mathrm{Be}$ is $4.02 \pm 0.18 \mathrm{at} / \mathrm{g} / \mathrm{yr}$ (Borchers et al 2016). The standardization method used at ASTER (SM-Al-11/07KNSTD) implies that the ${ }^{26} \mathrm{Al} /{ }^{10} \mathrm{Be}$ spallation production ratio is $6.61 \pm 0.52$. Muons scheme is based on Braucher et al. (2011). ${ }^{9} \mathrm{Be}$ carrier added is from an in house solution with $\left[{ }^{9} \mathrm{Be}\right]=3025 \pm 9 \mathrm{ppm}$ (Merchel et al. 2008). Stable ${ }^{27} \mathrm{Al}$ concentrations, intrinsically present in the samples are measured in liquid aliquots by inductively coupled plasma optical emission spectrometry (ICP-OES). ${ }^{10} \mathrm{Be} /{ }^{9} \mathrm{Be}$ and ${ }^{26} \mathrm{Al} /{ }^{27} \mathrm{Al}$ blank ratios were $3.35 \times 10^{-15}( \pm 44 \%)$ for beryllium and $2.35 \times 10^{-15}( \pm 75 \%)$ for aluminum.

\begin{tabular}{|c|c|c|c|c|c|c|c|c|c|c|c|c|c|c|}
\hline $\begin{array}{c}\text { Sample } \\
\text { name }\end{array}$ & $\begin{array}{c}\text { Depth } \\
(\mathrm{cm})\end{array}$ & $\begin{array}{l}\text { Topographic } \\
\text { Shielding } \\
\text { factor }\end{array}$ & $\begin{array}{l}\text { Thickness } \\
(\mathrm{cm})\end{array}$ & $\begin{array}{l}\text { Sample } \\
\text { weight } \\
(\mathrm{g})\end{array}$ & $\begin{array}{c}\text { Stone } \\
\text { Scaling }\end{array}$ & $\begin{array}{c}\mathrm{Be} \\
\text { production } \\
\text { rate - } \\
\text { spallation } \\
\text { (at } / \mathrm{g} / \mathrm{yr}) \\
\end{array}$ & $\begin{array}{c}\mathrm{Be} \\
\text { Carrier } \\
(\mathrm{g})\end{array}$ & ${ }^{10} \mathrm{Be} /{ }^{9} \mathrm{Be}(\mathrm{x}) \mathrm{10}$ & $\begin{array}{c}{ }^{10} \mathrm{Be} \\
\text { concentration } \\
\text { (atoms/g) }\end{array}$ & $\begin{array}{l}\text { Al production } \\
\text { rate - } \\
\text { spallation } \\
(\mathrm{at} / \mathrm{g} / \mathrm{yr})\end{array}$ & $\begin{array}{c}\text { Stable }^{27} \mathrm{Al} \\
\text { concentration } \\
(\mathrm{ppm})\end{array}$ & ${ }_{-14}^{26} \mathrm{Al} /{ }^{27} \mathrm{Al}(\mathrm{x} 10$ & ${ }^{26} \mathrm{Al}($ atoms $/ \mathrm{g})$ & $\begin{array}{c}\text { Ratio } \\
{ }^{26} \mathrm{Al} /{ }^{10} \mathrm{Be}\end{array}$ \\
\hline TAL-40 & 40 & 0.93 & 5 & 24.08 & 4.77 & 17.84 & 0.1012 & $7.518 \pm 0.356$ & $61817 \pm 2933$ & 117.89 & $6.37 \pm 0.52$ & $10.023 \pm 1.057$ & $347427 \pm 46251$ & $5.62 \pm 0.79$ \\
\hline TAL-60 & 60 & 0.93 & 5 & 18.20 & 4.77 & 17.84 & 0.1021 & $5.050 \pm 0.259$ & $54185 \pm 2783$ & 117.89 & $8.58 \pm 1.63$ & $7.607 \pm 0.873$ & $357263 \pm 79161$ & $6.59 \pm 1.5$ \\
\hline TAL-80 & 80 & 0.93 & 5 & 19.95 & 4.77 & 17.84 & 0.1012 & $6.640 \pm 0.311$ & $65491 \pm 3068$ & 117.89 & $5.68 \pm 0.63$ & $9.222 \pm 0.943$ & $458804 \pm 69400$ & $7.01 \pm 1.11$ \\
\hline TAL-110 & 110 & 0.93 & 5 & 27.44 & 4.77 & 17.84 & 0.1022 & $5.540 \pm 0.306$ & $39713 \pm 2196$ & 117.89 & $7.59 \pm 0.73$ & $4.974 \pm 0.719$ & $225647 \pm 39190$ & $5.68 \pm 1.04$ \\
\hline TAL- 150 & 150 & 0.93 & 5 & 22.22 & 4.77 & 17.84 & 0.1022 & $2.955 \pm 0.209$ & $24688 \pm 1751$ & 117.89 & $2.4 \pm 0.19$ & $3.835 \pm 0.681$ & $99260 \pm 19284$ & $4.02 \pm 0.83$ \\
\hline TAL-190 & 190 & 0.93 & 5 & 22.42 & 4.77 & 17.84 & 0.1018 & $1.943 \pm 0.179$ & $14969 \pm 1384$ & 117.89 & $4.95 \pm 0.44$ & $2.700 \pm 0.528$ & $120553 \pm 25934$ & $8.05 \pm 1.89$ \\
\hline TAL-250 & 250 & 0.93 & 5 & 22.81 & 4.77 & 17.84 & 0.1016 & $4.592 \pm 0.309$ & $38844 \pm 2616$ & 117.89 & $7.37 \pm 0.64$ & $4.658 \pm 0.591$ & $216894 \pm 33347$ & $5.58 \pm 0.94$ \\
\hline TAL-300 & 300 & 0.93 & 5 & 25.02 & 4.77 & 17.84 & 0.1013 & $2.743 \pm 0.222$ & $19978 \pm 1618$ & 117.89 & $6.38 \pm 0.53$ & $3.573 \pm 0.741$ & $155780 \pm 34785$ & $7.8 \pm 1.85$ \\
\hline
\end{tabular}

() 2019 American Geophysical Union. All rights reserved. 
Table 3: Sample information for ${ }^{36} \mathrm{Cl}$ dating. Natural ${ }^{35} \mathrm{Cl} /{ }^{37} \mathrm{Cl}$ is $3.127,{ }^{36} \mathrm{Cl} /{ }^{35} \mathrm{Cl}$ and ${ }^{35} \mathrm{Cl} /{ }^{37} \mathrm{Cl}$ ratios were measured at the ASTER (the french AMS facility - Aix en Provence) after normalization to an inhouse standard SM-CL12, using an assigned value of $1.428 \times 10^{-12}$ ( $\pm 1.5 \%$ ) for ${ }^{36} \mathrm{Cl} /{ }^{35} \mathrm{Cl}$.

\begin{tabular}{|c|c|c|c|c|c|c|c|c|c|c|c|c|c|}
\hline Sample & $\begin{array}{l}\text { Latitude } \\
\left({ }^{\circ} \mathrm{N}\right)\end{array}$ & $\begin{array}{l}\text { Longitude } \\
\left({ }^{\circ} \mathrm{E}\right)\end{array}$ & $\begin{array}{l}\text { Elevation } \\
\text { (m) }\end{array}$ & Depth (cm) & $\begin{array}{l}\text { Topographic } \\
\text { Shielding } \\
\text { Factor }\end{array}$ & $\begin{array}{c}\text { Sample } \\
\text { weight (g) }\end{array}$ & $\begin{array}{l}\text { mass of } \mathrm{Cl} \text { in } \\
\text { spike }(\mathrm{g})\end{array}$ & ${ }^{35} \mathrm{Cl} /{ }^{37} \mathrm{Cl}$ & ${ }^{36} \mathrm{Cl} /{ }^{35} \mathrm{Cl}\left(\times 10^{-14}\right)$ & ${ }^{36} \mathrm{Cl}\left(\mathrm{x} 10^{3}\right.$ atoms $\left./ \mathrm{g}\right)$ & $\mathrm{Cl}$ (ppm) & $\mathrm{Ca}(\%)$ & $\begin{array}{c}\% \text { of atoms }{ }^{36} \mathrm{Cl} \\
\text { by capture of } \\
\text { thermal and } \\
\text { epithermal } \\
\text { neutrons }\end{array}$ \\
\hline TAL & 41.1399 & 73.9369 & 2045 & 0 & 0.94 & 78.25 & 0.2718 & $4.902 \pm 0.017$ & $45.173 \pm 1.923$ & $510.8 \pm 22.4$ & 56.2 & 36.6 & 24.79 \\
\hline TAL & 41.1408 & 73.9360 & 2036 & 0 & 0.94 & 68.37 & 0.2718 & $3.802 \pm 0.011$ & $13.304 \pm 0.720$ & $349.6 \pm 19.9$ & 169.4 & 37.3 & 5239 \\
\hline TAL17-07 & 41.1403 & 73.9389 & 2065 & 0 & 0.96 & 77.43 & 0.2733 & $3.536 \pm 0.012$ & $11.880 \pm 0.624$ & $427.1 \pm 25.5$ & 248.6 & 27.5 & 67.88 \\
\hline TAL17-10 & 41.1398 & 73.9379 & 2055 & 0 & 0.93 & 73.03 & 0.2733 & $19.516 \pm 0.058$ & $77.753 \pm 3.226$ & $407.6 \pm 17.3$ & 6.3 & 39.0 & 4.16 \\
\hline TAL17-40 & 41.1407 & 73.9345 & 2020 & 40 & 0.93 & 43.36 & 0.2735 & $4.330 \pm 0.012$ & $18.746 \pm 0.854$ & $499.1 \pm 23.6$ & 150.7 & 32.7 & 57.21 \\
\hline TAL & 41.1407 & 73.9345 & 2020 & 60 & 0.93 & 45.94 & 0.2743 & $4.220 \pm 0.035$ & $30.402 \pm 1.208$ & $826.0 \pm 39.1$ & 157.1 & 33.9 & 50.89 \\
\hline TAL17-80 & 41.1407 & 73.9345 & 2020 & 80 & 0.93 & 45.35 & 0.2741 & $4.146 \pm 0.015$ & $20.354 \pm 0.881$ & $588.1 \pm 26.9$ & 170.5 & 32.8 & 58.15 \\
\hline
\end{tabular}




\begin{tabular}{|c|c|c|c|c|c|c|c|c|c|c|c|c|c|}
\hline TAL17-110 & 41.1407 & 73.9345 & 2020 & 110 & 0.93 & 32.74 & 0.2736 & $4.304 \pm 0.016$ & $13.397 \pm 0.683$ & $478.8 \pm 25.5$ & 204.4 & 30.9 & 60.65 \\
\hline $\begin{array}{l}\text { TAL17- } \\
150\end{array}$ & 41.1407 & 73.9345 & 2020 & 150 & 0.93 & 41.23 & 0.2728 & $4.057 \pm 0.019$ & $12.243 \pm 0.640$ & $414.2 \pm 23.2$ & 205.1 & 30.4 & 60.15 \\
\hline $\begin{array}{r}\mathrm{TA} \\
1\end{array}$ & 41.1407 & 73.9345 & 2020 & 190 & 0.93 & 29.27 & 0.2733 & $4.289 \pm 0.011$ & $11.530 \pm 0.604$ & $461.9 \pm 25.1$ & 230.5 & 28.9 & 56.71 \\
\hline $\begin{array}{c}\text { TAL17- } \\
250\end{array}$ & 41.1407 & 73.9345 & 2020 & 250 & 0.93 & 6.36 & 0.2730 & $8.098 \pm 0.051$ & $15.427 \pm 0.736$ & $1241.1 \pm 62.2$ & 246.1 & 30.1 & 49.21 \\
\hline $\begin{array}{c}\text { TAL17- } \\
300\end{array}$ & 41.1407 & 73.9345 & 2020 & 300 & 0.93 & 14.20 & 0.2692 & $4.937 \pm 0.016$ & $16.490 \pm 0.757$ & $1008.2 \pm 48.1$ & 304.8 & 29.8 & 38.56 \\
\hline Blank & - & - & - & - & - & $\begin{array}{ll}- \\
-\end{array}$ & 0.2731 & 409.913 & $0.776 \pm 0.011$ & $\begin{array}{c}\text { Total atoms }{ }^{36} \mathrm{Cl}(\mathrm{x} 10 \\
\left.{ }^{4}\right): 25.33 \pm 3.46\end{array}$ & $\begin{array}{l}\text { Total atoms } \mathrm{Cl} \\
\left(\mathrm{x} 10^{17}\right): 1.825 \\
\quad \pm 0.156\end{array}$ & - & - \\
\hline
\end{tabular}

(c) 2019 American Geophysical Union. All rights reserved. 
Table 4: Summarized elemental concentrations for dose rates calculation and equivalent dose measurements. The Central Age Model (CAM) and Minimum Age Model (MAM) are calculated following Galbraith et al. (1999). The overdispersion (OD) parameter is given in percentage.

\begin{tabular}{|c|c|c|c|c|c|c|c|c|c|c|c|c|}
\hline Sample & Water & $\mathrm{K}$ & u & Th & $\begin{array}{l}\text { Total Dose } \\
\text { Rate }\end{array}$ & $\begin{array}{l}\text { CAM Equivalent } \\
\text { Dose }\end{array}$ & OD & Skew $^{b}$ & g-value & $\begin{array}{l}\text { fading- } \\
\text { corrected CAM } \\
\text { Age }\end{array}$ & $\begin{array}{l}\text { MAM Equivalent } \\
\text { Dose }\end{array}$ & $\begin{array}{l}\text { fading- } \\
\text { corrected } \\
\text { MAM Age }\end{array}$ \\
\hline & (\%) & $(\%)^{a}$ & $(p p m)^{a}$ & $(\mathbf{p p m})^{\mathrm{a}}$ & (Gy/yr) & (Gy) $\left(n^{c}\right)$ & (\%) & & $\begin{array}{ll}(\% & \text { per } \\
\text { decade }) & \end{array}$ & (kyr) & (Gy) & (kyr) \\
\hline \multicolumn{13}{|l|}{$\frac{\text { IR50 }}{\text { Analyses }}$} \\
\hline TAL13-OSL1 & 3.1 & 2.78 & 3.05 & 13.50 & $5.10 \pm 0.20$ & $54.7 \pm 6.3(27)$ & $56 \pm 8$ & $1.2 \pm 0.5$ & $4.7 \pm 0.5$ & $17.9 \pm 2.7$ & $23.7 \pm 1.3$ & $7.5 \pm 0.6$ \\
\hline TAL13-OSL3 & 1.20 & 1.46 & 1.62 & 5.80 & $3.07 \pm 0.11$ & $36.6 \pm 6.8(15)$ & $\begin{array}{ll}71 & \pm \\
13 & \end{array}$ & $0.4 \pm 0.6$ & $3.8 \pm 0.4$ & $17.3 \pm 3.6$ & $18.0 \pm 2.6$ & $8.5 \pm 1.3$ \\
\hline
\end{tabular}

$\mathrm{pIRIR}_{225}$

Analyses

\begin{tabular}{|l|l|l|l|l|l|l|l|l|l|l|l|l|}
\hline TAL13-OSL1 & & 2.1 & 3.05 & 13.50 & $5.10 \pm 0.2$ & $96.2 \pm 11.1(27)$ & $56 \pm 8$ & $0.7 \pm 0.5$ & $1.2 \pm 1.2$ & $19.1 \pm 2.3$ & $39.2 \pm 3.9$ \\
\hline TAL13-OSL3 & 1.20 & 1.46 & 1.62 & 5.80 & $3.07 \pm 0.11$ & $61.1 \pm 13.3(18)$ & $\begin{array}{l}90 \\
15\end{array}$ & $0.3 \pm 0.6$ & $1.8 \pm 0.3$ & $19.9 \pm 4.4$ & $24.7 \pm 4.0$ \\
\hline
\end{tabular}

${ }^{a}$ Analyses obtained using inductively-coupled plasma mass spectrometry, carried out in the School of Geography, Geology and the Environment, University of Leicester. $10 \%$ relatively uncertainties were applied to $\mathrm{U}$, Th concentrations and $5 \%$ uncertainties to $\mathrm{K}$.

${ }^{\mathrm{b}}$ The skeweness parameter was calculated following Bailey and Arnold (2006).

${ }^{\mathrm{C}}$ number of measured aliquots 
Table 5: AMS radiocarbon $\left({ }^{14} \mathrm{C}\right)$ dates collected from Talas Fergana Kyldau site. Samples with "SUERC" prefix are analyzed at NERC Radiocarbon Facility; samples with a "Beta" prefix are analyzed at Beta Analytic Facility. Calibrated ages have been calculated using the Calib Radiocarbon Calibration Program 7.0.4 (Stuiver \& Reimer, 1993) using the Intcal13 calibration curve (Reimer et al., 2013).

\begin{tabular}{|c|c|c|c|c|c|c|c|}
\hline Unit & Sample & $\begin{array}{c}\text { Sample } \\
\text { Laboratory } \\
\text { Code Identifier }\end{array}$ & $\begin{array}{c}\text { Measured Radiocarbon } \\
\text { Age (years B.P., } \\
\text { uncertainties at } 1 \sigma \text { ) }\end{array}$ & $\begin{array}{l}\delta^{13} \mathrm{C} \\
\text { VPDB\% } \\
\pm 0.1\end{array}$ & \multicolumn{2}{|c|}{$\begin{array}{c}\text { Calibrated Ages in BP } \\
\text { (calendric, } 2 \sigma)\end{array}$} & Type of material \\
\hline \multicolumn{8}{|l|}{ PROFILES } \\
\hline P1-unit2b & TAL13-S1 & SUERC-54436 & $5733 \pm 39$ & -6.3 & 6415 & 6639 & Gastropod shell \\
\hline P1-unit2b & TAL13-S2 & SUERC-54437 & $5015 \pm 41$ & -7.9 & 5656 & 5893 & Gastropod shell \\
\hline P1-unit2b & TAL13-S3 & SUERC-54438 & $5261 \pm 42$ & -7.7 & 5928 & 6180 & Gastropod shell \\
\hline P1-unit2a & TAL13-S4 & SUERC-54439 & $6302 \pm 41$ & -5.6 & 7162 & 6180 & Gastropod shell \\
\hline $\mathrm{P} 2$ & TAL13-C1 & SUERC-54452 & $4152 \pm 40$ & -23.6 & 4539 & 4829 & Detrital Charcoal \\
\hline $\begin{array}{l}\text { Ground } \\
\text { surface }\end{array}$ & $\begin{array}{c}\text { KGZ13-TF- } \\
\text { SM1 } \\
\end{array}$ & Beta-395363 & $1.0776 \pm 0.0027$ & -11.0 & $1957 \mathrm{AD}$ & $1998 \mathrm{AD}$ & Modern Shell \\
\hline $\begin{array}{l}\text { Ground } \\
\text { surface }\end{array}$ & $\begin{array}{l}\text { KGZ13-TF- } \\
\text { SM2 }\end{array}$ & Beta-395364 & $1.04970 \pm 0.0026$ & -12.9 & $1955 \mathrm{AD}$ & $1957 \mathrm{AD}$ & Modern Shell \\
\hline $\begin{array}{l}\text { Ground } \\
\text { surface }\end{array}$ & $\begin{array}{l}\text { KGZ13-TF- } \\
\text { SM3 }\end{array}$ & Beta-395564 & $1.0616 \pm 0.0026$ & -11.6 & $1957 \mathrm{AD}$ & $1998 \mathrm{AD}$ & Modern Shell \\
\hline \multicolumn{8}{|l|}{ TRENCH } \\
\hline U100 & TAL13-TR1 & SUERC-54443 & $958 \pm 41$ & -25.8 & 785 & 939 & Detrital Charcoal \\
\hline $\mathrm{f} 1$ & TAL13-TR2* & UCIAMS-144583 & $2635 \pm 30$ & $-2.6^{* *}$ & $2728^{* * * *}$ & $2836^{* * *}$ & Gastropod shell \\
\hline U90 & TAL13-TR4 & Beta-409071 & $240 \pm 30$ & N.A** & 147 & 424 & Detrital Charcoal \\
\hline
\end{tabular}

(C) 2019 American Geophysical Union. All rights reserved. 


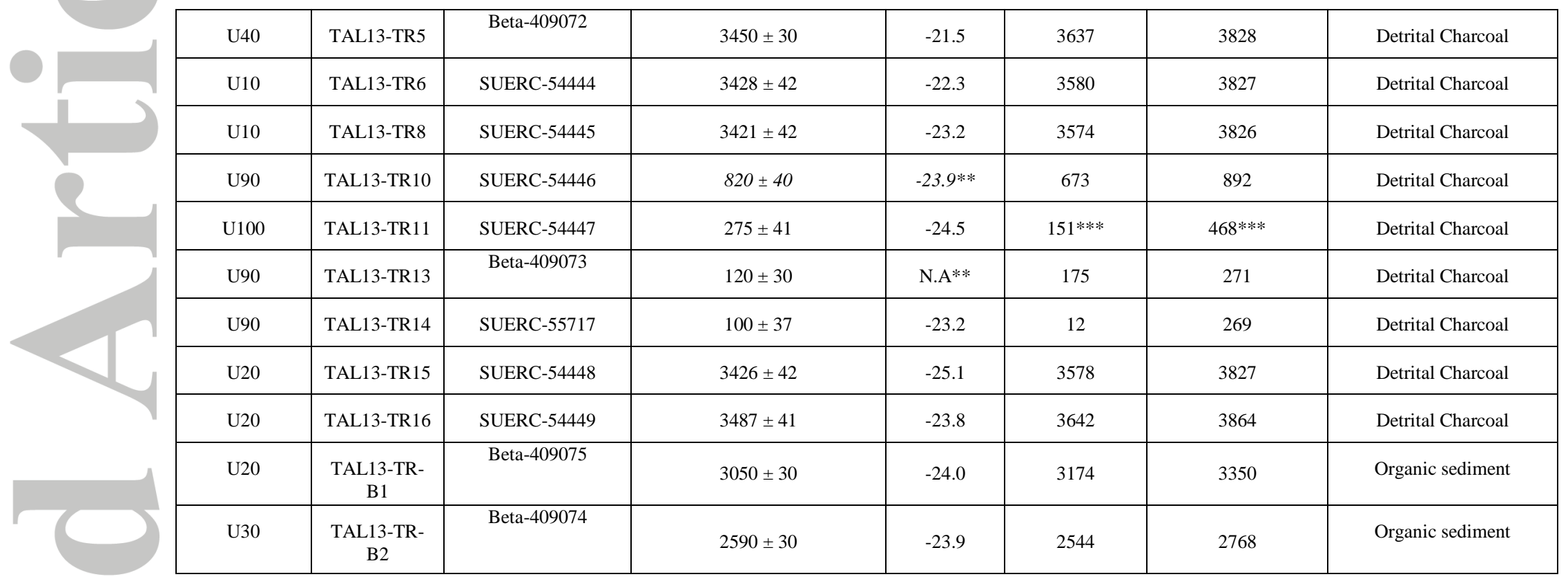

* TAL-13 TR2 contained 445 $\mu$ g carbon and was analyzed by AMS at low current. Preparation of additional standards was required to match the sample carbon weights. $13 \mathrm{C} / 12 \mathrm{C}$ ratios for samples were measured by AMS during $14 \mathrm{C}$ determination and used to model the $\delta 13 \mathrm{C}$ value by comparison to the Craig (1957) $13 \mathrm{C} / 12 \mathrm{C}$ value for PDB. This value is considered the most appropriate to normalise the $14 \mathrm{C}$ data to $\delta 13 \mathrm{CVPDB} \%=-25$, but is not necessarily representative of the $\delta 13 \mathrm{C}$ in the original sample material. The result was corrected (as described in Santos et al., 2007) for modern carbon contamination (using data from process background and standard materials). The uncertainty reported considers the overall analytical uncertainty, including the corrections applied and observed scatter in process standards of comparable size to the samples analyzed.

**estimated $\delta 13 \mathrm{C}$ value as sample produced insufficient $\mathrm{CO} 2$ for an independent measurement

*** Age ranges given at 1-sigma limit 


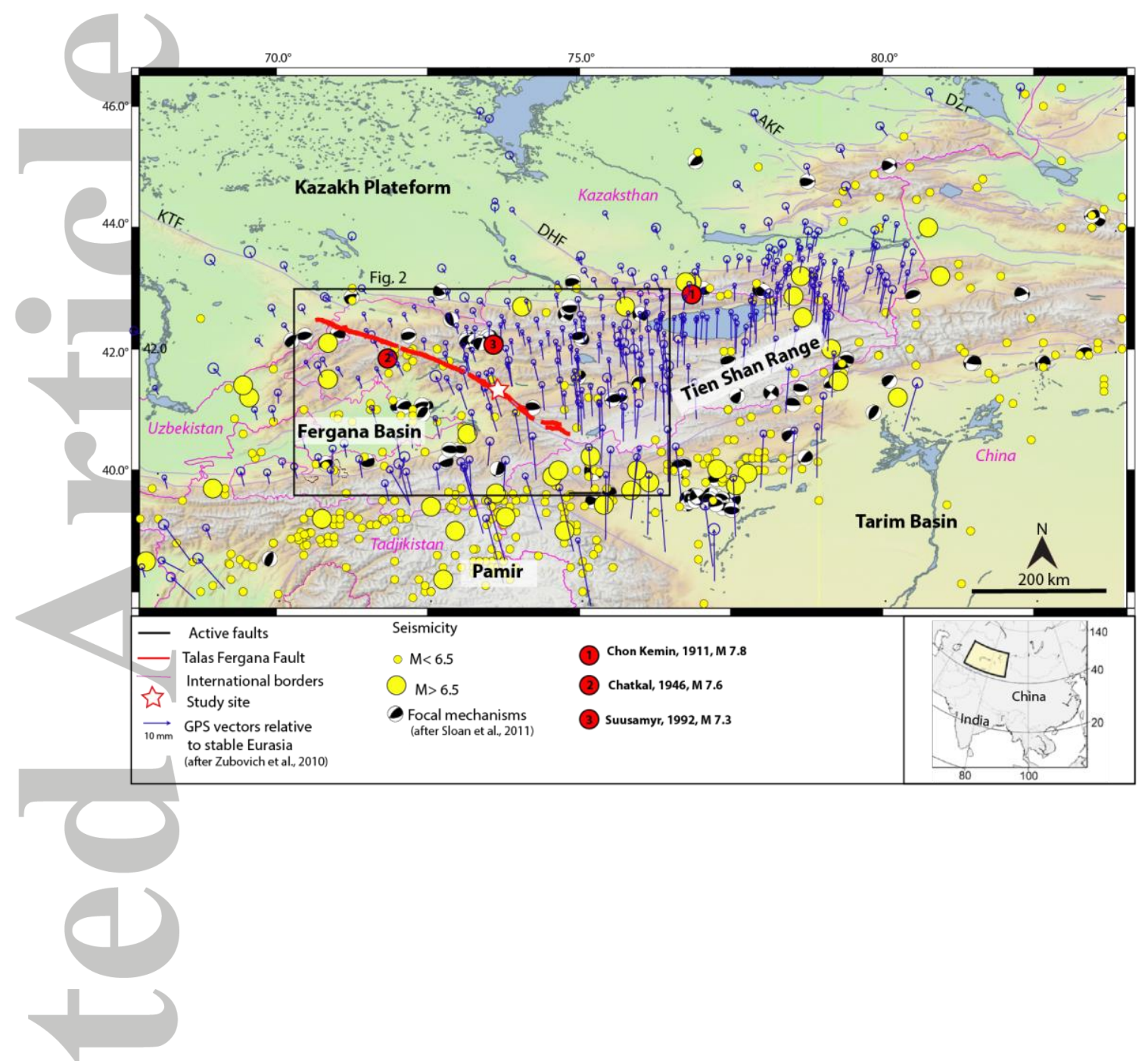

Figure 1: Active faults (black solid lines, modified after Tapponnier and Molnar, 1979 and Campbell et al., 2015), instrumental seismicity (yellow dots, USGS catalog), focal mechanisms (in black, after Sloan et al., 2011) and GPS velocities (blue arrows, Zubovich et al., 2010) for the Tien Shan region. Country borders are drawn in pink and major lakes in blue. KTF : Karatau Fault, DHF: Dzhalair-Naiman Fault, AKF: Aktas Fault, DZF: Dzungarian Fault. The Talas Fergana fault is drawn with a solid red line. Our study site is located by the white star. The black box shows the location of Figure 2. 

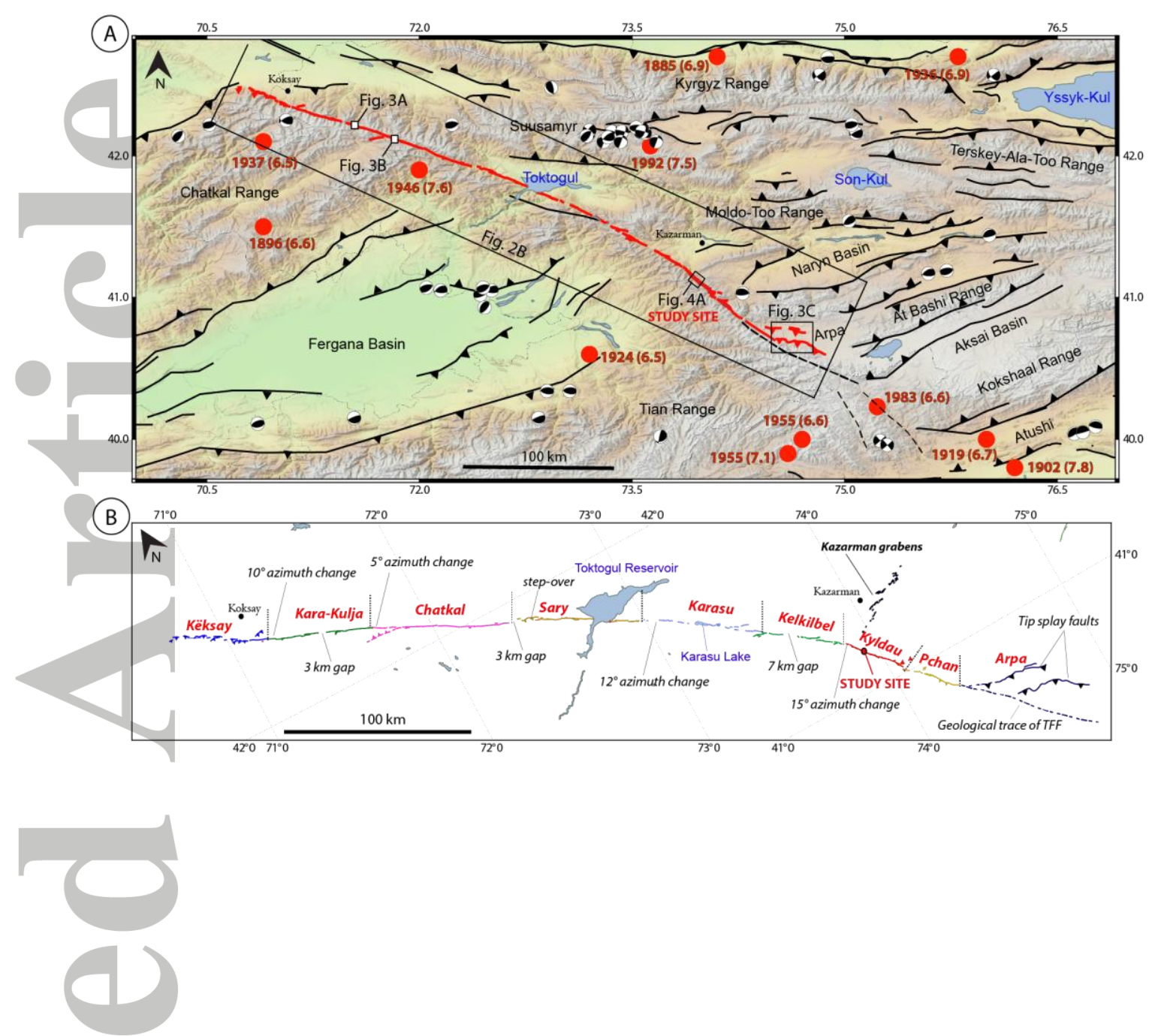

Figure 2: A) Topography (SRTM) and active faults of the Western and Central Tien Shan region. Active faults are drawn in black and the Talas Fergana fault in red. Instrumental and historical seismicity $(M>6.5)$ from Kalmetieva (2009) is represented by the red circles and focal mechanisms are from Sloan et al. (2011). A black box shows the location of figure 2B. B) Fault segmentation of the Talas-Fergana fault based on our mapping. Each color represents an individual fault segment (names in red). We define nine fault segments based on their geometric characteristics. The study site is located on the Kyldau segment by the red dot. 

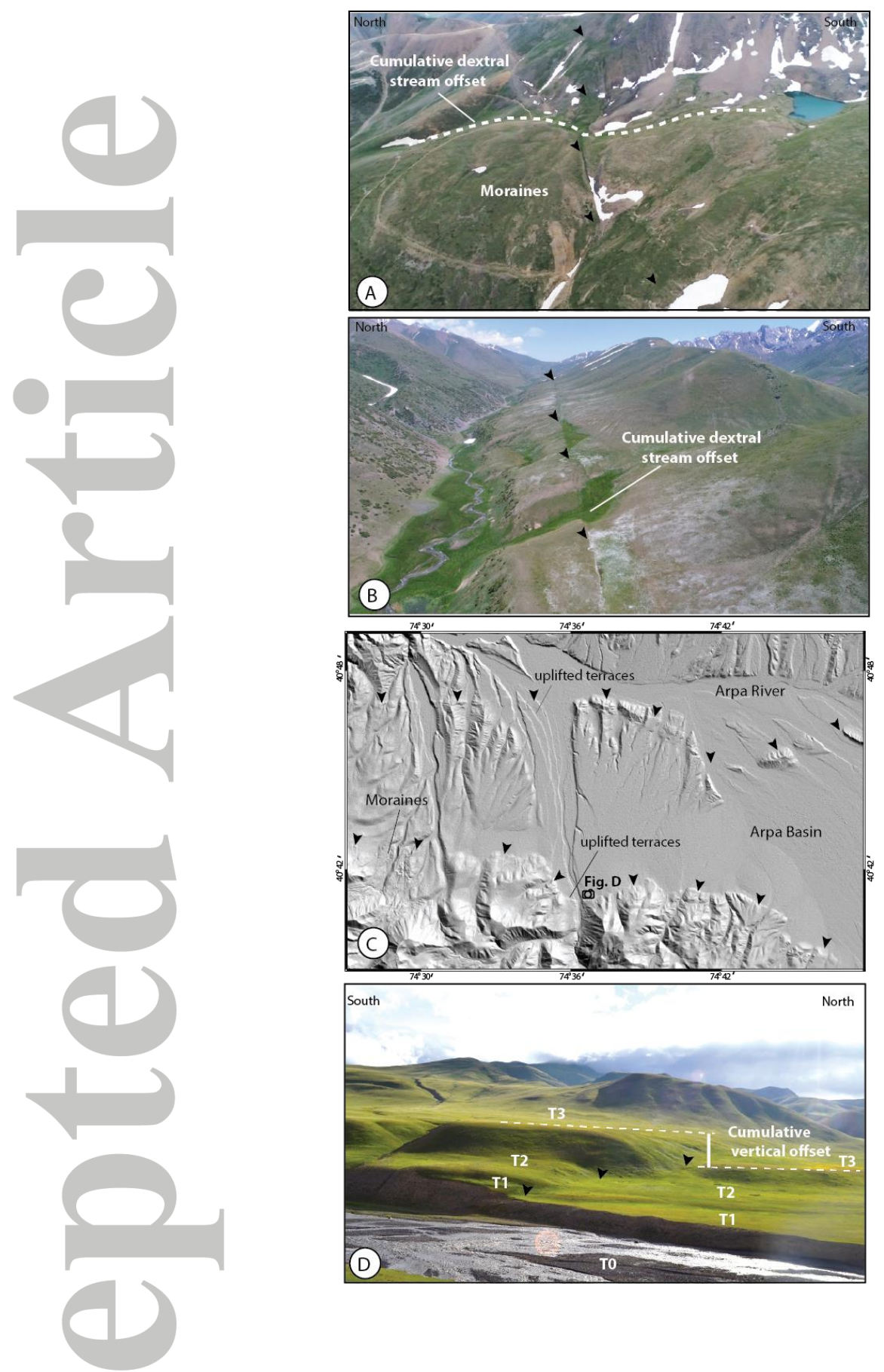

Figure 3: A) Drone view ( $\left.42.208^{\circ} \mathrm{N}, 71.565^{\circ} \mathrm{E}\right)$ looking eastward taken during summer 2017 at the Kara-Bura pass where the TFF crosses series of moraines. Location of this picture is indicated in Figure 2A. The black arrows underline the fault trace in the morphology. At this site cumulative dextral offsets of offset streams (see one example with a white dashed line) and within moraines are observed. B) Drone view $\left(\sim 42.108^{\circ} \mathrm{N}, 71.859^{\circ} \mathrm{E}\right)$ looking eastward taken during summer 2017 along the Chatkal segment when the TFF is running parallel to the Karakulja river. Location of this picture is indicated in Figure 2A. The fault 
scarp is well-preserved in the morphology, attesting to a recent surface rupture and numerous offsets are observed. C) Digital elevation Model (3m of resolution) was produced using tristereo SPOT 6/7 images (Airbus DS distribution, 2015). Location of the covered area is indicated in Figure 2A. At this location, two reverse fault segments (see black arrows) are crossing alluvial surfaces in the Arpa Basin. D) Field view $\left(\sim 40.684^{\circ} \mathrm{N}, 74.606^{\circ} \mathrm{E}\right)$ taken in summer 2017 at the outlet of a river (see location in C). Series of terraces (T1, T2 and T3) are deformed and uplifted in the hangingwall of the reverse fault segment dipping to the south. The black dashed lines are drawn to see the apparent vertical cumulative offset within T3 terrace.

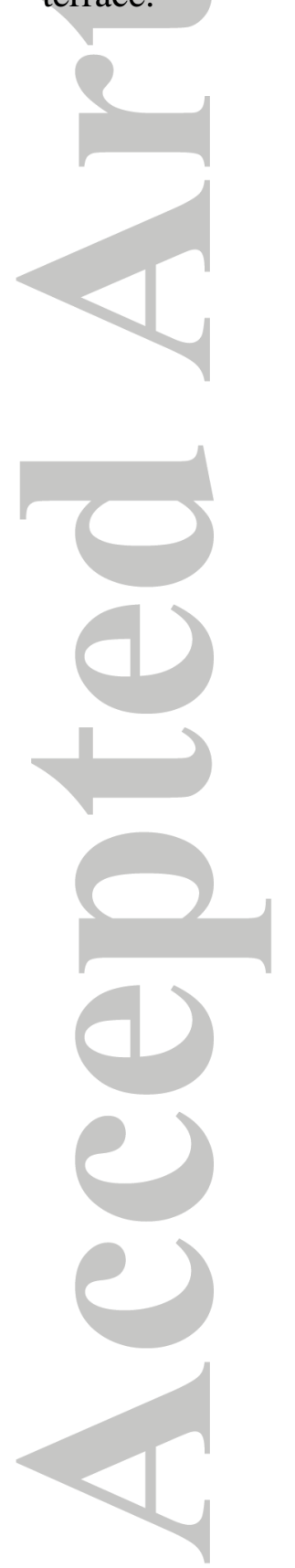



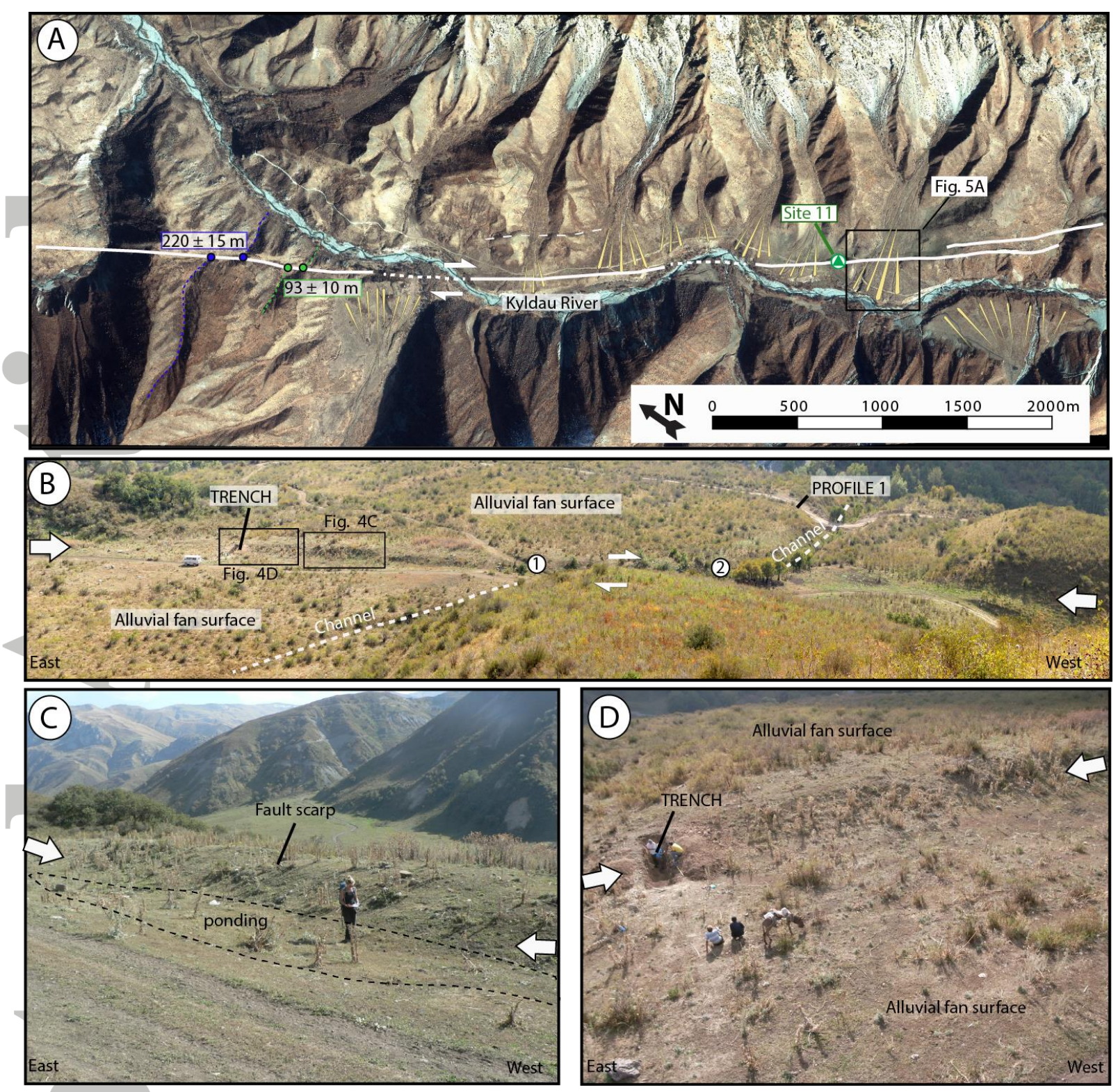

Figure 4: A) Worldview satellite image of the Kyldau area. Location of this site is indicated in Figure 2A. The white line shows the location of the fault trace at the surface. Green and blue dashed lines are for piercing lines corresponding to cumulative offset streams measured along the fault (see also Table 1). The associated colored dots are for the piercing points used to measure the offsets reported in table 1 . The green label "site 11" and the green triangle referred to Burtman et al. (1996). B) Panorama of the study area with white arrows pointing the fault trace and numbers 1 and 2 (in white dots) corresponding to the piercing points used to measure the cumulative channel offset of $27 \pm 5 \mathrm{~m}$ presented in Figure 5 (see also Table 1). The stream bed of the channel is highlighted by the white dashed line. The location of the trench and the location of the sampling site Profile 1 are reported in the photography. C) 
Field photography of the fault scarp crossing the alluvial fan surface at the study site before trench excavation. The scarp forms a $\sim 0.5$ to $1.5 \mathrm{~m}$-high (see person for scale) north-facing scarp that ponds water and sediments at its toe. D) Field view taken from a telescopic pole of the trench opened across the fault scarp.
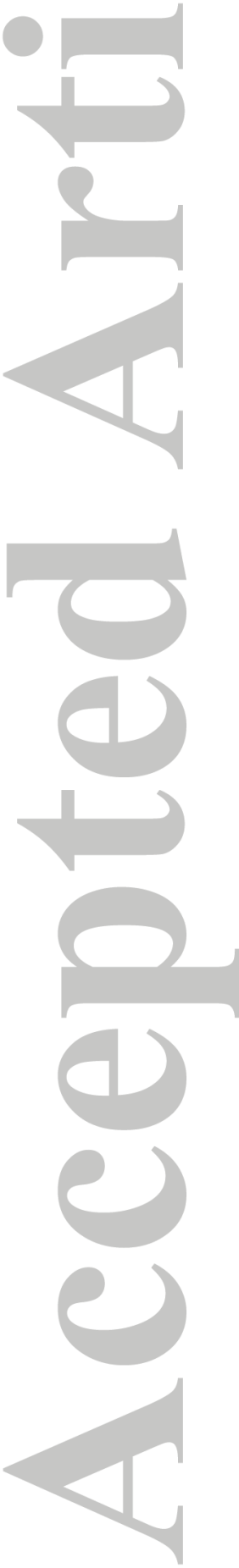

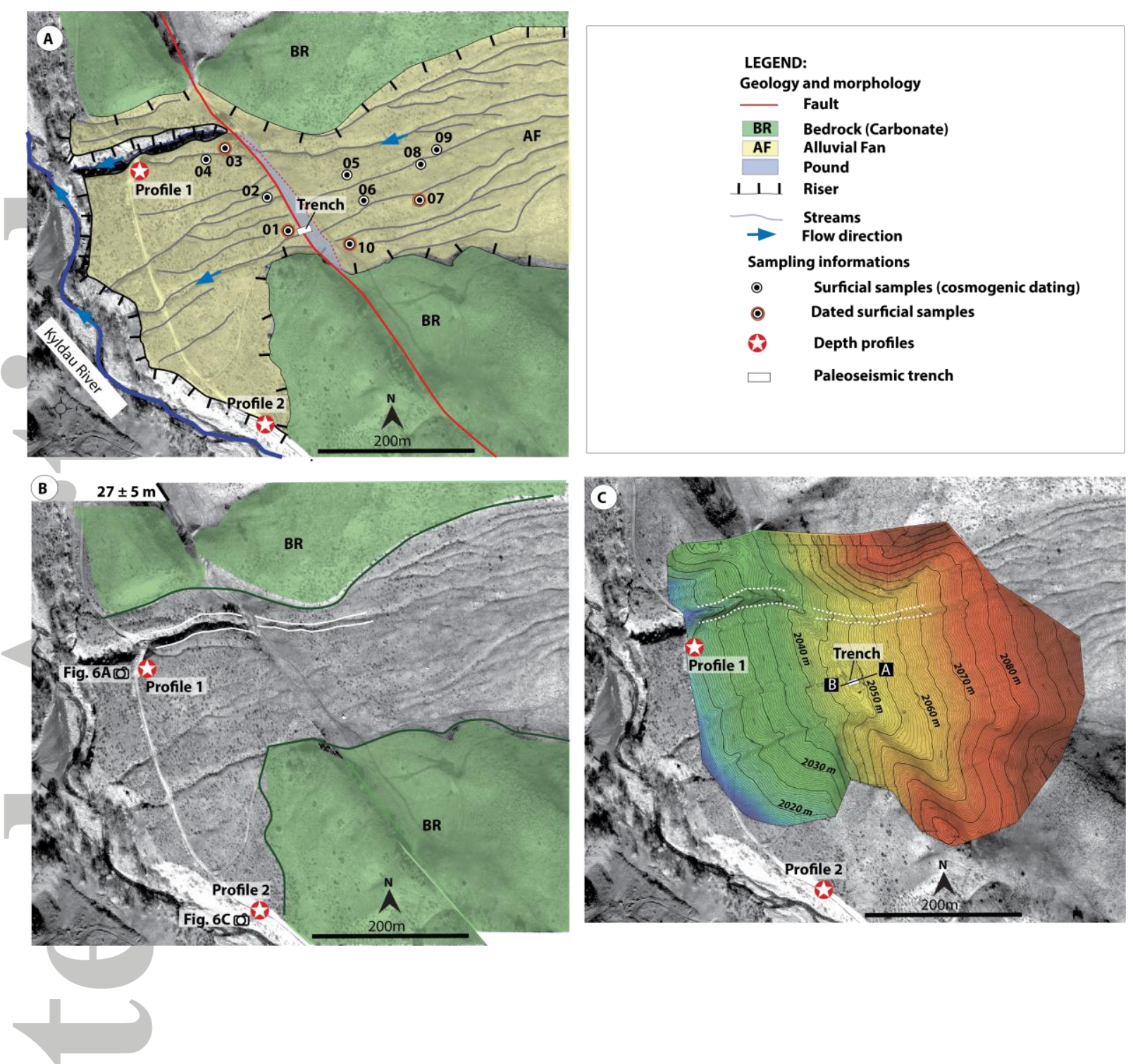

Figure 5: Morphotectonic analyses on a displaced alluvial fan surface. Location of this site is indicated by the black box in Figure 4A. A) Morphotectonic interpretations draped on Worldview image with location of sampling and trench investigations. White stars in red dots show the location of Profile 1 and Profile 2. The fault trace is represented by the red line. B) Best-fit reconstruction for the channel offset of $27 \mathrm{~m}$. The white solid lines are representing our piercing lines to reconstruct our minimum and maximum values. C) DEM from our RTK GPS survey draped on top of the Worldview image. The white dashed lines are the same piercing lines presented on Figure 5B. The thick topographic lines are drawn with spacing of $5 \mathrm{~m}$. The black solid line A-B is for the topographic profile presented on Figure 9A.

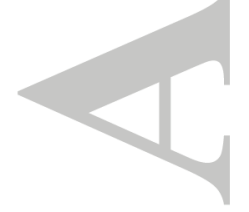




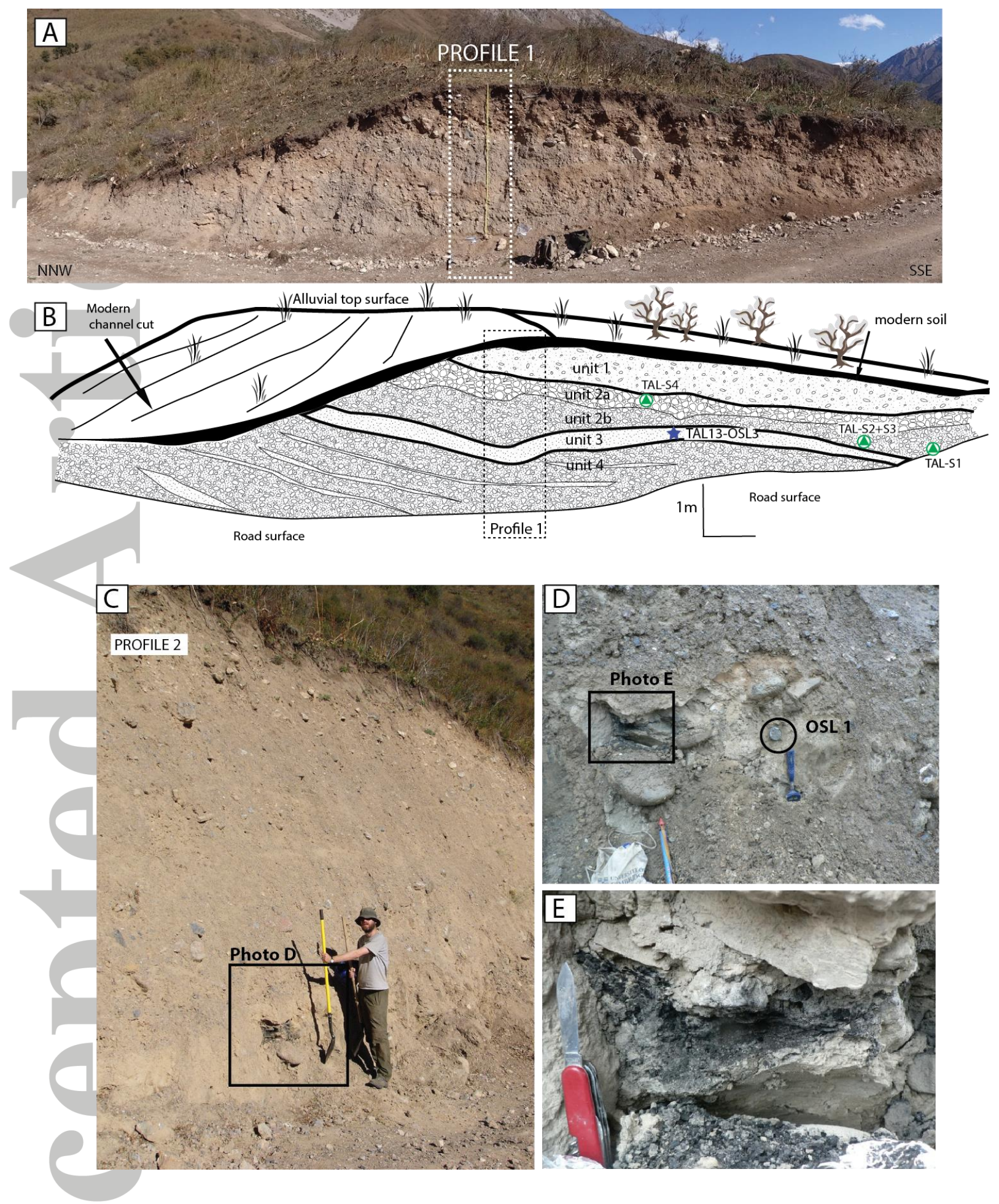

Figure 6: A) Field view of the sampling site (profile 1) along the road cut. B) Our log interpretation with the stratigraphic column and the different logged alluvial units and location of the OSL (blue stars) and radiocarbon samples (green triangles). See text in section 4.2 for stratigraphic details. C) Field view of the road section for profile 2. We sampled at 4.5-5 $\mathrm{m}$ below the surface. D) Zoom on sampling location of OSL1 and TAL13-C1. E) Photo with a zoom on TAL13-C1 sample, which is a big piece of burned wood. 


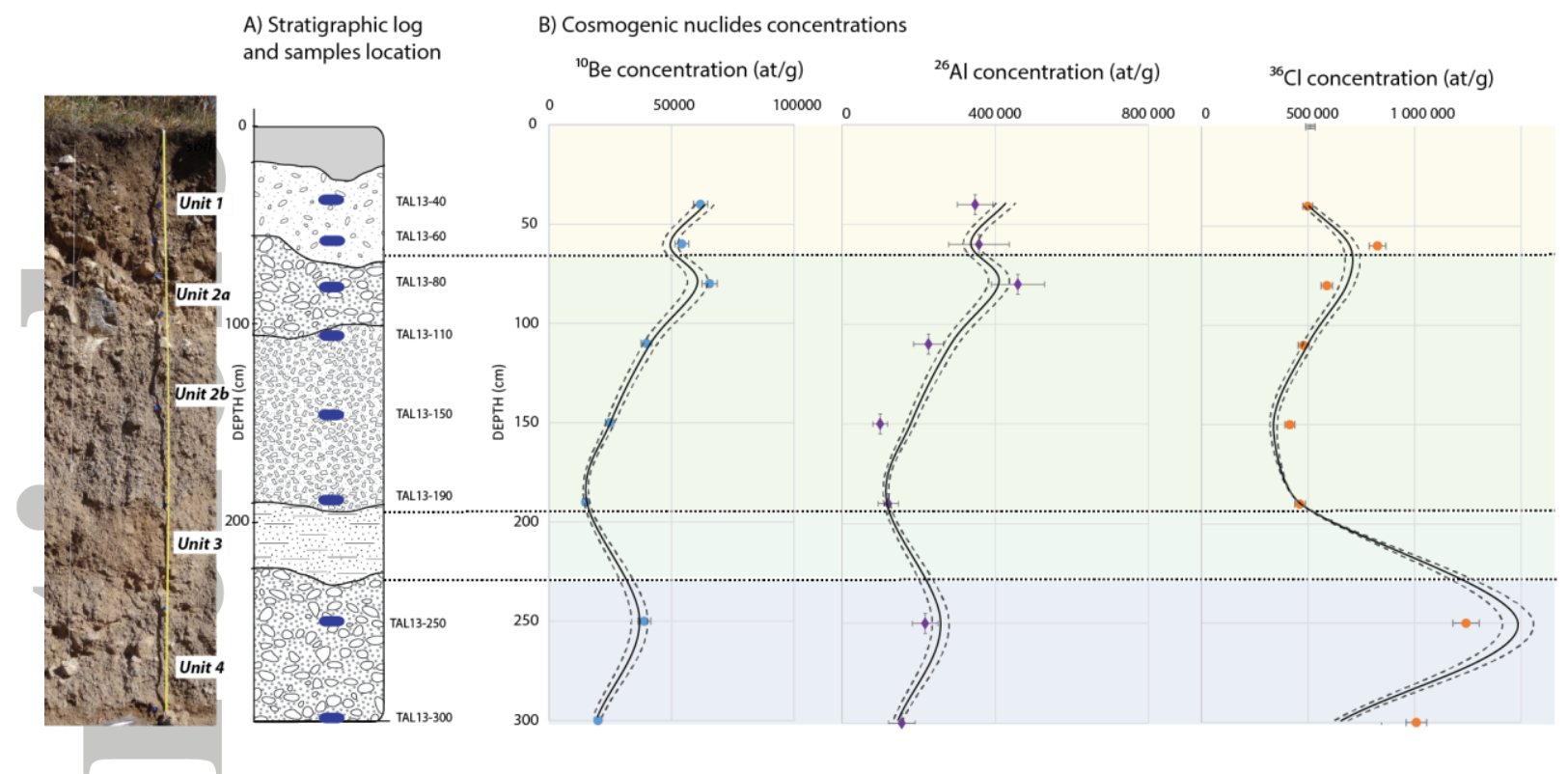

Figure 7: A) Stratigraphic column for profile 1 and samples locations (blue boxes). B) ${ }^{10} \mathrm{Be}$ (blue), ${ }^{26} \mathrm{Al}$ (purple) and ${ }^{36} \mathrm{Cl}$ (orange) measured concentrations as a function of depth. For each isotopes, the solid lines indicate the calculated best-fit model and the dashed lines indicate the calculated profiles for the $1 \sigma$ upper and lower bounding age estimates. The horizontal dashed lines highlight the bases of the different stratigraphic units 


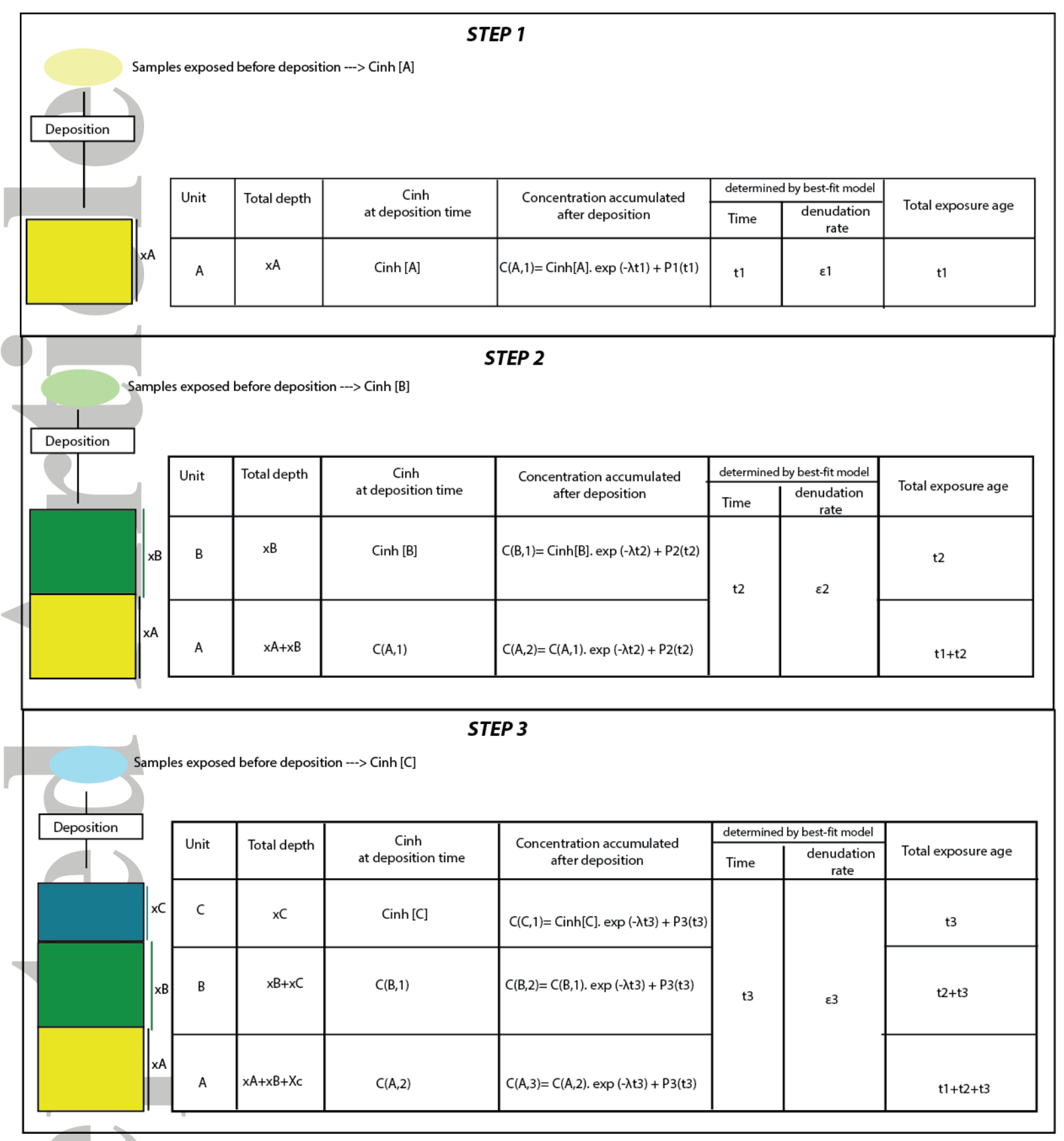

Figure 8: Sketch presenting the step by step model used to calculate exposure ages and denudation rates for 3 layers $(\mathrm{A}, \mathrm{B}, \mathrm{C})$ deposited in a stratigraphic column. $\mathrm{xA}, \mathrm{xB}$ and $\mathrm{xC}$ are the depths for samples collected in units A, B and C, respectively. P: Surface production rate, $\mathrm{N}$ : Concentration, $\lambda$ radioactive decay constant, $\varepsilon$ : denudation rate, $\mathrm{t}:$ exposure time. At each step, simplified equations are given for the calculation of the inherited concentration at deposition time, the concentration accumulated after deposition, the exposure time ( $\mathrm{t}$ ) and denudation rate $(\varepsilon)$. The different step and details for this model are presented in section 4.4.1. 

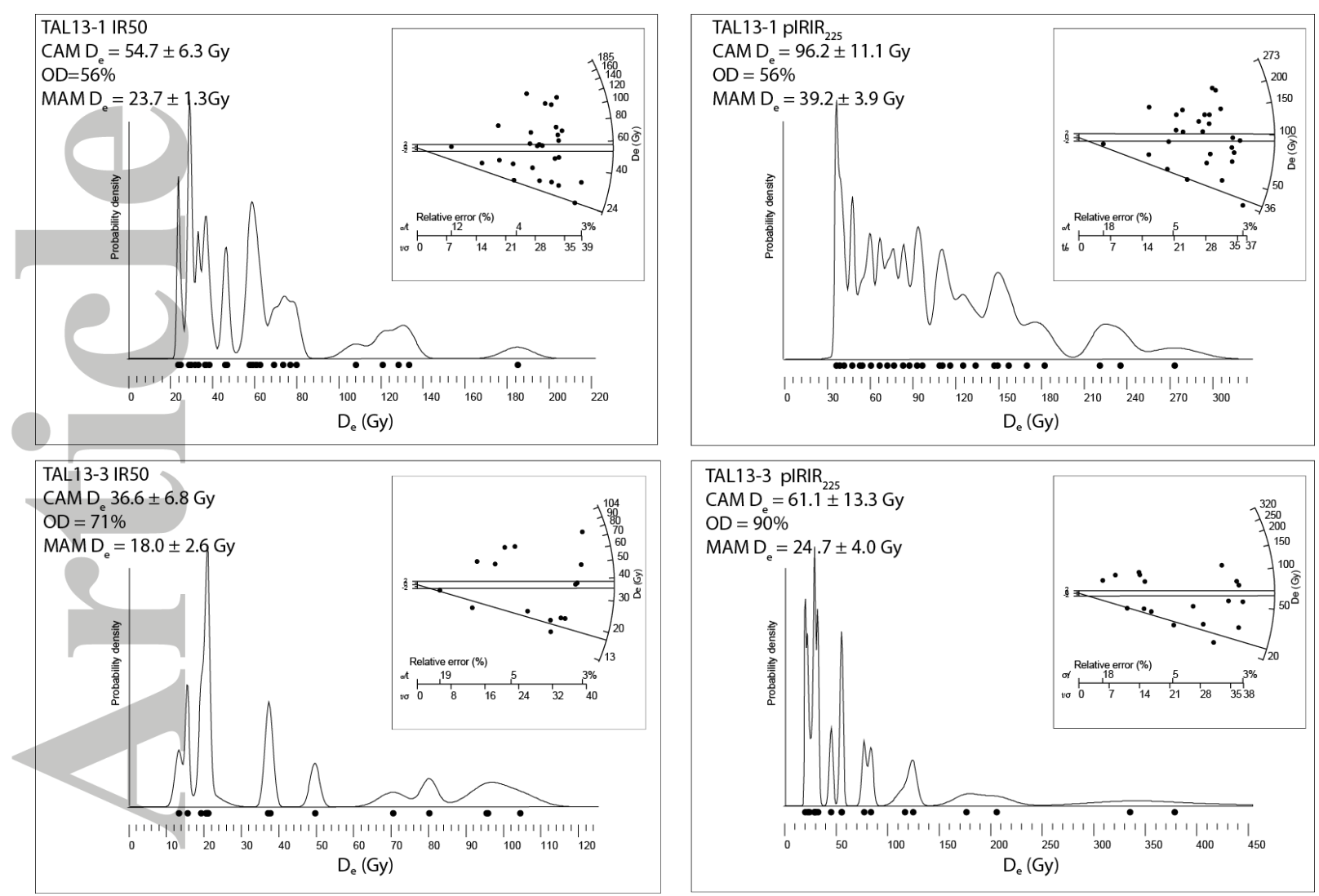

Figure 9: pIRIR225 and IR50 analyses made for TAL13-OSL1 and TAL13-OSL3 samples. Black dots represent the individual equivalent dose estimates and are presented in probability density plots. All samples present a high dispersion (OD) in equivalent doses. The associated central age models (CAM) and minimum age models (MAM) are shown. The same individual equivalent dose estimates are plotted as radial diagrams within the different insets. The plots show all measured aliquots and are centered ( 2 horizontal bars) on the Central Age De. 

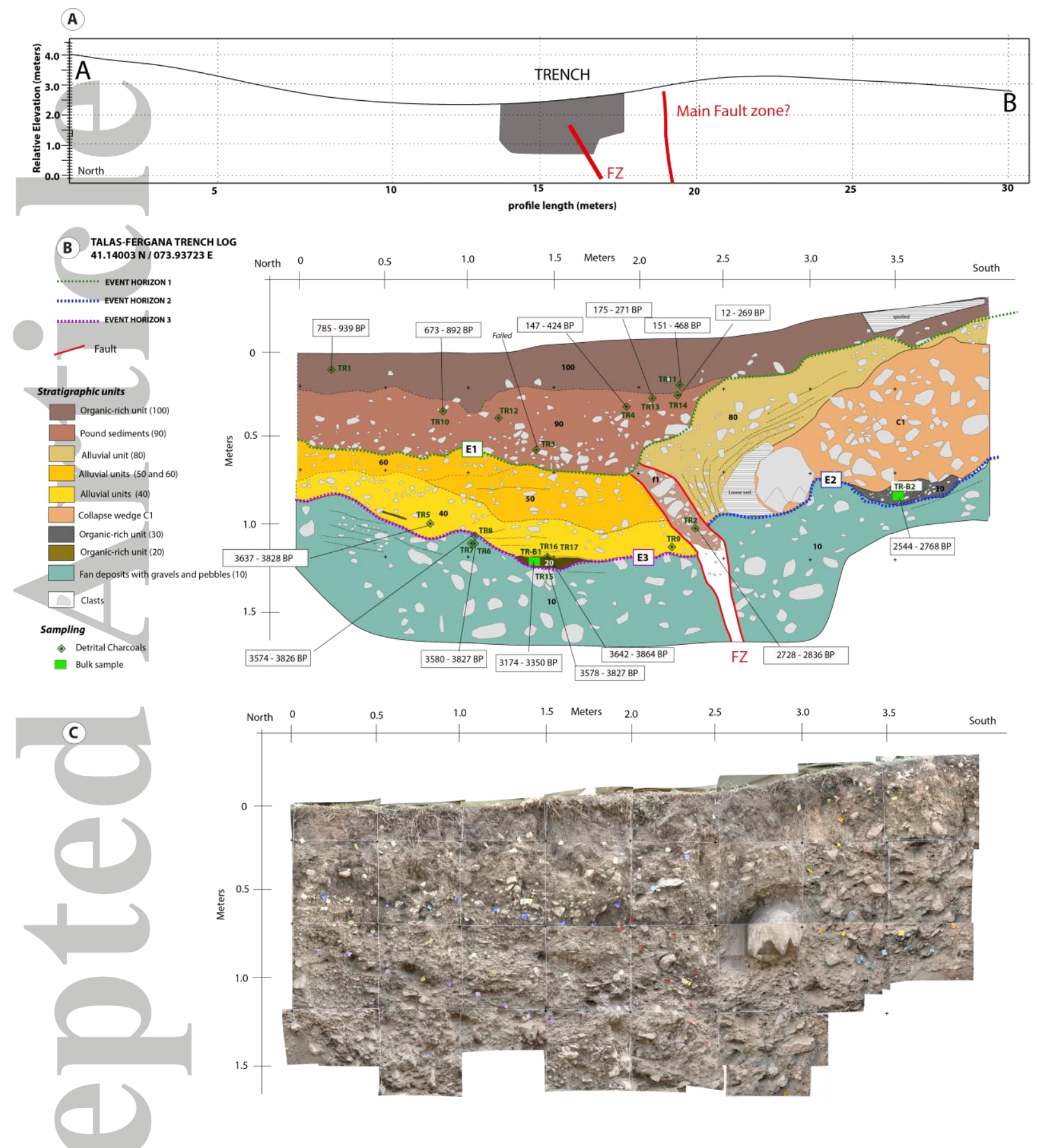

Figure 10: Paleoseimic investigation at the Kyldau site. A) Topographic profile across the fault scarp (see location on Figure 5C). The position of the trench is represented in gray, faults are represented by thick red lines. B) Log interpretation (see text in section 4 for details) with positions of detrital charcoals collected in the trench. The reported ages are calibrated using Intcal13 curves (Reimer et al., 2013). C) Ortho-photo mosaic of the trench.

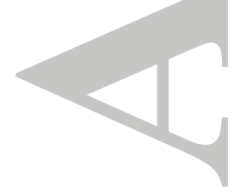




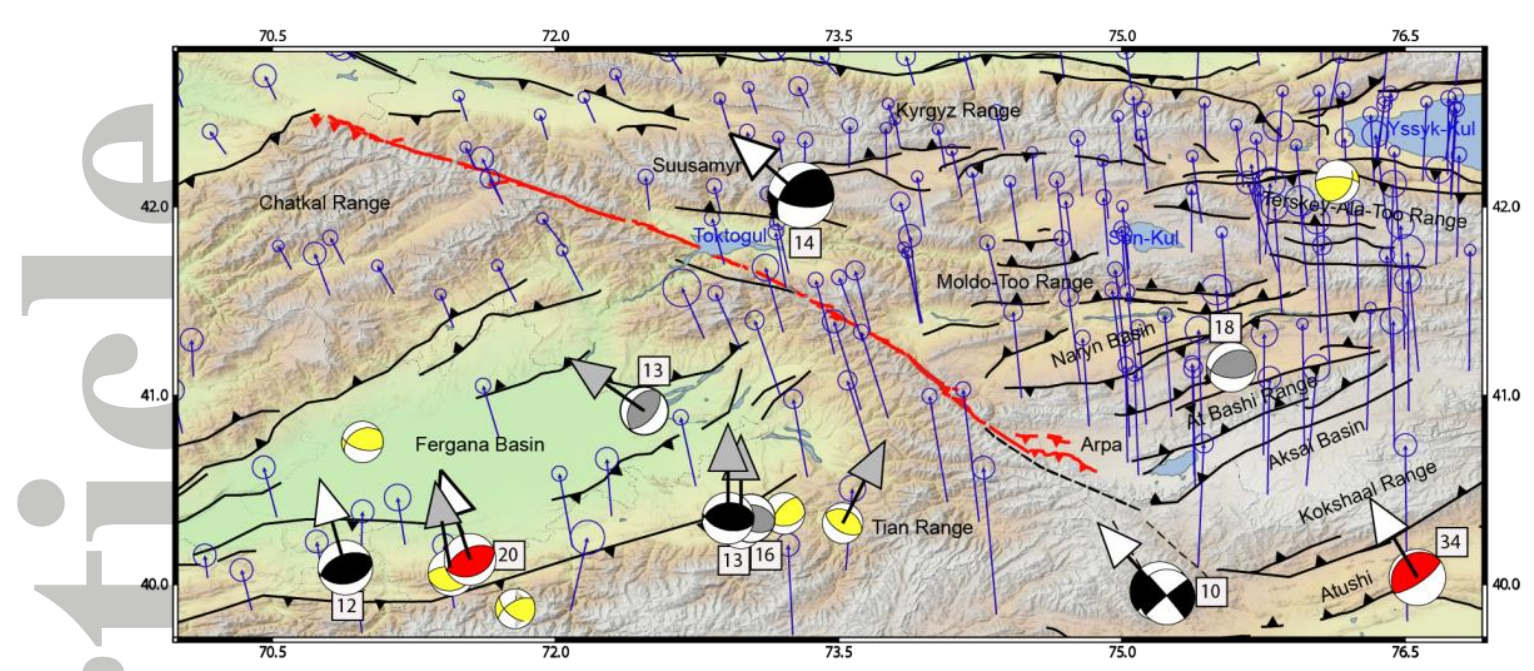

Figure 11: Topography (SRTM), active faults, earthquake mechanisms with centroid depths and GPS velocities relative to stable Eurasia (blue arrows and ellipses at $2 \sigma$, Zubovich et al., 2010) of the Western and Central Tien Shan region. Earthquakes whose depths and mechanisms are confirmed by $\mathrm{P}$ and $\mathrm{SH}$ body-wave modelling are colored by depth (black $<20 \mathrm{~km}$, red $>20 \mathrm{~km}$ ). Grey and yellow earthquake mechanisms are for gCMT solutions (those in grey have depths only confirmed by P-wave modelling). Numbers in boxes indicate centroid depths confirmed by waveform modelling. Large arrows are slips vectors from either: almost-pure thrust-faulting solutions in which the two possible slip vectors differ by less than $15^{\circ}$ (the average is shown); or where the nodal plane that is the fault plane is shown (for the 19 August 1992 Suusamyr earthquake at $42.1^{\circ} \mathrm{N} 73.3^{\circ} \mathrm{E}$ ); or where it is assumed that the right-lateral plane is the fault plane $\left(40^{\circ} \mathrm{N} 75^{\circ} \mathrm{E}\right)$. White arrows are from body-wave modelled mechanisms, grey are from gCMT solutions. 


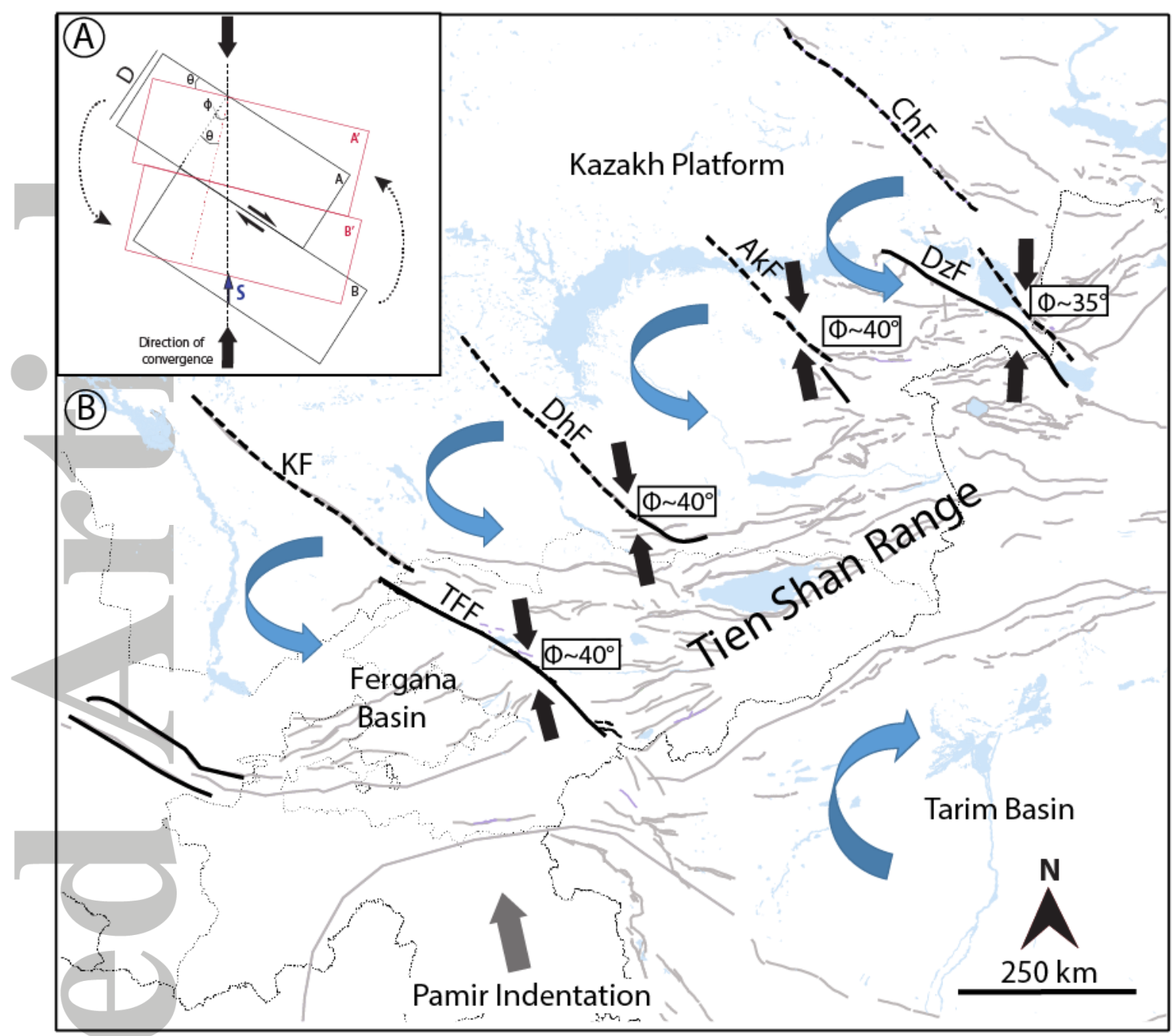

Figure 12: A) Fault rotation model for the NW-SE right lateral faults of the Tien Shan Range (modified after Campbell et al., 2015); see Campbell et al. (2015) and text for details. The black blocks denote the original fault orientation; the red blocks indicate the fault orientation after right-lateral slip and counterclockwise rotation. Overall shortening (large black arrows) is for rates issued from GPS data (Zubovich et al., 2010). B) Global tectonic map of the Tien Shan Range with major faults drawn in gray. The solid and dashed black lines highlight the strike-slip fault systems. KF: Karatau Fault; TFF: Talas-Fergana Fault, DhF: DzhalairNaiman Fault; AkF: Aktas Fault; Dzh: and Dzhungarian Fault; ChF: Chingiz. The blue arrows are for the clockwise rotations of blocks. The $\phi$ values are the clockwise rotation rates.

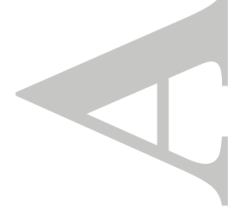

